Pontifícia Universidade Católica $_{\text {a }}$

Mildre Karina Silva Salas

Estudo da Injeção de Água na Recuperação Melhorada de Petróleo: Efeito da Salinidade e Surfactante

Dissertação de Mestrado

Dissertação apresentada como requisito parcial para obtenção do título de Mestre pelo Programa de PósGraduação em Engenharia Mecânica da PUC - Rio.

Orientador: Prof. Márcio da Silveira Carvalho Co-orientador: Prof. Vladimir Alvarado 
Mildre Karina Silva Salas

\section{Estudo da Injeção de Água na Recuperação Melhorada de Petróleo: Efeito da Salinidade e Surfactante}

Dissertação apresentada como requisito parcial para obtenção do grau de Mestre pelo Programa de PósGraduação em Engenharia Mecânica do Centro Técnico Científico da PUC-Rio. Aprovada pela Comissão Examinadora abaixo assinada.

\section{Prof. Márcio da Silveira Carvalho \\ Orientador \\ Departamento de Engenharia Mecânica - PUC - Rio}

Prof. Vladimir Alvarado

Co-Orientador

Department of Chemical and Petroleum Engineering - University of

Wyoming

Prof. Marcos Sebastião de Paula Gomes Departamento de Engenharia Mecânica - PUC - Rio

Prof. Paulo Roberto de Souza Mendes Departamento de Engenharia Mecânica - PUC - Rio

Prof. José Eugênio Leal Coordenador Setorial do Centro Técnico Científico - PUC-Rio

Rio de Janeiro, 20 de outubro de 2014 
Todos os direitos reservados. É proibida a reprodução total ou parcial do trabalho sem autorização da universidade, do autor e do orientador.

\section{Mildre Karina Silva Salas}

Graduou-se em Engenharia de Petróleo na UIS (Universidad Industrial de Santander-Colombia) em 2009. Durante a graduação, atuou como pesquisadora na área de simulação de reservatórios de petróleo no convenio UIS-ICP (Instituto Colombiano del Petróleo). Trabalhou em ICP no departamento de Recuperação Melhorada de Petróleo.

Ficha Catalográfica

Salas, Mildre Karina Silva

Estudo da Injeção de Água na Recuperação Melhorada de Petróleo: Efeito da Salinidade e Surfactante / Mildre Karina Silva Salas; orientador: Márcio da Silveira Carvalho; co-orientador: Vladimir Alvarado. - 2014.

116 f.: il. (color.) ; $30 \mathrm{~cm}$

Dissertação (mestrado) - Pontifícia Universidade Católica do Rio de Janeiro, Departamento de Engenharia Mecânica, 2014.

Inclui bibliografia.

1. Engenharia Mecânica - Teses. 2. Salinidade. 3. Recuperação de óleo. 4. Injeção de surfactantes. 5. Tensão interfacial. I. Carvalho, Márcio da Silveira. II. Alvarado, Vladimir. III. Pontifícia Universidade Católica do Rio de Janeiro. Departamento de Engenharia Mecânica. IV. Título. 
Dedico este trabalho a vocês que sempre me fizeram acreditar na realização dos meus sonhos:

Mãe Ligia Salas,

Irmãs: María C., Jenny L. Nosso Anjo: Luis Evelio Salas e Namorado Miguel A. Chaparro. 


\section{Agradecimento}

Agradeço a Deus em primeiro lugar, por estar comigo em todos os momentos, por acompanhar-me e brindar-me força, coragem e sabedoria nos momentos mais difíceis, para questionar realidades e propor sempre novas possibilidades.

A minha mãe linda, irmãzinhas e namorado, obrigada pela paciência, pelo incentivo, pela força e principalmente pelo carinho. Valeu a pena toda distância, todas as renúncias. Hoje estamos colhendo, juntos, os frutos deste esforço. Esta vitória é muito mais suas do que minha.

Ao meu orientador, professor Márcio da Silveira Carvalho, o fato de me ter dado a oportunidade de realizar este trabalho. Agradeço-lhe a confiança demonstrada e pela orientação durante o desenvolvimento do trabalho.

Ao meu co-orientador professor Vladimir Alvarado pela paciência, tempo, apoio e por compartilhar seu valioso conhecimento no desenvolvimento deste trabalho.

Aos profissionais do grupo de trabalho do professor Márcio da Silveira Carvalho, ao Felicle e à Ranena, por sua amizade e ajuda valiosa e incondicional nas inúmeras dificuldades em que enfrentei.

Aos professores Santiago Drexler e Aurora Pérez pelas orientações e esclarecimentos fundamentais para a culminação deste trabalho.

Ao Thiago Pereira e Gabriel Natan da PUC, por sua amizade e apoio durante os primeiros passos deste trabalho.

A Eduardo Manrique, pelo apoio e amizade incondicional, sempre estarei grata com você.

A minha amiga de luta Ruby Hernandez, pelo apoio companhia e conselhos. 
Aos meus colegas e amigos da PUC, pela amizade e apoio, em especial ao José, Tálita, e Luis.

À Banca examinadora, pelas observações contribuídas ao presente trabalho.

Ao departamento de Engenharia Mecânica da Pontifícia Universidade Católica do Rio de Janeiro, que me proporcionou a oportunidade de cursar Pós-graduação, por se constituir na minha casa de estudos e valorizar minha formação profissional.

Agradeço à Coordenação de Aperfeiçoamento de Pessoal de Nível SuperiorCAPES pela concessão da bolsa de mestrado.

A todos aqueles que neste período estiveram presentes e contribuíram de alguma forma na minha caminhada. 


\section{Resumo}

Salas, Mildre Karina Silva; Carvalho, Márcio da Silveira; Alvarado, Vladimir. Estudo da Injeção de Água na Recuperação Melhorada de Petróleo: Efeito da Salinidade e Surfactante. Rio de Janeiro, 2014. 116p. Dissertação de Mestrado - Departamento de Engenharia Mecânica, Pontifícia Universidade Católica do Rio de Janeiro.

As interações óleo/água/rocha podem ter grande influência no deslocamento do óleo em um reservatório. As forças capilares, responsáveis em parte pela retenção de óleo, são um dos parâmetros que podem ser alterados buscando a optimização do processo. Durante um processo de injeção de água, as altas tensões interfaciais água-óleo diminuem a capacidade de escoamento do óleo e deixam altas saturações deste em forma de glóbulos imóveis e desconectados, nas regiões já contatadas pelo fluido injetado. Com a injeção de surfactante, a tensão interfacial diminui e consequentemente as forças necessárias para mobilizar glóbulos de óleo. No entanto, a interação da salinidade com a solução de surfactante pode trazer importantes efeitos no escoamento bifásico dentro do meio poroso. O objetivo deste trabalho é estudar o efeito da salinidade da água e concentração de surfactante em um processo de deslocamento de óleo. Neste estudo, foram realizados testes de deslocamento em amostras de arenito de Bentheimer de alta permeabilidade, para soluções salinas com e sem surfactante não iónico Álcool Laurílico Etoxilado- 8EO (L80), submetidos a uma temperatura de $40{ }^{\circ} \mathrm{C}$. As saturações residuais bem como as permeabilidades efetivas das fases ao final do processo de embebição e drenagem foram medidas para as diferentes soluções aquosas. Os resultados obtidos mostram a variação na eficiência do processo de deslocamento, influenciada principalmente pelo comportamento de fases, a tensão interfacial, concentração de eletrólitos em solução (salinidade), e a formação de emulsão durante o escoamento bifásico no meio poroso.

\section{Palavras-chave}

Salinidade; recuperação de óleo; injeção de surfactantes; tensão interfacial. 


\section{Abstract}

Salas, Mildre Karina Silva; Carvalho, Márcio da Silveira (Advisor); Alvarado, Vladimir. Study of Water Injection in Enhanced Oil Recovery: Effect of Salinity and Surfactant. Rio de Janeiro, 2014. 116p. MSc. Dissertation - Departamento de Engenharia Mecânica, Pontifícia Universidade Católica do Rio de Janeiro.

The interactions oil/water/rock may have strong influence in displacement of the oil in a reservoir. The capillary forces, responsible in part by the trapped oil, is one of the parameters that allow the optimization of water injection processes. During water injection, the high interfacial tension of water-oil decreases the flow capacity of oil and leave high saturations of this phase in the form of immobile and disconnected ganglia, in the regions already contacted by injected water. With the injection of surfactants, the interfacial tension decreases and some of the oil ganglia are mobilized. However, the interaction of salinity with the surfactant solution can bring important effects in the two-phase flow within porous media. The aim of this work is to study the effect of water salinity and concentration of surfactant in oil displacement process. In this study, the displacement tests were performed on Bentheimer sandstone of high permeability, for saline solution with and without non-ionic surfactant Lauryl Alcohol Ethoxylates- 8EO (L80), subjected to a temperature of $40^{\circ} \mathrm{C}$. The saturation and effective permeability of each phase at the end of imbibition and drainage were determined for the different water solutions. The results obtained show the variation in the efficiency of the displacement process, mainly influenced by the behavior of phases, the interfacial tension, concentration of electrolytes in solution (salinity) and in-situ emulsion formation.

\section{Keywords}

Salinity; oil recovery; surfactant flooding; interfacial tension. 


\section{Sumário}

1. Introdução 16

$\begin{array}{ll}\text { 1.1. Motivação } & 18\end{array}$

$\begin{array}{ll}\text { 1.2. Revisão bibliográfica } & 18\end{array}$

1.2.1. Injeção de Água de Baixa Salinidade 18

1.2.2. Injeção de Soluções de Surfactantes 26

1.3. Objetivos da dissertação 28

1.4. Estrutura da dissertação 28

2. Fundamentos Teóricos 29

2.1. Propriedades básicas fluido e rocha 29

2.1.1. Viscosidade 29

2.1.1.1. Lei de Newton da Viscosidade $\quad 29$

2.1.2. Porosidade 30

2.1.3. Permeabilidade 30

$\begin{array}{ll}\text { 2.1.3.1. Permeabilidade Absoluta ou Específica } & 31\end{array}$

2.1.3.2. Permeabilidade Efetiva 31

2.1.3.3. Permeabilidade Relativa 32

2.1.4. Tensão Interfacial 34

2.1.5. Pressão Capilar $\quad 35$

$\begin{array}{ll}\text { 2.1.6. Número de Capilaridade } & 37\end{array}$

2.1.7. Molhabilidade 39

2.1.8. $\mathrm{pH} \quad 41$

2.1.9. Surfactantes ou Tensoativos 41

2.1.9.1. Classificação dos Surfactantes 42

2.1.9.2. Propriedades dos Tensoativos 43

2.2. Recuperação avançada de petróleo 50

2.2.1. Injeção de Água e Razão de Mobilidade 52

2.2.2. Modelo de Poro Duplo 54

2.2.3. Fenômeno de Quebra de Gota 55

3. Experimento 58

3.1. Descrição do Dispositivo Experimental 58 
3.2. Procedimento Experimental 61

3.3. Amostra de Rocha 65

3.4. Fase Aquosa 68

$\begin{array}{ll}\text { 3.4.1. Salinidade } & 68\end{array}$

3.4.2. Surfactante 70

3.5. Tensão Interfacial e Concentração Micelar Critica 74

3.5.1. Gota Pendente $\quad 75$

3.6. Propriedades dos Fluidos 78

3.7. Testes de Garrafa 79

3.8. $\mathrm{pH} \quad 80$

3.9. Limpeza das Amostras 81

4. Resultados $\quad 82$

4.1. Porosidade e Propriedades dos Fluidos Injetados 83

4.2. Surfactante 85

4.3. Tensão Interfacial Óleo-Soluções Salinas 86

4.3.1. Número de Capilaridade 88

4.3.2. Testes de Garrafa 88

4.4. Medidas de Concentração Micelar Crítica 89

4.5. Testes de Deslocamento 91

4.5.1. Permeabilidade Absoluta 92

4.5.2. Permeabilidade Efetiva 95

4.5.2.1. Drenagem 95

4.5.2.2. Embebição 99

4.6. Medição de $\mathrm{pH} \quad 103$

4.7. Resumo dos resultados finais 105

5. Comentários Finais e Sugestões 111

5.1. Comentários Finais 111

5.2. Sugestões 113

6. Referências Bibliográfica 114 


\section{Lista de figuras}

Figura 1-1: Representação esquemática de um processo

de injeção de surfactante.

Figura 1-2: Número de publicações e apresentações focadas

em LSE (Low Salinity Effects). [4]

Figura 1-3: Efeito da salinidade salmoura injetado na recuperação de petróleo por injeção de água (Petróleo e Berea, Prudhoe Bay). [6]

Figura 1-4: Efeito da salinidade da água conata na recuperação de óleo, por injeção de água, com petróleo de Prudhoe Bay em Berea. [6]

Figura 1-5: Efeito do tipo de óleo e salinidade da salmoura da água contata, na recuperação de óleo por injeção de água. Petróleo de Prudhoe Bay e Shell A-1, em Berea. [6]

Figura 1-6: Efeito da salinidade da salmoura na recuperação de óleo por injeção de água (Dodecene, Berea). Salinidade da salmoura de injeção e conata são iguais. [6]

Figura 1-7: Recuperação por injeção LSW em cores de arenito de reservatório a) Recuperação terciaria com LSW

b) Comparação recuperação secundaria por LSW. [7]

Figura 1-8: Fator de recuperação de óleo mineral em core com molhabilidade mista. [7].

Figura 1-9: Efeito do número capilaridade na recuperação

de óleo. [11]

Figura 1-10: Efeito da salinidade sobre o comportamento da solubilização e tensão interfacial de óleos solúveis equilibrados com solução salina ou polímero. [13]

Figura 2-1: Fluxo linear em um meio poroso horizontal. [10]

Figura 2-2: Representação de um meio poroso saturado com dois fluidos.

Figura 2-3: Curva de permeabilidade relativa em função da saturação de água.

Figura 2-4: Óleo escoando em uma garganta de poro. 34

Figura 2-5: Elevação de água em um tubo capilar. 
Figura 2-6: Capilaridade em um empacotamento

de grãos esféricos.

Figura 2-7: Correlação entre o número de capilaridade e a saturação de óleo residual em reservatórios molháveis à água. [2] 38

Figura 2-8: Molhabilidade em rochas reservatório. [17] 39

Figura 2-9: Representação esquemática dos surfactantes. [2] 42

Figura 2-10: Propriedades físicas do Laurilsulfato de Sódio. [2] 45

Figura 2-11: Diagrama de fases para o ambiente Tipo II(-). [2] 46

Figura 2-12: Diagrama de fases para o ambiente Tipo III. [2] 47

Figura 2-13: Tensão interfacial e Salinidade ótima. [2] 48

Figura 2-14: Parâmetros de solubilização e salinidade ótima. [2] 49

Figura 2-15: Classificação dos métodos EOR/IOR. [19] 50

Figura 2-16: Formação de digitação viscosa em bloco

de arenito saturado com óleo viscoso submetido à injeção

de água pela face inferior. [14] 53

Figura 2-17: Representação esquemática do modelo de poro duplo. [14] 55

Figura 2-18: Representação do fenômeno do snap-off em um poro. [14] 56

Figura 2-19: Mecanismos de formação da saturação

de óleo remanente. [14] 56

Figura 3-1: Esquema simplificado do experimento. 59

Figura 3-2: Equipamento Original, Core Flooding

System - modelo CFS-830-SS. 60

Figura 3-3: Visão geral do arranjo experimental, dentro do forno. 61

Figura 3-4: Esquema de saturação das amostras. 63

Figura 3-5: Esquema Indicando como calcular

a permeabilidade absoluta.

Figura 3-6: Esquema do Procedimento para Medir

a Permeabilidade Relativa. $\quad 65$

Figura 3-7: Amostra de Bentheimer medida com um paquímetro 66

Figura 3-8: PSD Arenito Bentheimer baseado na Injeção

$\begin{array}{ll}\text { Padrão de Mercúrio. [21] } & 67\end{array}$

Figura 3-9: Emulsões com os diferentes surfactantes. 71

Figura 3-10: Emulsão sendo criada com o Ultra-Turrax T25. 72

Figura 3-11: Foto do Mastersizer 2000 da Malvern. 72

Figura 3-12: Testes de estabilidade e repetibilidade das soluções

com água do mar e Ultrol L80 e CS-330. 73 
Figura 3-13: Distribuição do tamanho de gotas para a solução com o SDS.

Figura 3-14: Tensiômetro Tracker da Teclist. $\quad 74$

Figura 3-15: Geometria de uma gota pendente. [23] 76

Figura 3-16: Geometria de uma gota pendente. [23] 77

Figura 3-17: Metodologia de agitação das amostras. 80

Figura 3-18: Medidor de pH Oakton PC 700. 80

Figura 3-19: Soxhlet para limpeza das amostras. $\quad 81$

Figura 4-1: Resumos dos experimentos realizados. 82

Figura 4-2: Estrutura química de um surfactante não iônico. 85

Figura 4-3: Tensão intefacial óleo-água a $40^{\circ} \mathrm{C} . \quad 86$

Figura 4-4: Numero de capilaridade soluções salinas. 88

Figura 4-5: Teste de garrafa soluções com surfactante, relação água/óleo $50 / 50 \mathrm{~V} / \mathrm{V}$ a $40^{\circ} \mathrm{C}$. 89

Figura 4-6: Teste de garrafa soluções sem surfactante, relação água/óleo 50/50 V/V a $40^{\circ} \mathrm{C}$. 89

Figura 4-7: Tensão superficial X concentração do Ultrol L80 $40^{\circ} \mathrm{C} . \quad 90$

Figura 4-8: Comportamento da pressão em função do volume injetado de água do mar (em VP).

Figura 4-9: Comportamento dados de pressão X vazão amostra A35. 93

Figura 4-10: Históricos de uso das amostras Bentheimer. 94

Figura 4-11: Comportamento do diferencial de pressão na injeção de óleo nas amostras saturadas com soluções sem surfactante - Drenagem a $40^{\circ} \mathrm{C}$.

Figura 4-12: Comportamento do diferencial de pressão na injeção de óleo nas amostras saturadas com soluções com surfactante - Drenagem a $40^{\circ} \mathrm{C}$.

Figura 4-13: Comportamento do diferencial de pressão na injeção das soluções salinas nas sem surfactante - Embebição a $40^{\circ} \mathrm{C}$.

Figura 4-14: Comportamento do diferencial de pressão na injeção de a) Solução $\mathrm{NaCl} 15 \mathrm{~g} / \mathrm{l}$ e b) $\mathrm{NaCl} 33,9 \mathrm{~g} / \mathrm{l}$ - Embebição a $40^{\circ} \mathrm{C}$.

Figura 4-15: Comportamento do diferencial de pressão na injeção de a) Solução $\mathrm{NaCl} 24,53 \mathrm{~g} / \mathrm{l}$ e b) Água do Mar (SW) - Embebição a 40 $\mathrm{C} .102$ Figura 4-16: Linha de produção-efluente produzidos durante a embebição. 103 Figura 4-17: Comparação do pH dos efluentes das soluções salinas sem surfactante a $24^{\circ} \mathrm{C}$. 
Figura 4-18: $\mathrm{pH}$ dos efluentes produzidos para a soluções de $\mathrm{NaCl} 24,5 \mathrm{~g} / \mathrm{l}$ e $\mathrm{L} 80$ a $24^{\circ} \mathrm{C}$.

Figura 4-19: Saturações água conata e óleo residual: a) Soluções sem surfactante, b) Soluções com surfactante.

Figura 4-20: Razão de mobilidade e eficiência deslocamento: a) Soluções sem surfactante, b) Soluções com surfactante.

Figura 4-21: Fatores de recuperação soluções salinas com e sem surfactante.

Figura 4-22: Breakthrough Solução $\mathrm{NaCl} 15 \mathrm{~g} / \mathrm{l}$.

Figura 4-23: Permeabilidade relativa $X$ saturação de água: a) Soluções salinas sem surfactante; b) Soluções salinas com surfactante. 


\section{Lista de tabelas}

Tabela 1-1: Fatores de recuperação de óleo observados sob a injeção de água em cores com saturações de água de alta salinidade. [4]

Tabela 2-1: Classificação da molhabilidade segundo os diferentes métodos. [16]

Tabela 3-1: Tabela com detalhes técnicos de cada componente da bancada experimental.

Tabela 3-2: Composição mineral do arenito de Bentheimer, obtidos a partir de XRD (Standard X-Ray Diffraction). [21]

Tabela 3-3: Testes realizados nas amostras de Bentheimer.

Tabela 3-4: Composição da água do mar sintética. [22] 69

Tabela 3-5: Drakeol 7.

Tabela 3-6: Viscosidade e densidade soluções com L80 79

Tabela 3-7: Viscosidade e densidade soluções sem surfactante.

79

Tabela 4-1: Dados medidos e usados para o cálculo da porosidade.

Tabela 4-2: Viscosidade dinâmica e densidade soluções

sem surfactante.

Tabela 4-3: Viscosidade dinâmica e densidade soluções com surfactante.

Tabela 4-4: Viscosidade dinâmica e densidade soluções com surfactante. $\quad 84$

Tabela 4-5: Propriedades do surfactante Ultrol L-80. 85

Tabela 4-6: Tensão superficial DK7 e as soluções com e sem L80 a $40^{\circ} \mathrm{C} . \quad 87$

Tabela 4-7: Tensão superficial da solução de água do mar com diferentes concentrações de Ultrol L80 a $40^{\circ} \mathrm{C}$. 90

Tabela 4-8: Condições de injeção para os testes de deslocamento. 91

Tabela 4-9: Dados de vazões e diferencial de pressão usados no cálculo da permeabilidade absoluta amostra A35 com água do mar e surfactante L80.

Tabela 4-10: Permeabilidade absoluta medidas com as diferentes soluções para amostras arenito a $40^{\circ} \mathrm{C}$. 94

Tabela 4-11: Dados obtidos testes de drenagem soluções salinas a $40^{\circ} \mathrm{C} . \quad 96$

Tabela 4-12: Dados obtidos testes de drenagem soluções salinas a $40^{\circ} \mathrm{C} . \quad 99$ 


\section{1 \\ Introdução}

A vida de um campo de petróleo pode ser resumida em três fases de recuperação: primária, secundária e terciária. $\mathrm{Na}$ fase de recuperação primária, 0 óleo é deslocado devido à energia natural (pressão) do reservatório, gravidade e em alguns casos, com ajuda de técnicas de elevação artificial; os valores de recuperação variam em torno de $10-20 \%$ OOIP (Original Oil in Place).

$\mathrm{Na}$ recuperação secundária, técnicas como a injeção de água (waterflooding) ou gás são implementadas para aumentar ou manter a pressão do reservatório. Finalmente a recuperação terciária, se refere aos processos aplicados depois da recuperação secundária. [1]

A recuperação melhorada de petróleo EOR (Enhanced Oil Recovery) representa um conjunto de técnicas que utilizam fontes externas de energia e/ou materiais com as quais busca-se incrementar o fator de recuperação de óleo depois de uma etapa de recuperação primária e/ou secundária.

A injeção de água é uma das técnicas mais usadas na recuperação de petróleo para manter a pressão do reservatório, depois da depleção primária. $\mathrm{O}$ sucesso desta e outras técnicas dependem da capacidade de produzir quantidades significativas de óleo no menor tempo possível e a baixo custo. No entanto, a complexidade das interações petróleo-água requer uma melhor compreensão da fenomenologia envolvida. Jadhunandan \& Morrow (1995) e Yildiz \& Morrow (1996) demostraram com testes de laboratório que a composição da água conata e de injeção têm um efeito significativo na recuperação melhorada de óleo por injeção de água (secundária).

$\mathrm{Na}$ recuperação de petróleo em reservatórios que apresentam óleos com viscosidade moderada e altas tensões interfaciais, as aplicações dos métodos convencionais de recuperação secundária deixam de ser suficientes. Técnicas como a injeção de químicos, que utilizam surfactantes, componentes alcalinos e/ou polímeros, modificam as condições do deslocamento e aumentam o volume de óleo recuperado, conforme esquematizado na Figura 1-1.

Ureh \& Fahmy (1927) sugeriram o uso de surfactantes para recuperação avançada (EOR), mostrando o incremento obtido na recuperação de óleo para 
baixas tensões interfaciais com a adição de diferentes tipos de eletrólitos à água de injeção. [2]

Os surfactantes ou tensoativos são utilizados na recuperação avançada, tanto na etapa secundária como na terciária do gerenciamento do reservatório, e representa uma alternativa atrativa para o incremento do fator de recuperação de óleo, reduzindo a tensão interfacial (IFT) óleo/água. Se a formulação química for apropriada, é possível modificar o comportamento molecular na interface entre os fluidos que coexistem no mesmo lugar, e tensões interfaciais ultra baixas na ordem de 0 a $10^{-3}$ são obtidas e, consequentemente, o número de capilaridade e a recuperação de óleo são incrementados.

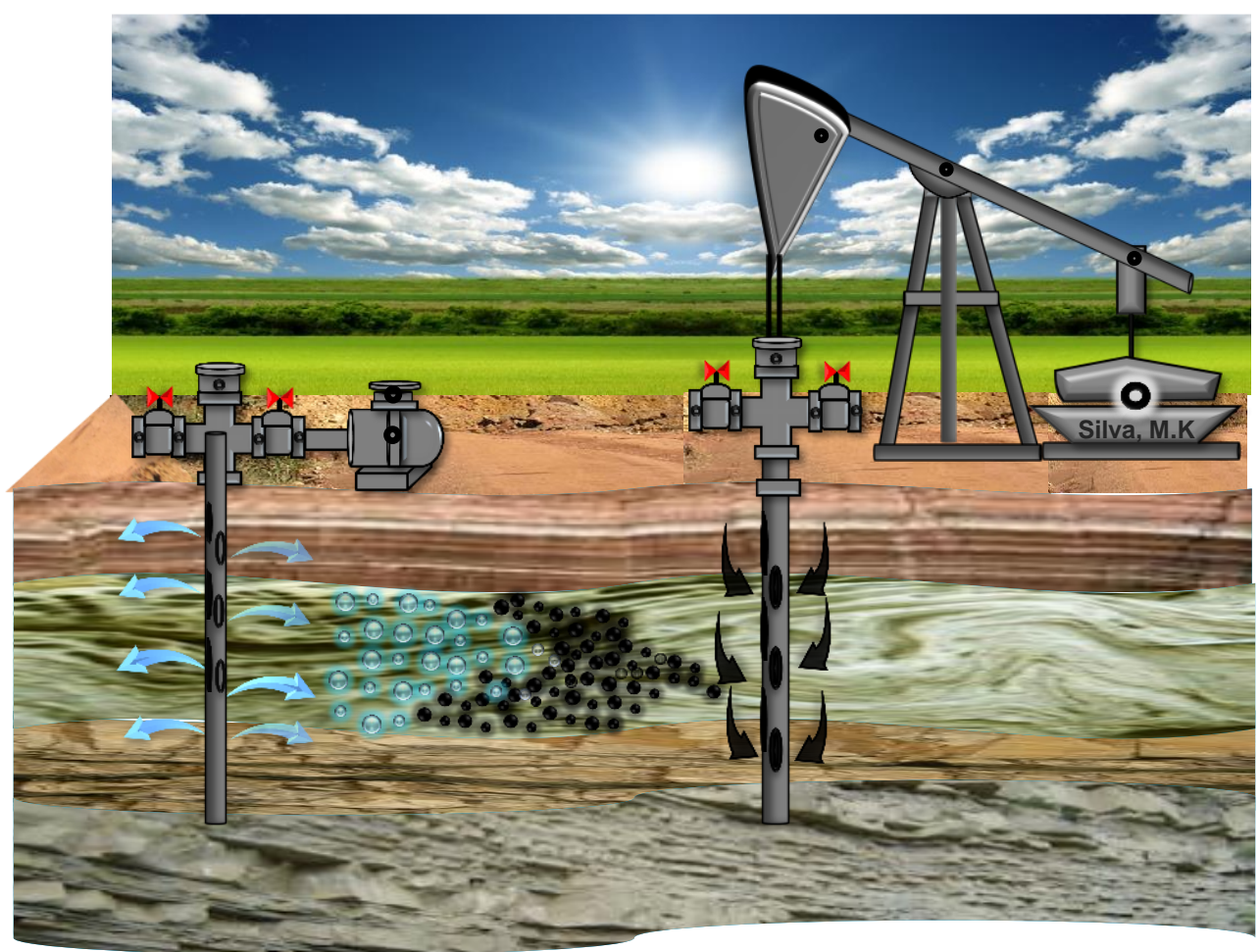

Figura 1-1: Representação esquemática de um processo de injeção de surfactante.

A salinidade da água conata e mineralogia da rocha podem afetar a injeção de surfactante através do comportamento das fases, tesões interfaciais entre o banco de solução de surfactante e óleo residual, razão de mobilidade, assim como a diminuição da concentração de surfactante devido à adsorção e precipitação durante o escoamento através do espaço poroso. [3] 


\section{1 Motivação}

Em um campo de petróleo típico, os métodos de produção convencionais extraem aproximadamente um terço do OOIP (original oil in situ), ficando cerca de $70 \%$ no reservatório. Além disso, na medida que a produção de petróleo declina, torna-se cada vez mais difícil extrair o óleo remanescente e levá-lo à superfície. A tensão interfacial entre o óleo e a água provoca o aprisionamento do óleo devido às forças capilares. A tensão interfacial é função da composição do óleo, da salinidade da água conata e de injeção, da composição da rocha dentre outros fatores. Uma possível solução é a injeção de surfactantes, que age reduzindo a tensão interfacial entre a água e o óleo.

No entanto, a eficiência do processo de deslocamento é influenciada pelas características das soluções de surfactantes, concentração de eletrólitos em solução (salinidade), a adsorção à superfície sólida da rocha, etc. Portanto, é necessário um melhor entendimento da interação destes parâmetros para optimização do processo de deslocamento de óleo.

\section{2 \\ Revisão bibliográfica}

\subsection{1 \\ Injeção de Água de Baixa Salinidade}

A injeção de água é uma das tecnologias mais utilizadas na recuperação melhorada de petróleo. As vantagens desta tecnologia são principalmente a sua capacidade para manter a pressão do reservatório e deslocar o óleo remanescente, além dos baixos custos de investimento e operação em relação com às outras tecnologias. Uma questão que vem sendo estudada na última década de forma mais rigorosa é o efeito da salinidade das salmouras de injeção na recuperação melhorada de óleo. Resultados recentes mostram que é recomendável realizar uma análise experimental extensiva do reservatório, com rocha, fluidos e condições do reservatório (e.g. temperatura e pressão) antes da execução de pilotos de injeção de salmouras de baixa salinidade (LS), de modo que a tecnologia possa ser avaliada.

No Simpósio SPE / DOE sobre IOR em Tulsa em 2006, o Low Salinity Water (LSW) foi classificado como método IOR pela primeira vez. A partir deste ano, houve um crescente interesse em entender os efeitos que permitem aumentar a 
recuperação de óleo, o que se refletiu em um aumento do número de publicações, como pode ser mostrado na Figura 1-2. [4]

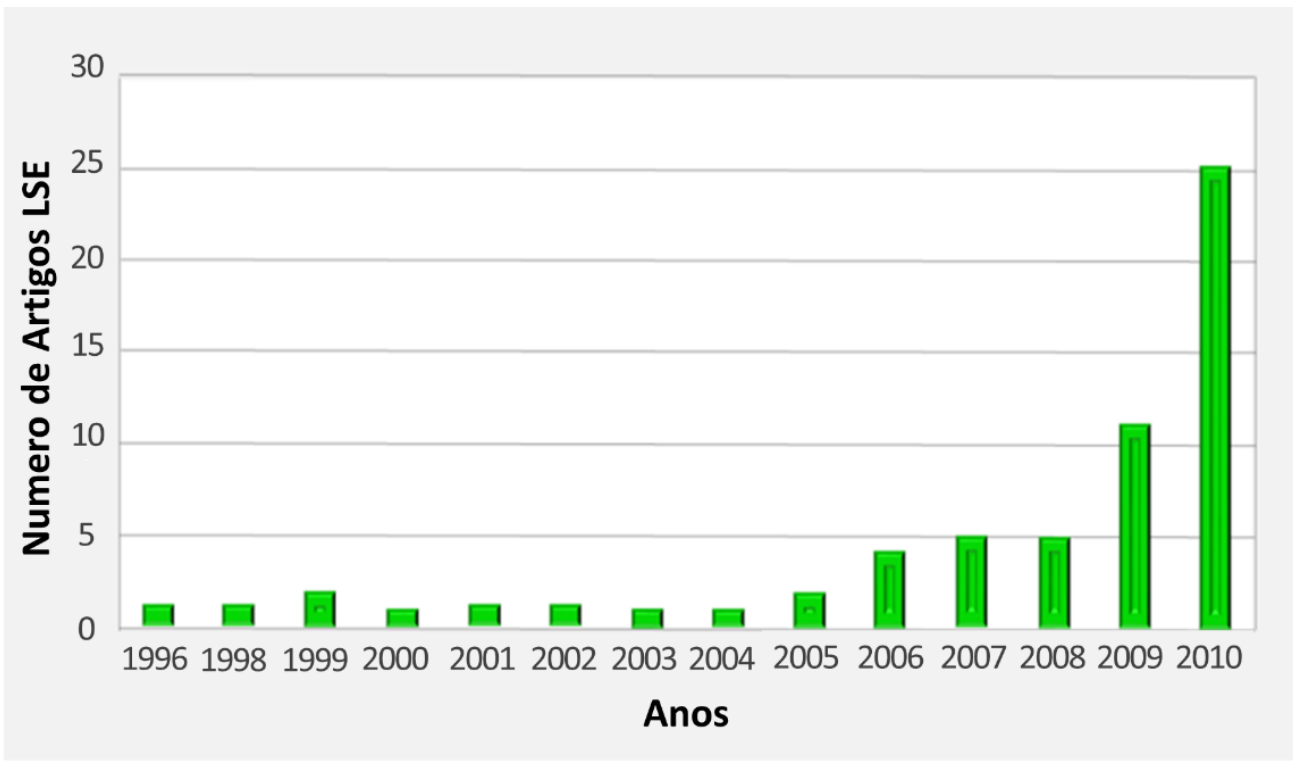

Figura 1-2: Número de publicações e apresentações focadas em LSE (Low Salinity Effects). [4]

Muitas teorias sobre o efeito da salinidade da água injetada têm sido propostas, mas os mecanismos principais ainda são questões de debate. Smith (1942) observou, durante seus estudos iniciais com petróleo de Kansas e amostras de rocha, que não houve nenhuma diferença significativa nas recuperações de óleo entre a injeção de salmoura e água deionizada ou doce.

Martim (1959) observou um aumento na recuperação de petróleo pesado por injeção de água deionizada em amostras de arenito, e supôs que este aumento ocorreu devido a um possível inchamento de argilas e emulsificação.

Bernard (1967) notou que a injeção de água deionizada pode aumentar a recuperação de petróleo em amostras de arenito com conteúdo de argila. O bloqueio das gargantas de poro por migração de finos e inchamento das argilas diminuiu o espaço poroso disponível para óleo/água, e formou novos canais de fluxo com os quais produziu uma maior quantidade de óleo. [5]

Diversos testes de deslocamento de óleo com salmouras de baixa salinidade mostraram um aumento da produção diante a recuperação secundária e terciária, para a maioria dos casos estudados por Zhang et al. (2007) e Agbalaka et al. (2009). 
Sharma \& Filoco (2000) fixaram a concentração da água conata em seus testes, e demonstraram que a redução da salinidade da água de injeção (0.3 20\%) não aumentou a recuperação de óleo, como apresentado na Figura 1-3. [6]

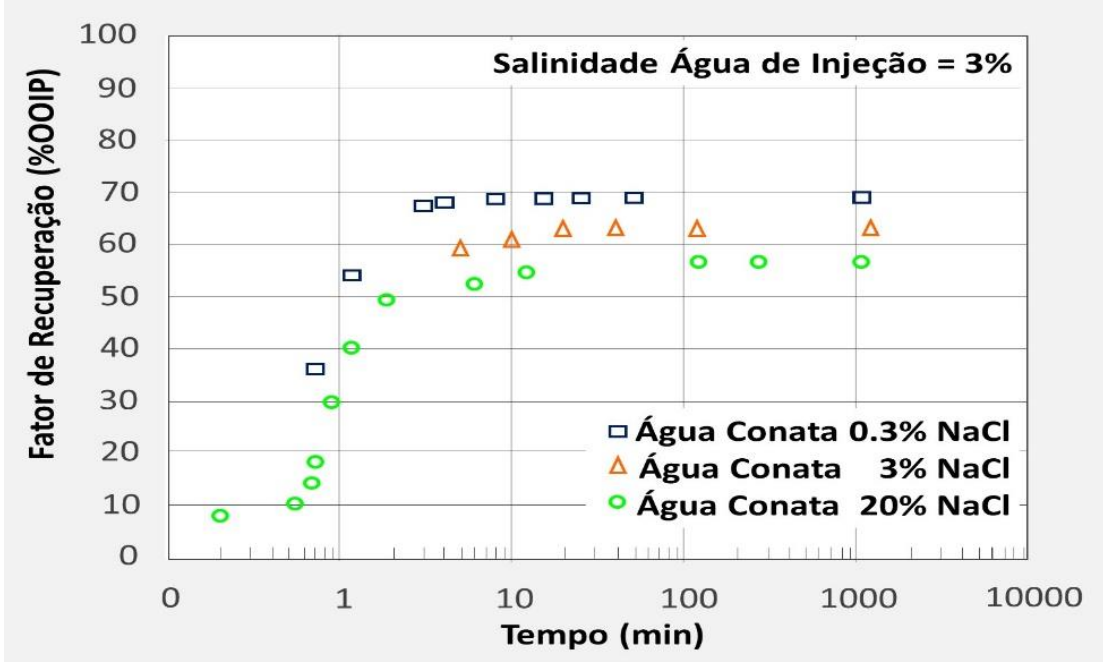

Figura 1-3: Efeito da salinidade salmoura injetado na recuperação de petróleo por injeção de água (Petróleo e Berea, Prudhoe Bay). [6]

Além disso, estes autores demonstraram em testes que a redução da salinidade da água de injeção aumentou a recuperação de óleo apenas quando a salinidade da água conata foi reduzida, como mostra a Figura 1-4.

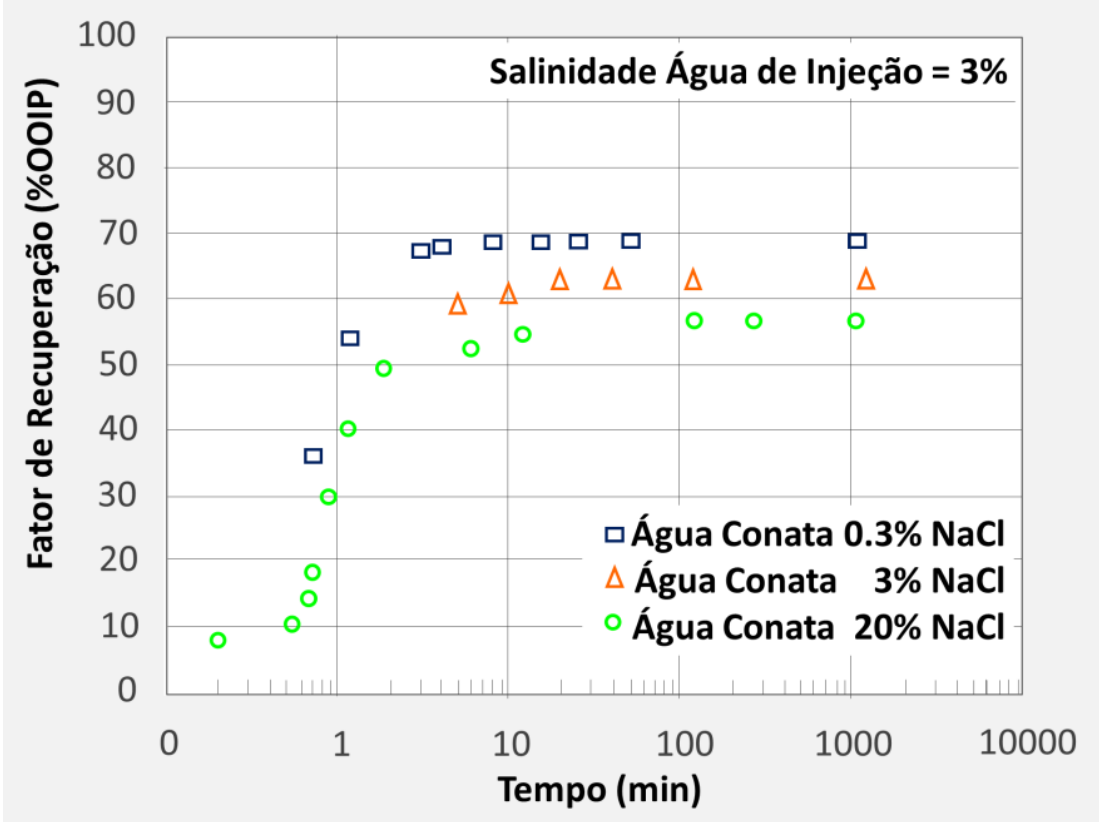

Figura 1-4: Efeito da salinidade da água conata na recuperação de óleo, por injeção de água, com petróleo de Prudhoe Bay em Berea. [6] 
Para avaliar os resultados apresentados anteriormente, novos experimentos foram realizados com três óleos diferentes, mantendo fixa a concentração da água de injeção e variando a concentração de sal da água conata. Os resultados são apresentados na Figura 1-5. A maior recuperação de petróleo foi atingida para água conata com menor salinidade. No entanto, a forma da curva de recuperação de óleo foi diferente à observada com petróleo Prudhoe Bay.

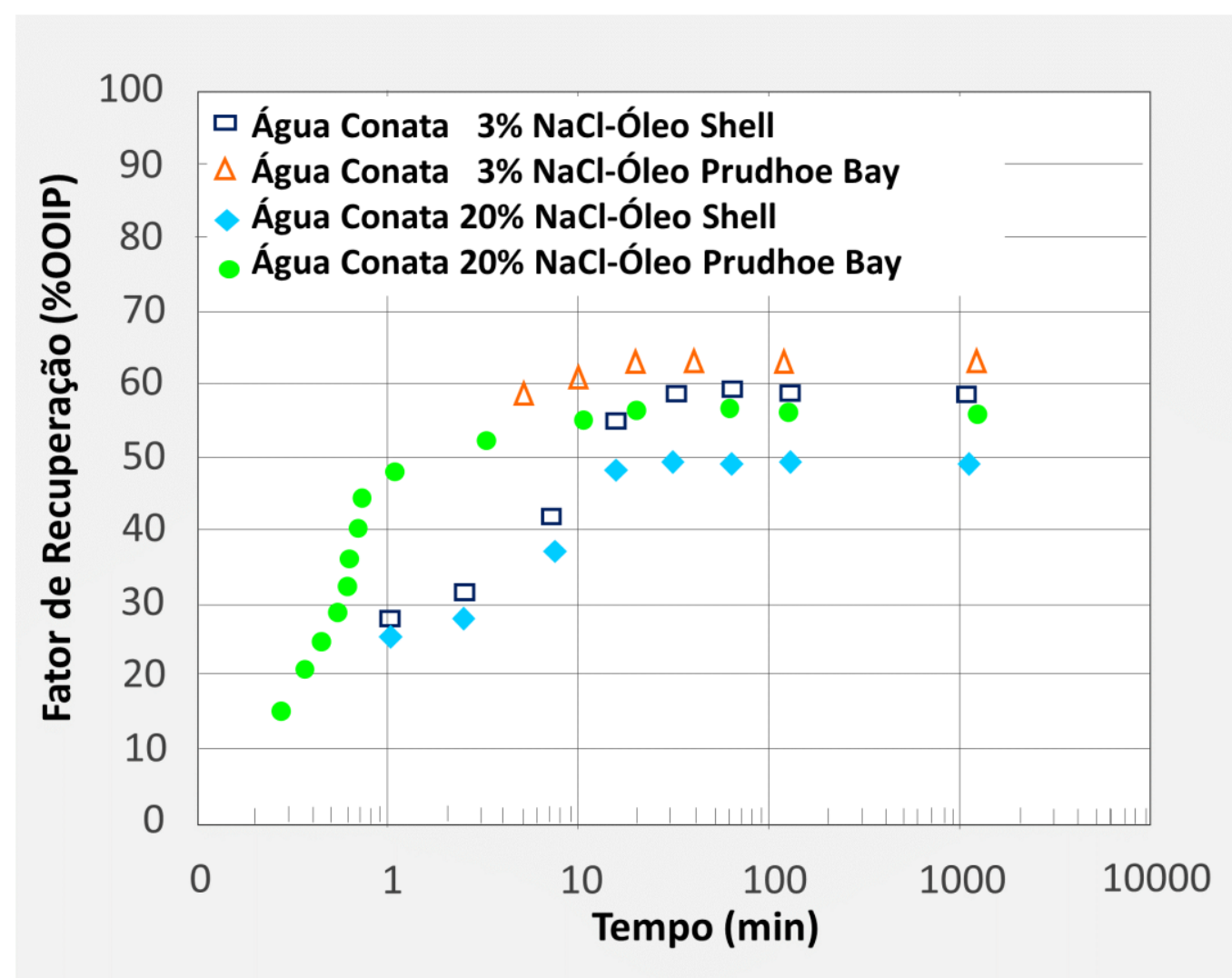

Figura 1-5: Efeito do tipo de óleo e salinidade da salmoura da água contata, na recuperação de óleo por injeção de água. Petróleo de Prudhoe Bay e Shell A-1, em Berea. [6]

Sharma \& Filoco [6], encontraram uma outra diferença ao usar óleo Dodeceno. Uma pequena diferença na recuperação de óleo foi observada quando a salinidade da água conata foi variada entre 3 a $20 \%$, como apresentado na Figura 1-6. A composição da fase de óleo desempenhou um papel importante na determinação do efeito da salinidade.

McGuire et al. (2005) atribuiu o incremento na recuperação de óleo à formação de surfactantes in situ (saponificação) devido à injeção de água de baixa salinidade. A saponificação mudou a molhabilidade e reduziu a IFT. [7] 
Em 2006 Webb observou incrementos na recuperação de óleo com a injeção de salmouras de até 5.000 ppm. [7]

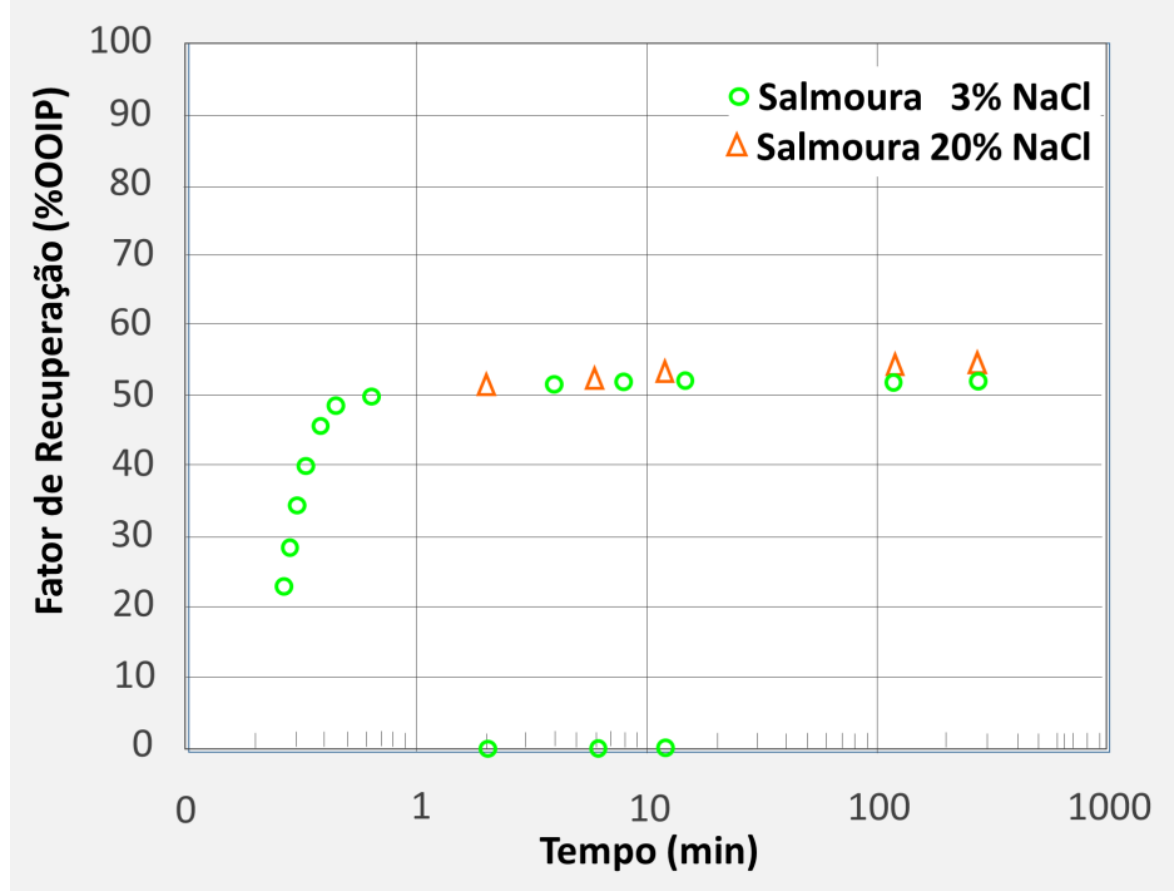

Figura 1-6: Efeito da salinidade da salmoura na recuperação de óleo por injeção de água (Dodecene, Berea). Salinidade da salmoura de injeção e conata são iguais. [6]

Lager et al. (2006) [8] reportaram respostas de recuperação terciária a baixa salinidade com incremento na recuperação na ordem de 2 até $18 \%$ para 18 reservatórios de arenito. A partir de resultados observados em laboratório sobre a composição da salmoura do efluente, um aumento na recuperação de óleo como produto do intercambio multicomponente iônico produzido pela diminuição nas ligações iônicas entre o petróleo e a superfície da rocha.

Testes com ou sem resposta de recuperação por injeção de LSB (Low Salinity Brine) em reservatórios que contem água conata de alta salinidade também foram estudados por vários pesquisadores (Tang \& Morrow, 1999; Sharma \& Filoco, 2000; Zhang \& Morrow, 2006; Tong et al., 2006).

Zhang et al. [7] estudaram o efeito da injeção de água com alta (29690 ppm) e baixa salinidade (1479 ppm), (Figura 1-7a), e duas soluções de $\mathrm{NaCl}$ com 1500 e 8000 ppm em rochas de arenito com permeabilidade em torno de $600 \mathrm{mD}$. Cada amostra de rocha foi testada com dois tipos de petróleo e um óleo mineral. Observou-se um aumento na recuperação de petróleo com a injeção da salmoura de baixa salinidade, tanto na recuperação secundária quanto na terciária. A falta de resposta na injeção de 8000 ppm de $\mathrm{NaCl}$ mostrou que a remoção de íons 
bivalentes e redução da salinidade da salmoura não foi suficiente para obter uma melhor recuperação terciária. Na injeção de água a 1500 ppm e adição posterior de íons bivalentes LSB (Low Salinity Brine) foi observado um aumento na recuperação terciária de petróleo e queda de pressão, conforme mostrado na Figura 1-7b.
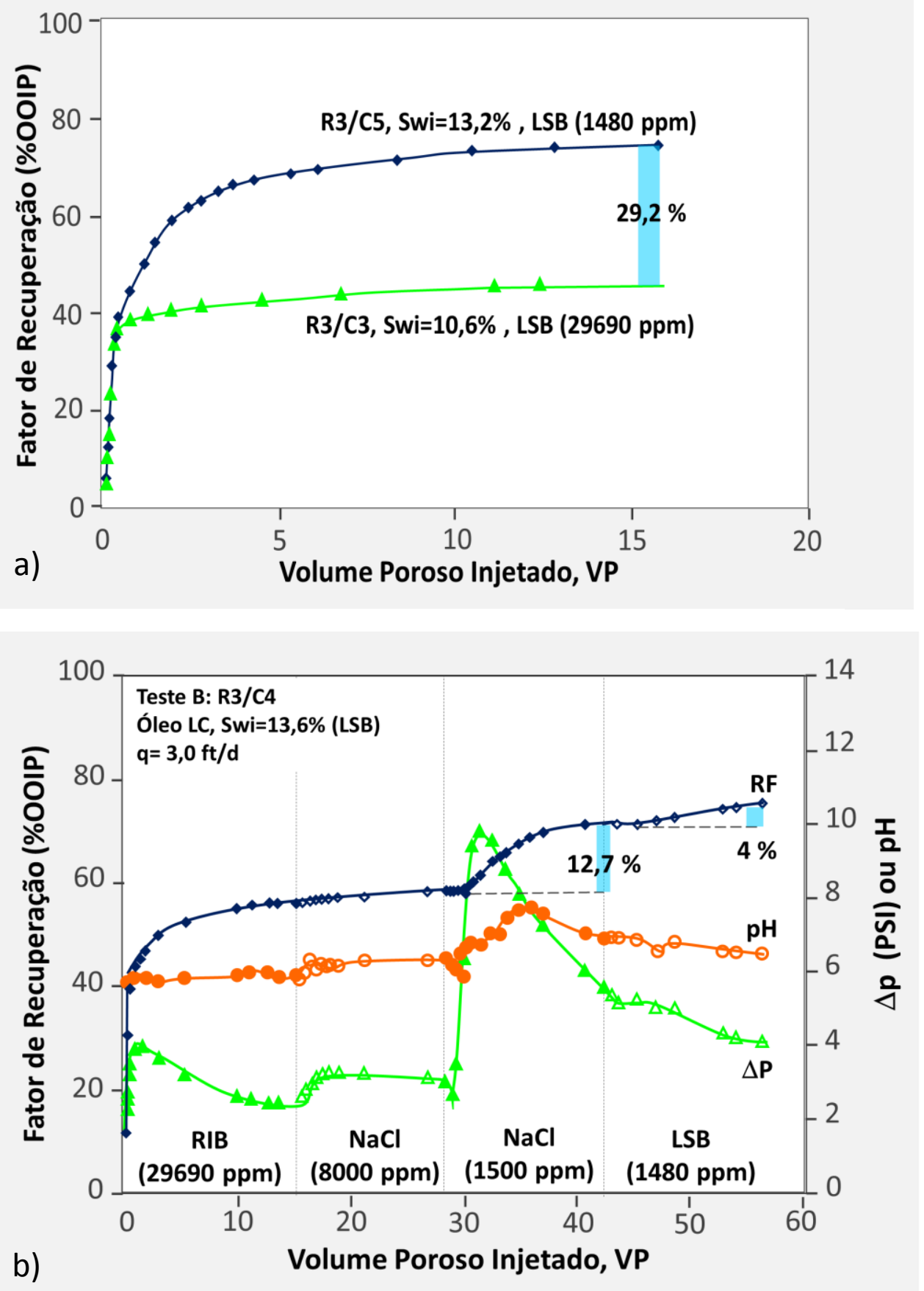

Figura 1-7: Recuperação por injeção LSW em cores de arenito de reservatório a) Recuperação terciaria com LSW b) Comparação recuperação secundaria por LSW. [7] 
Interações salmoura / rocha podem contribuir para o aumento de pressão, mas um pequeno aumento na resposta da pressão para o óleo mineral pode ser atribuído a efeitos de migração de argila e inchamento por causa do bloqueio, conforme mostrado na Figura 1-8. As alterações na resistência ao fluxo por bloqueio dos poros causam mudanças na localização e mobilidade do petróleo.

$\mathrm{O}$ aumento na velocidade do fluido seria suficiente para sobrepor-se às forças capilares que retêm a gota na garganta, forçando-a a se deformar e escoar pelo capilar. Outras fontes adicionais de resistência ao fluxo podem ser a rugosidade da superfície e as bordas (Morrow, 1975). [7]

Zhang \& Xie [7], observaram também, que não houve incremento na recuperação de óleo em rocha com molhabilidade mista para injeção primaria com RIB (Reservoir Injection Brine) e secundaria com água de baixa salinidade; concluindo que as propriedades do óleo são críticas na definição do desempenho da injeção de salmouras de baixa salinidade, conforme na Figura 1-8.

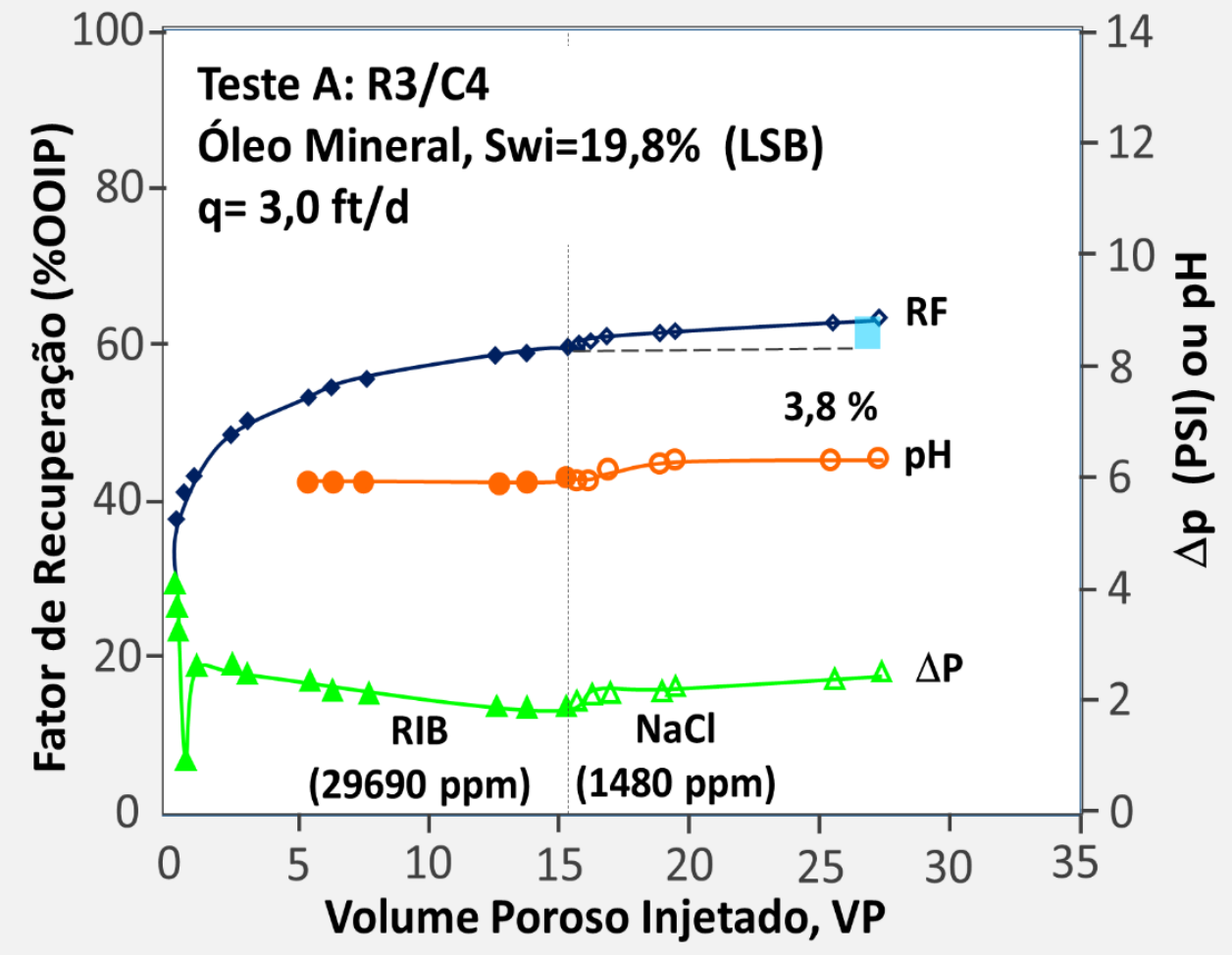

Figura 1-8: Fator de recuperação de óleo mineral em core com molhabilidade mista. [7].

Morrow \& Buckley [4], apresentaram dados da quantidade de óleo recuperado como uma percentagem do OOIP em arenito Berea. A saturação foi feita com misturas de água conata e de injeção com alta salinidade (HS - salmoura 
do reservatório de 24168 ppm), diluições da salmoura de HS de 1/10 para salinidade moderada (MS) e 1/100 para baixa salinidade (LS). O petróleo utilizado para saturar as amostras foi do campo Dagang. A maior recuperação de óleo foi atingida para o caso da salmoura de menor concentração onde não houve mudança na composição iônica entre a água conata e de injeção, como pode ser observado na Tabela 1-1.

Fator De Recuperação De Óleo, \%OOIP

\begin{tabular}{cccc}
\hline Água Conata & HS & MS & LS \\
\hline Água Injetada & & & \\
\hline \hline HS & 50 & 65 & 80 \\
MS & 50 & 71 & 80 \\
LS & 56 & & \\
\hline
\end{tabular}

Tabela 1-1: Fatores de recuperação de óleo observados sob a injeção de água em cores com saturações de água de alta salinidade. [4]

Outro fator que afeta as tecnologias de recuperação melhorada, e que têm um maior impacto na recuperação do óleo, é a molhabilidade. Se a molhabilidade do reservatório é alterada para uma condição mais molhável à água, a recuperação de petróleo tende a aumentar, como pode ocorrer também com o efeito da baixa salinidade. Austad et al. (2010), propuseram um novo mecanismo químico sobre o efeito de baixa salinidade. Este mecanismo proposto consiste da substituição de $\mathrm{Ca}^{2+}$ por $\mathrm{H}^{+}$sobre a superfície das argilas que estão carregadas negativamente. A injeção de água de baixa salinidade faz com que o $\mathrm{Ca}^{2+}$ seja retirado da superfície da argila, aumente $\mathrm{opH}$ local e retire parte do material orgânico, podendo resultar em aumentos da recuperação de óleo. [8]

Da literatura disponível sobre o efeito da salinidade no comportamento da injeção de água na EOR, pode-se resumir que esta tecnologia depende das interações entre petróleo/salmoura/rocha. [9]. Os mecanismos principais são:

- Propriedades, tipo e quantidade de argila presente na rocha;

- Separação e migração de argilas, Tang \& Morrow (1999);

- Intercâmbio iônico multicomponente, entre a superfície mineral e a salmoura deslocante (Lager et al., 2006);

- No caso de petróleo, tanto componentes polares quanto ácidos bases;

- Composição da salmoura de formação e pH;

- Redução da IFT (McGuire et al., 2005); e

- Mudança da Molhabilidade, Zhang \& Austad, (2006). 
Em contrapartida, Rivas \& Gutiérrez (1999), propõem que o deslocamento de óleo residual está sujeito a uma competição entre as forças viscosas e capilares. Os efeitos viscosos são responsáveis pelo impedimento do escoamento do óleo e as forças capilares responsáveis pela retenção do óleo por efeitos microscópicos no meio poroso. [10]

\section{2 .2}

\section{Injeção de Soluções de Surfactantes}

No caso de injeção de surfactante, o volume de óleo residual é reduzido quando o número de capilaridade é maior $10^{-6}$. [11]. A saturação de óleo residual tende a zero para número de capilaridade da ordem de $10^{-2}$, conforme apresentado na Figura 1-9. [12]

Salager [11] concluiu que a condição de mobilidade é favorecida pelo aumento da vazão de injeção e a viscosidade da água injetada. Além disso, a mobilidade é também favorecido por a queda da tensão interfacial.

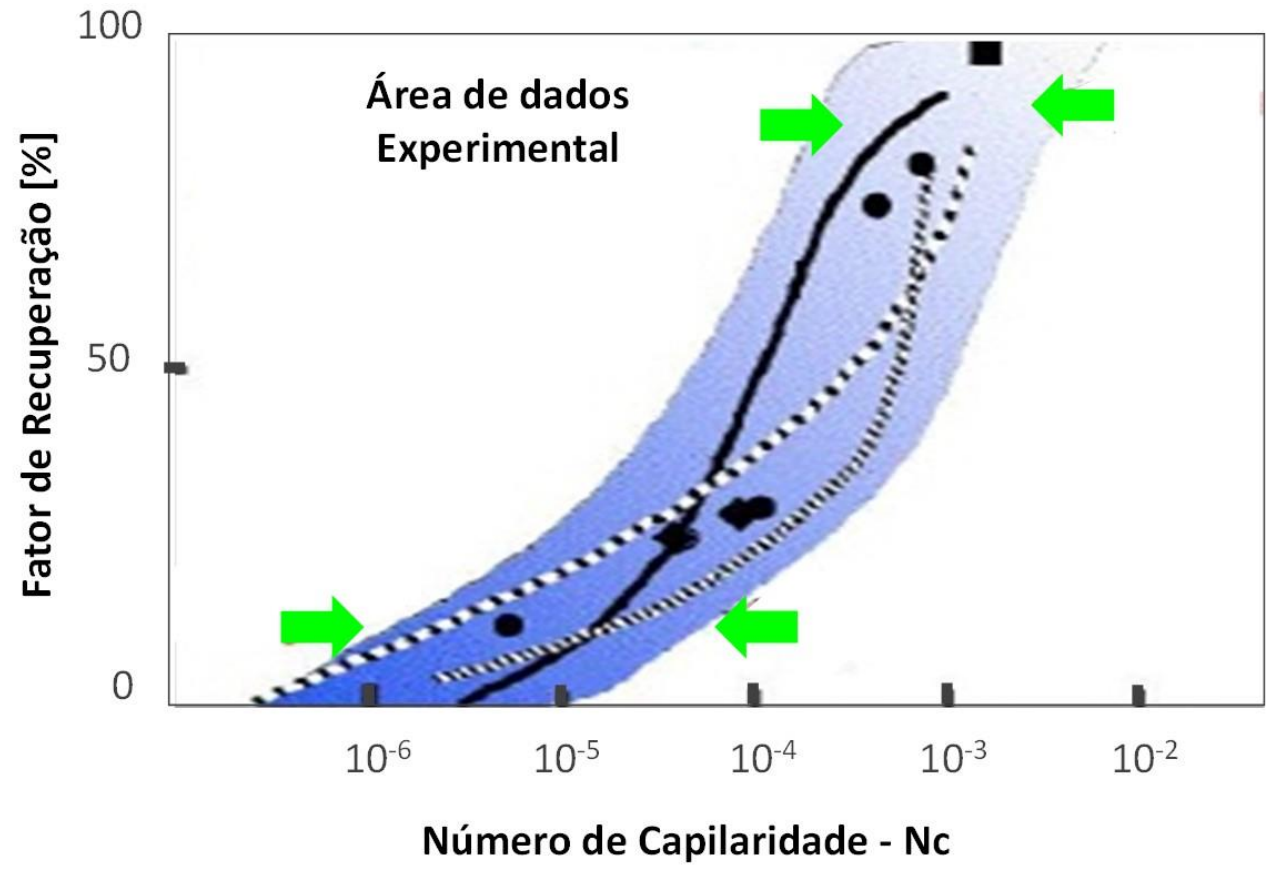

Figura 1-9: Efeito do número capilaridade na recuperação de óleo. [11]

O desempenho da injeção de surfactantes sobre o deslocamento do óleo residual e o controle de mobilidade é afetado pelos seguintes fatores: a salinidade da água conata, molhabilidade do reservatório, tensão interfacial óleo-água 
(capilaridade), mineralogia, interações rocha-fluido, perda de surfactante devido aos processos de adsorção, precipitação, etc.

Chou \& Shah [3], observaram que a adição de pequenas quantidades de argilas ou minerais em areias empacotadas diminuíam consideravelmente a eficiências da recuperação de óleo, mesmo quando as argilas ou cátions bivalentes estão ausentes ou em poucas quantidades. Somente a presença do composto $\mathrm{NaCl}$ reduz o desempenho dos processos. Estes efeitos prejudiciais podem frequentemente ser minimizados por meio de preflush e o estudo da salinidade ótima da batelada de surfactante. Este estudo da salinidade é feito para encontrar a concentração na qual as fases (óleo, salmoura e surfactante) se encontram em equilíbrio e a tensão interfacial é mínima. Esta salinidade é definida como a salinidade ótima da formulação de surfactante, (Figura 1-10). Os autores ressaltam que não há uma correlação bem estabelecida entre os valores de tensão interfacial, salinidade ótima e a eficiência na recuperação de petróleo.

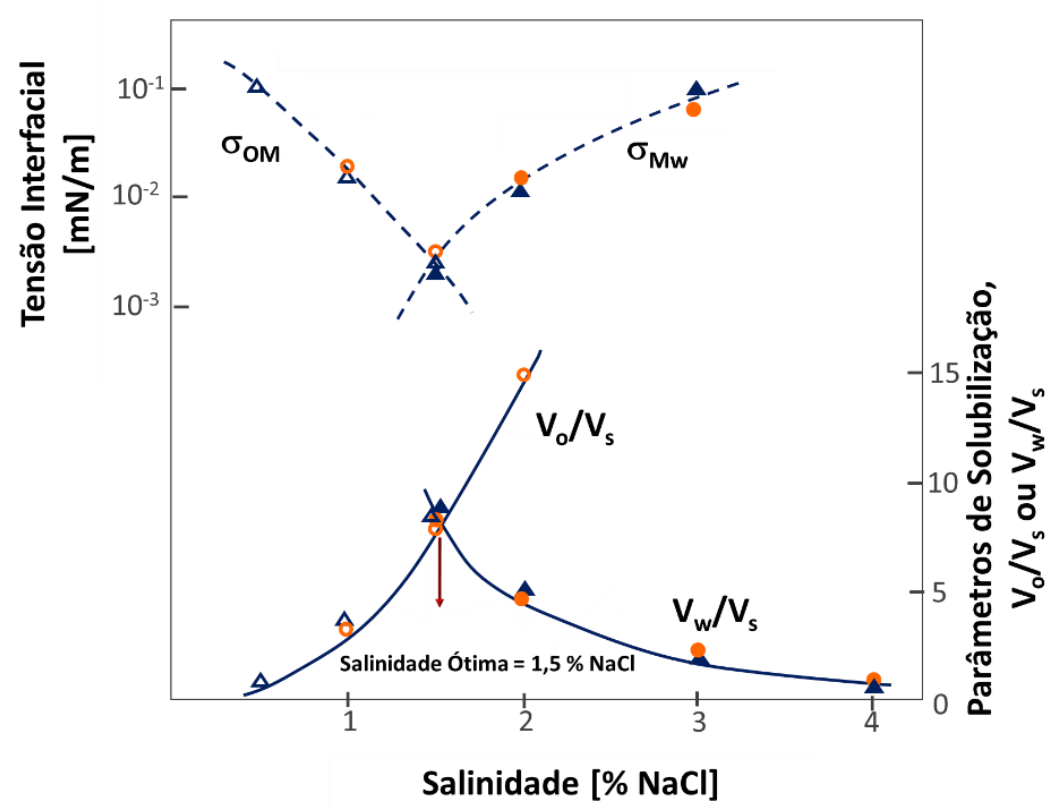

Figura 1-10: Efeito da salinidade sobre o comportamento da solubilização e tensão interfacial de óleos solúveis equilibrados com solução salina ou polímero. [13]

Vale destacar que maiores concentrações de surfactante na batelada de surfactante não necessariamente levam a tensões interfaciais mais baixas. Por exemplo, uma solução de polímero de baixa salinidade é capaz de dissolver elevadas concentrações de surfactante, porém, não necessariamente apresenta tensões interfaciais suficientemente baixas para deslocar o óleo residual. [3] 
A aplicação de surfactantes demanda um importante estudo de parâmetros como: a salinidade, a temperatura, a estabilidade química, o conteúdo de íons bivalentes, entre outros. Parâmetros estes que podem afetar as formulações a serem injetadas, as tensões superficial e interfacial, a concentração micelar crítica, o comportamento de fases e a adsorção, contribuindo para uma melhor ou pior recuperação do óleo residual.

\section{3}

\section{Objetivos da dissertação}

Pode-se observar que o efeito da salinidade da água injetada na recuperação de petróleo ainda não é bem entendida. A iteração da salinidade com a solução de surfactante pode trazer importantes efeitos no escoamento bifásico dentro do meio poroso.

O objetivo deste trabalho é estudar experimentalmente o efeito da salinidade da água e concentração de surfactante no processo de deslocamento de óleo.

\section{4 \\ Estrutura da dissertação}

Esta dissertação foi dividida em cinco capítulos:

Capitulo N¹ "Introdução": Nesta seção é apresentada a motivação, revisão bibliográfica e os objetivos da dissertação.

Capitulo №2 "Fundamentos Teóricos": Apresenta uma breve descrição sobre os conceitos mais relevantes relacionados às propriedades da rocha-fluido, recuperação melhorada de petróleo e mecanismos propostos para os efeitos da salinidade. Além de conceitos sobre injeção de surfactantes.

Capitulo N³ "Experimento": Este capítulo apresenta uma descrição detalhada dos procedimentos e a bancada experimental utilizados na obtenção dos resultados.

Capitulo N4 "Resultados": Apresentará os resultados obtidos a partir dos ensaios experimentais com uma pequena discussão.

Capitulo $N^{\circ} 5$ "Conclusões e sugestões": São citadas as conclusões de forma resumida e objetiva, assim como recomendações para trabalhos futuros. 


\section{2 \\ Fundamentos Teóricos}

\section{1}

\section{Propriedades básicas fluido e rocha}

Conhecer e entender as propriedades básicas da rocha-reservatório e dos fluidos no meio poroso é fundamental para determinar as forças que governam o fluxo através do meio poroso bem como as interações dos fluidos no interior da rocha e a sua capacidade de deslocamento.

As principais propriedades relevantes ao presente estudo são apresentadas a seguir.

\subsection{1 \\ Viscosidade}

É a medida da resistência ao escoamento de um fluido quando o mesmo é submetido a uma tensão cisalhante. Quanto mais viscoso o fluido, menor será a vazão para uma mesma diferença de pressão imposta.

\subsubsection{1 \\ Lei de Newton da Viscosidade}

De acordo com o Modelo de Newton, o valor da tensão de cisalhamento $\sigma$ é proporcional ao gradiente de velocidade $\gamma$ (taxa de deformação) gerado ao longo das camadas do fluido. Então, a viscosidade $\mu$ representa a constante de proporcionalidade entre eles, como é mostrado na equação (2.1).

$$
\sigma=\mu \gamma
$$

em que $\sigma$ é a tensão de cisalhamento; $\gamma$ é o gradiente de velocidade ou taxa de deformação e $\mu$ é a viscosidade. 


\subsection{2 Porosidade}

A porosidade $\phi$ de um meio poroso é uma medida da capacidade de armazenamento (volume de poros) dos fluidos ou da quantidade de espaço (vazios) entre os grãos do meio. Quantitativamente, a porosidade é a relação entre o volume poroso e o volume total (volume bruto), a qual pode ser dividida em:

- Porosidade absoluta;

- Porosidade efetiva.

A porosidade absoluta toma em consideração o espaço vazio total (incluindo poros não interconectados), enquanto, a porosidade efetiva só considera os poros interconectados vazios. Tanto na engenharia de reservatório como no presente trabalho é utilizado o valor da porosidade efetiva, que representa o espaço que contém os fluidos recuperáveis. [1]

Esta propriedade é definida pela seguinte relação:

$$
\phi=\frac{\text { Volume Porosolnterconectado }}{\text { VolumeTotal }}
$$

\subsection{3 \\ Permeabilidade}

A permeabilidade é uma propriedade física e complexa do meio poroso, que fornece informação sobre o grau de interconexão entre os poros, fraturas e a capacidade de deixar escoar os fluidos. Esta depende de fatores como o tamanho e interconectividade dos poro.

Esta propriedade foi definida matematicamente por primeira vez por Henry Darcy em 1856. Em termos quantitativos, é definida pela Lei de Darcy.

A equação de Darcy (2.3) foi desenvolvida para fluxo linear horizontal de fluidos incompressíveis em uma amostra de rocha de comprimento $L$ e uma área de seç̧ão transversal A, conforme esquematizado na Figura 2-1: 


$$
v=-\frac{k}{\mu} \frac{d p}{d L}
$$

em que v é a velocidade aparente do fluido escoando ou a vazão por unidade de área, $\mathrm{k}$ é a permeabilidade, $\mu$ é a viscosidade do fluido escoando e $\mathrm{dp} / \mathrm{dL}$ é a queda de pressão por unidade de comprimento.

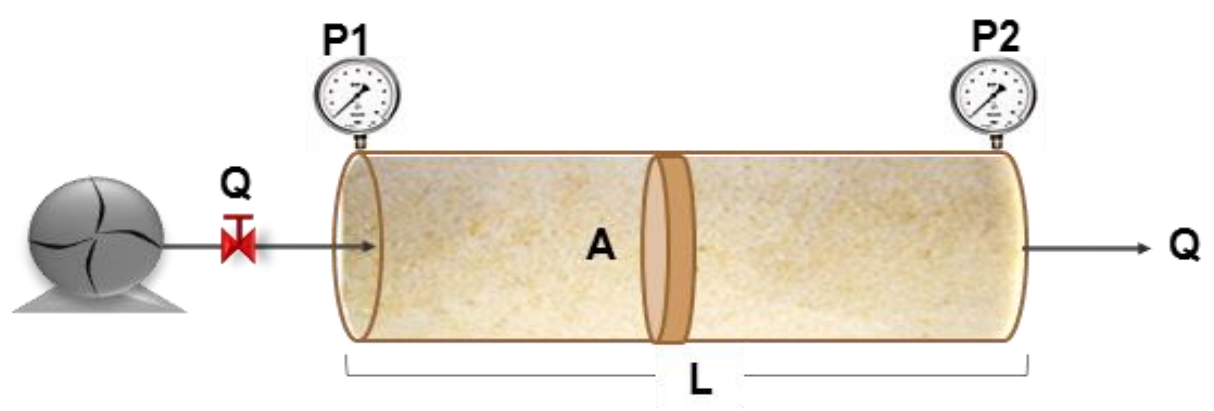

Figura 2-1: Fluxo linear em um meio poroso horizontal. [10]

A velocidade aparente da equação (2.3) pode ser determinada dividindo a vazão q, pela área da secção transversal $A$, através da qual o fluido irá escoar. Substituindo v, pela relação q / A se obtém:

$$
q=-\frac{k A}{\mu} \frac{d p}{d L}
$$

Existem três tipos de permeabilidade:

\subsubsection{1}

\section{Permeabilidade Absoluta ou Específica}

É uma propriedade do meio poroso e é medida na presença de uma única fase escoando através dele.

\subsubsection{2}

\section{Permeabilidade Efetiva}

É menor do que a permeabilidade absoluta, e mede a capacidade de um fluido se deslocar através do meio poroso na presença de outros fluidos. A facilidade com que os fluidos escoam, é prejudicada pela presença de outros 
fluidos no espaço poroso. Quanto maior for a presença de um determinado fluido, maior será a permeabilidade efetiva do mesmo, portanto, a permeabilidade efetiva varia fortemente com a saturação.

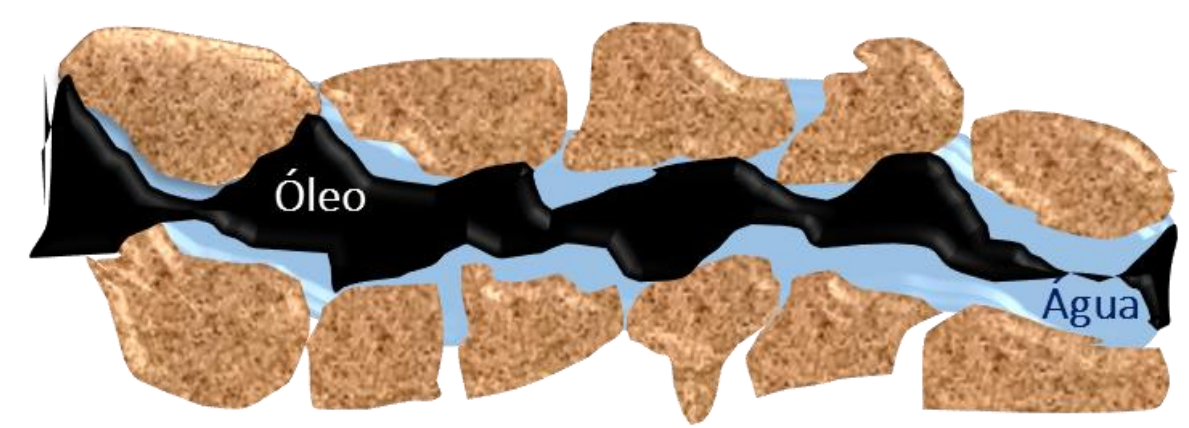

Figura 2-2: Representação de um meio poroso saturado com dois fluidos.

\subsubsection{3 \\ Permeabilidade Relativa}

É uma forma adimensional de representar a permeabilidade efetiva. É definida como a razão entre a permeabilidade efetiva $\left(K_{o}, K_{w}\right.$ ou $\left.K_{g}\right)$ e a permeabilidade absoluta $(\mathrm{K})$. A soma das permeabilidades relativas $\left(\mathrm{K}_{\mathrm{ro}}+\mathrm{K}_{\mathrm{rw}}+\mathrm{K}_{\mathrm{rg}}\right)$ é variável, e sempre menor ou igual que a unidade quando dois ou mais fluidos estão presentes, Lake (2007).

$$
\mathrm{K}_{\mathrm{ro}}=\frac{\mathrm{K}_{\mathrm{o}}}{\mathrm{K}} ; \mathrm{K}_{\mathrm{rw}}=\frac{\mathrm{K}_{\mathrm{w}}}{\mathrm{K}} ; \mathrm{K}_{\mathrm{rg}}=\frac{\mathrm{K}_{\mathrm{g}}}{\mathrm{K}}
$$

Os dados de permeabilidade relativa são extremamente importantes no gerenciamento do reservatório, já que descrevem como as fases escoam no reservatório e são dados de entrada essenciais aos simuladores de reservatórios usados pela indústria. Da Figura 2-3 podem ser obtidos dois valores de saturação importantes:

- Saturação de água conata $\left(\mathbf{S}_{\mathrm{wc}}\right)$ : é a saturação mínima de água a partir da qual a água se torna móvel, nesta saturação tanto a permeabilidade efetiva quanto a permeabilidade relativa da água são nulas. 
- Saturação de óleo residual (Sor): é a saturação de óleo que permanece nos poros após o deslocamento.

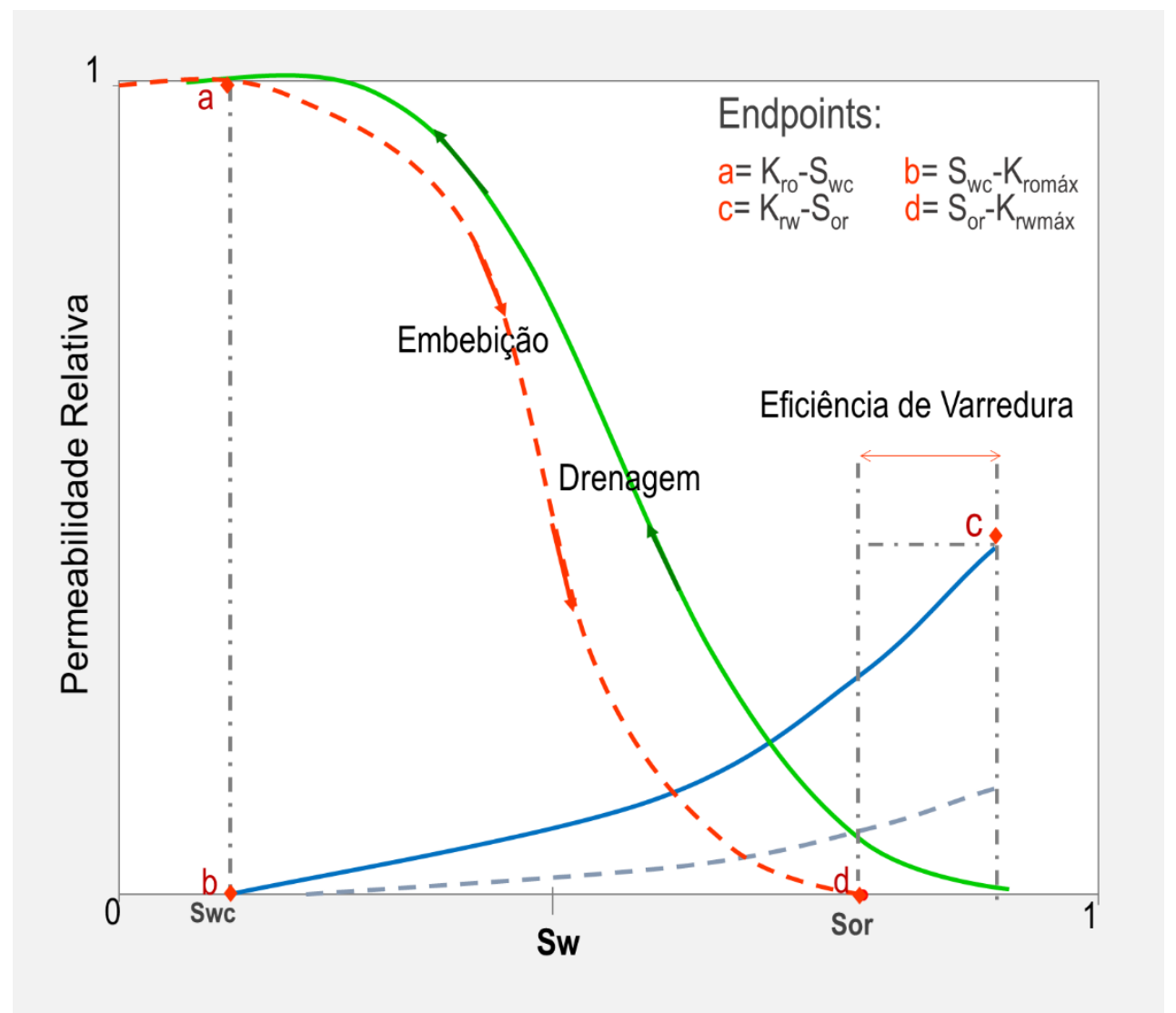

Figura 2-3: Curva de permeabilidade relativa em função da saturação de água.

O processo de saturação ocorre com a embebição ou drenagem em um meio poroso; durante estes processos os fluidos ocupam os poros da rocha em função do diferencial de pressão e da permeabilidade relativa.

- Drenagem: é referido como o processo onde a fase molhante é deslocada pela fase não-molhante, conforme indicado na Figura 2-4. A cada valor de pressão capilar, o espaço poroso é invadido pela fase não molhante até a interface atingir uma nova posição de equilíbrio, mudando assim a saturação das fases no meio poroso. [1]

- Embebição: é o processo onde a fase não-molhante é deslocada pela fase molhante a medida que a pressão capilar diminui. 


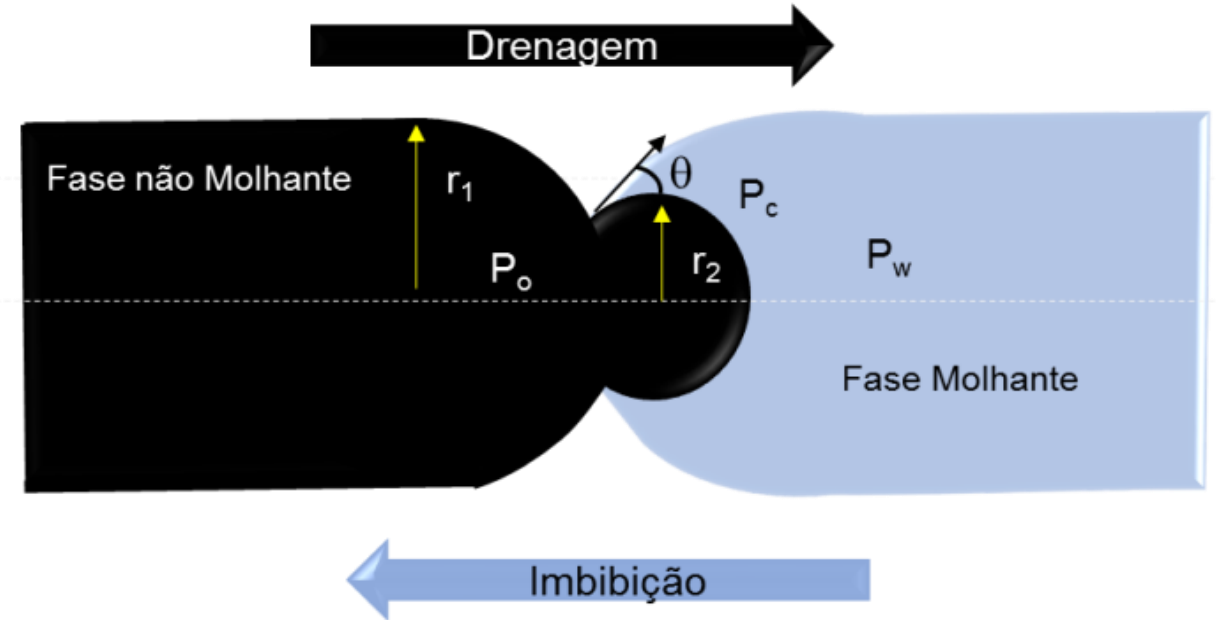

Figura 2-4: Óleo escoando em uma garganta de poro.

É habitual em testes de injeção de fluidos em meios porosos observar deslocamentos nas curvas de permeabilidade relativa depois da drenagem primária, quando se reverte a direção da saturação com o processo de embebição. As relações de drenagem e embebição primárias geralmente, diferem significativamente, para um sistema óleo / água como foi mostrado na Figura 2-3. Esta diferença é denominada efeito de histerese, e é resultado da forma complexa e das forças capilares. [13]

\subsection{4}

\section{Tensão Interfacial}

A tensão interfacial $(\sigma)$ é a força por unidade de comprimento ou energia por área e atua tangencialmente à superfície de contato entre dois fluidos imiscíveis. Representa o trabalho necessário para acrescentar uma unidade de área à interface, e pode ser medida sob condições de temperatura e pressão constantes.

$$
\mathrm{dw}=\sigma \mathrm{dA}
$$

A medida da tensão interfacial entre dois líquidos pode ser feita através de diversos tipos de ensaios como o método da placa de Wilhelmy, o método do anel de Du Nouy, o método da gota pendente, o método da gota girante e o método da coluna capilar. A escolha do método mais adequado vai depender principalmente, da natureza dos líquidos envolvidos e do grau de precisão requerido. Os métodos 
mais usados nas medidas da tensão interfacial entre as soluções oleosas e aquosas com surfactantes são da gota girante e da gota pendente. [14]

\subsection{5}

\section{Pressão Capilar}

A tensão interfacial agindo em uma interface curva entre dois fluidos causa uma diferença de pressão entre as duas fases. A pressão do fluido localizado no lado côncavo da interface é maior do que a pressão do lado convexo. A diferença de pressão é proporcional à tensão interfacial e inversamente proporcional ao raio de curvatura da interface. Quanto menor o raio de curvatura da interface, maior será a diferença de pressão entre as duas fases.

No meio poroso, o raio de curvatura das interfaces óleo-água é pequeno devido às dimensões dos poros, tornando maior a diferença de pressão entre as duas fases.

No reservatório a pressão capilar é definida como a diferença de pressão entre a fase não molhante e a fase molhante.

$$
\mathrm{P}_{\mathrm{c}}=\mathrm{P}_{\mathrm{nm}}+\mathrm{P}_{\mathrm{m}}
$$

em que Pc é a pressão capilar, Pnm é a pressão da fase não molhante, e Pm é pressão da fase molhante.

Na Engenharia de Petróleo, a pressão capilar em um sistema óleo-água é definida por:

$$
\mathrm{P}_{\mathrm{c}}=\mathrm{P}_{\mathrm{o}}+\mathrm{P}_{\mathrm{a}}
$$

em que Pc é a pressão capilar, Po é a pressão na fase oleosa e Pa é a pressão na fase aquosa. Assim, para um sistema óleo-água temos:

- $\quad P c>0$, superfície molhada pela água.

- $\quad$ Pc $<0$, superfície molhada pelo óleo.

O efeito da capilaridade é ilustrado na Figura 2-4. Ao se introduzir um capilar de vidro (molhado preferencialmente por água) em um recipiente contendo água e óleo, e logo passando pela interface das duas fases, é observado como a água 
sobe pelo capilar até que o equilíbrio das pressões da água e óleo sejam atingidas. O equilíbrio de pressão em um mesmo nível de referência pode ser escrito como:

$$
\begin{gathered}
\mathrm{P}_{\mathrm{o}}+\rho_{\mathrm{o}} g h=\mathrm{P}_{\mathrm{a}}-\rho_{\mathrm{a}} g h \\
\mathrm{P}_{\mathrm{c}}=\left(\rho_{\mathrm{a}}-\rho_{\mathrm{o}}\right) g h
\end{gathered}
$$

em que $\rho_{o}$ é a densidade do óleo, $\rho_{a}$ é a densidade da água e g é a aceleração da gravidade.

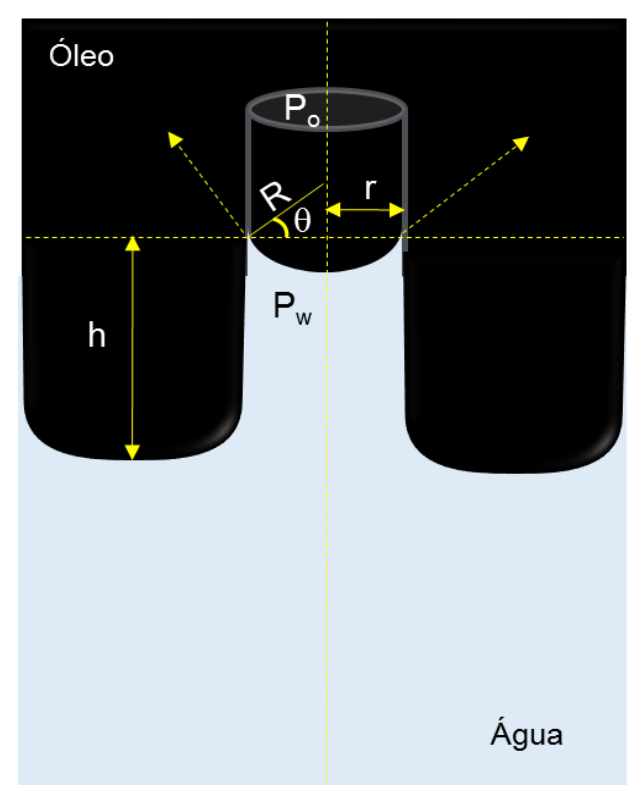

Figura 2-5: Elevação de água em um tubo capilar.

O lado côncavo da interface corresponde à fase não molhante (óleo), e sua pressão será sempre maior do que a pressão da fase molhante. Admitindo que a interface óleo-água é uma superfície esférica, a pressão capilar pode ser dada pela equação de Laplace:

$$
\mathrm{P}_{\mathrm{c}}=\frac{2 \sigma_{\mathrm{ao}}}{\mathrm{R}}=\frac{2 \sigma_{\mathrm{ao}} \operatorname{Cos} \theta}{\mathrm{r}}=\left(\rho_{\mathrm{a}}-\rho_{\mathrm{o}}\right)
$$

em que $\mathrm{R}$ é o raio de curvatura da superfície esférica que pode ser representada também como $\mathrm{R}=\frac{\mathrm{r}}{\cos \theta}$, sendo r o raio menor interno do tubo capilar.

A equação (2.11), indica que o efeito da capilaridade é mais forte nos poros menores da rocha e portanto, a água atingira as maiores alturas nos capilares de 
menor dimensão. Se o reservatório for considerado como um conjunto de capilares de diâmetros diferentes, a água estará presente em diferentes profundidades, dependendo do tamanho dos poros da rocha. A Figura 2-6 ilustra a água contida em um poro representado como dois grãos.

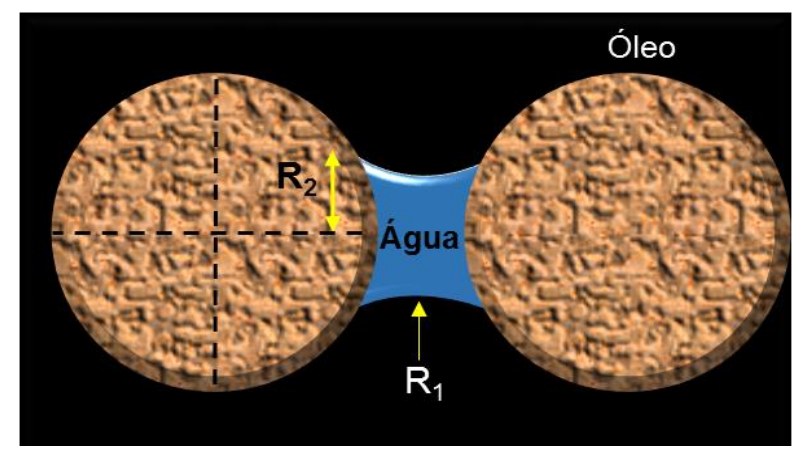

Figura 2-6: Capilaridade em um empacotamento de grãos esféricos.

A pressão capilar em qualquer ponto da interface dos fluidos pode ser obtida através da equação de Laplace:

$$
\mathrm{P}_{\mathrm{c}=\sigma_{\mathrm{ao}}}\left(\frac{1}{\mathrm{R}_{1}}-\frac{1}{\mathrm{R}_{2}}\right)
$$

em que $R_{1}$ e $R_{2}$ são os raios principais de curvatura da interface. Os raios são medidos em planos perpendiculares. A equação expressada anteriormente leva ao seguinte:

- $\mathrm{R}_{1}<\mathrm{R}_{2} \rightarrow \mathrm{P}_{\mathrm{c}}>0$ (molhabilidade à água)

- $\mathrm{R}_{1}>\mathrm{R}_{2} \rightarrow \mathrm{P}_{\mathrm{c}}<0$ (molhabilidade ao óleo)

Se o volume de água em torno dos grãos da rocha diminui, o raio de curvatura $\mathrm{R}_{1}$ decresce, e conforme à equação de Laplace, a pressão capilar aumentará. [15]

\subsection{6}

\section{Número de Capilaridade}

O número de capilaridade é uma variável adimensional que representa a relação entre as forças viscosas e forças capilares que atuam em uma interface entre dois fluidos imiscíveis. É definida pela equação (2.13). 


$$
\mathrm{N}_{\mathrm{c}}=\frac{\mathrm{F}_{\mathrm{v}}}{\mathrm{F}_{\mathrm{c}}}=\frac{\vartheta \mu_{\mathrm{w}}}{\sigma_{\mathrm{ow}} \cos \theta}
$$

em que $F_{v}$ e $F_{c}$ são as forças viscosas e capilares, respectivamente, $\vartheta$ é a velocidade intersticial, $\mu_{\mathrm{w}}$ é a viscosidade da fase deslocante, $\sigma_{o w}$ é a tensão interfacial entre as fases óleo e água e $\theta$ é o ângulo de contato. Se for assumido que o meio é fortemente molhável à água, então $\operatorname{Cos} \theta=1$, a equação (2.13) pode ser aproximada:

$$
\mathrm{N}_{\mathrm{c}}=\frac{\mathrm{F}_{\mathrm{v}}}{\mathrm{F}_{\mathrm{c}}}=\frac{\vartheta \mu_{\mathrm{w}}}{\sigma_{\mathrm{ow}}}
$$

No deslocamento de fluidos imiscíveis em reservatórios de petróleo, quanto maior for o número de capilaridade, maior será a predominância das forças viscosas sobre as forças capilares. Segundo Abrams (1975), os processos de injeção de água caracterizam-se por alcançar valores de número de capilaridade menores a $10^{-6}$, deixando no reservatório entre $30 \%$ e $50 \%$ do óleo recuperável distribuído em forma de pequenas gotas imóveis nos poros da rocha.

Abrams (1975) apresentou o comportamento decrescente da saturação de óleo residual com o incremento do número de capilaridade, conforme esquematizado na Figura 2-7, para um sistema molhável à água.

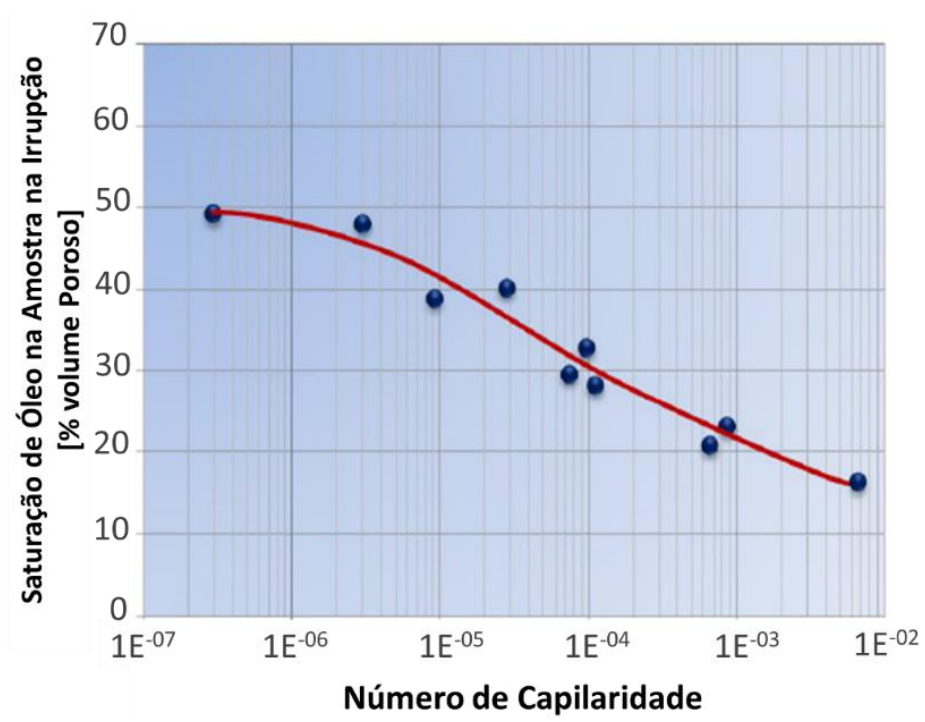

Figura 2-7: Correlação entre o número de capilaridade e a saturação de óleo residual em reservatórios molháveis à água. [2] 


\subsection{7}

\section{Molhabilidade}

O termo molhabilidade é utilizado para descrever a tendência de espalhamento ou aderência de um fluido sobre uma superfície sólida na presença de outro fluido imiscível.

Em um meio poroso, quando o sistema estiver em equilíbrio, a fase molhante irá ocupar completamente os poros menores e estará em contato com uma parte da superfície da rocha, se a saturação do fluido molhante for suficientemente elevada. O fluido não molhante ocupará o centro dos poros maiores e formará gotículas que se espalharam ao longo dos poros. O fluido que ocupa os poros maiores tem permeabilidade relativamente elevada, em comparação com o fluido que ocupa os poros menores. [16]

A forma da interface entre os fluidos imiscíveis resulta da interação entre as forças moleculares que atuam nas interfaces líquido-líquido e líquido-sólido. $\mathrm{Na}$ Figura 2-8, é apresentado um sistema óleo-água em contato com uma superfície de rocha.

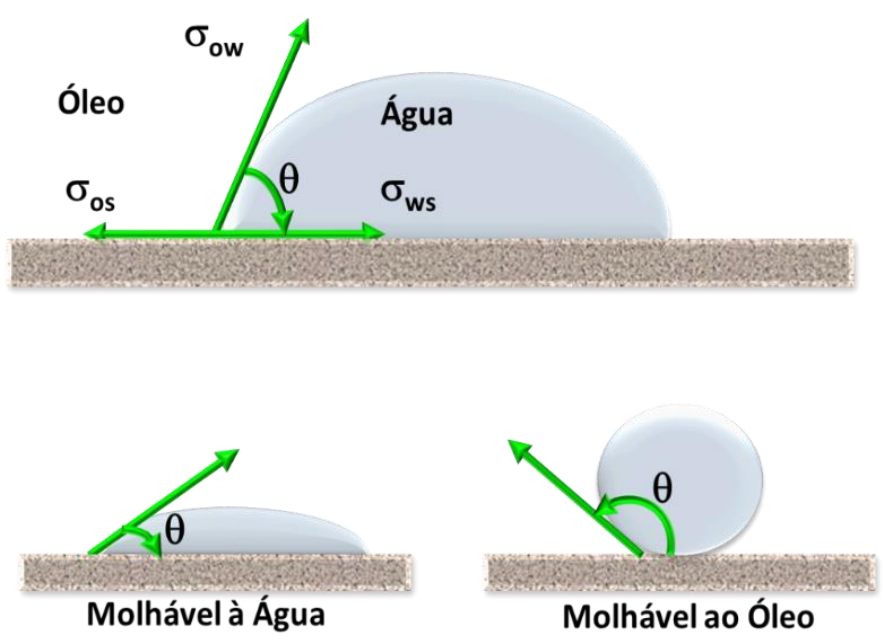

Figura 2-8: Molhabilidade em rochas reservatório. [17]

A tensão de adesão das fases presentes no reservatório At é definida como:

$$
A_{t}=\sigma_{o r}+\sigma_{a r}=\sigma_{a o} \cos \theta
$$

em que $\sigma_{o r}$ é a tensão interfacial entre o óleo e a rocha, $\sigma_{a r}$ é a tensão interfacial entre a água e a rocha, $\sigma_{a o}$ é a tensão interfacial água-óleo, e $\theta$ é o ângulo de contato. [17] 
Nos reservatórios existem diferentes tipos de molhabilidade dependendo da aderência do líquido à superfície dos poros. A seguir estão os diferentes tipos de molhabilidade:

- Fortemente molhável à água: a água ocupa os poros pequenos e a maior parte da superfície da rocha.

- Fortemente molhável ao óleo: o óleo ocupa os poros menores e espalha-se sobre a maioria da superfície da rocha, enquanto a água ocupa os poros maiores.

- Molhabilidade mista ou heterogênea: os componentes do petróleo são fortemente adsorvidos em certas áreas da rocha, portanto, parte da rocha é fortemente molhada ao óleo e o resto da área molhada pela água.

Os componentes mais pesados do óleo são adsorvidos sobre a superfície da rocha, e são conhecidos como surfactantes naturais, um exemplo deles são os asfaltenos. [16]

A tabela (2.1) contém a faixa de valores do ângulo de contato tipicamente encontrados em rochas-reservatório.

\begin{tabular}{cccc}
\hline Parâmetro & $\begin{array}{c}\text { Molhado } \\
\text { por Água }\end{array}$ & $\begin{array}{c}\text { Molhabilidade } \\
\text { Neutra }\end{array}$ & $\begin{array}{c}\text { Molhado por } \\
\text { Óleo }\end{array}$ \\
\hline \hline $\begin{array}{c}\text { Ângulo de Contato } \\
\text { Mínimo }\end{array}$ & 0 & $60-75$ & $105-120$ \\
Maximo & $60-75$ & $105-120$ & 180 \\
Índice USBM (U.S. Bureau of Mines) & $\sim 1$ & $\sim 0$ & $\sim-1$ \\
Índice de Amott & & & \\
Razão Deslocamento por Água & Positivo & Zero & Zero \\
Razão de Deslocamento por Óleo & Zero & Zero & Positivo \\
Índice Amott-Harvey & $0,3 / 1$ & $-0,3</<0,3$ & $-1 /-0,3$ \\
\hline
\end{tabular}

Tabela 2-1: Classificação da molhabilidade segundo os diferentes métodos. [16]

Existe uma relação forte entre a tensão superficial e a molhabilidade. As substâncias com elevada tensão superficial tendem a formar gotas praticamente esféricas sobre a superfície (molhando pouco). Isso é explicado pelas elevadas forças de atração entre as moléculas do líquido que as mantêm juntas. É possível, 
definir a molhabilidade do fluido pelo ângulo de contato medido entre as superfícies.

Quando um ângulo for menor que $90^{\circ}$ o fluido é considerado molhante. Para ângulos maiores que $90^{\circ}$ o fluido será considerado não molhante. Para o caso especial, quando o equilíbrio não possa ser alcançado $\theta$ terá um valor de $180^{\circ}$, e o fluido será chamado de totalmente molhante.

\subsection{8}

$\mathrm{pH}$

O pH de uma solução aquosa é uma medida da acidez e pode ser definido como o logaritmo negativo da concentração de íons de hidrogênio.

$$
p_{H}=-\log _{10}\left[H_{3} O^{+}\right]
$$

\subsection{9}

\section{Surfactantes ou Tensoativos}

Os surfactantes são conhecidos como agentes tensoativos, representam uma classe de moléculas anfifílicas e têm caráter ambivalente, pois uma parte da molécula é formada por um grupo polar ou iônico que possui grande afinidade com a fase aquosa (parte hidrofílica) e a outra parte é geralmente formada por uma cadeia hidrocarbonatos que possui pouca afinidade com a fase aquosa (parte hidrofóbica). Na maioria das vezes, essa cadeia está ligada através de radicais alquila que têm entre 8 e 18 átomos de carbono, possuindo uma estrutura ramificada ou linear.

As propriedades incomuns das soluções com diferentes tipos de surfactantes são resultado das fortes interações da parte hidrofílica com a fase aquosa. A classificação mais comum dos surfactantes é feita a partir da carga do grupo polar da cabeça da molécula como: Aniônicos, Catiônicos e Não-lônicos.

Um surfactante altera as propriedades da interface entre os fluidos, diminuindo a tensão interfacial entre as fases. Além disso, o surfactante forma 
uma barreira entre as fases que impede a coalescência entre as gotas da fase dispersa.

A representação de um surfactante é usualmente feita por uma longa cadeia carbônica de caráter oleofílica (cauda) e uma extremidade (cabeça) de característica hidrofílica. Os surfactantes mais utilizados na recuperação avançada de petróleo usualmente possuem uma cabeça composta por um íon $\left(\mathrm{Ca}^{+2}, \mathrm{Na}^{+}, \mathrm{Cl}^{-}\right.$ou $\left.\mathrm{Br}^{-}\right)$.

\subsubsection{1}

\section{Classificação dos Surfactantes}

Os tensoativos podem ser divididos em dois grupos de acordo com a natureza da porção hidrofílica, iônicos e não iônicos (Fernandes, 2005). A Figura 2-9 mostra a representação esquemática dos tipos de tensoativos:
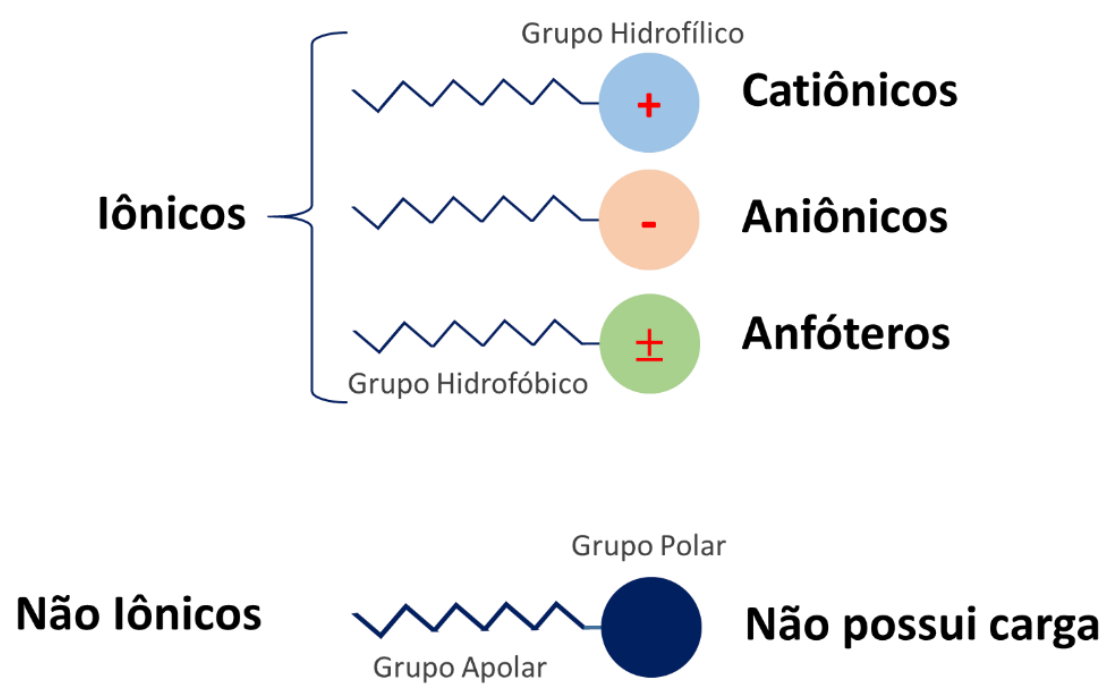

Figura 2-9: Representação esquemática dos surfactantes. [2]

- Surfactantes iônicos: são classificados de acordo com a estrutura do grupo hidrofílico em que o meio aquoso se dissocia em íons. As cargas dos tensoativos iônicos tendem a se repelir na superfície, e constituem um mecanismo de estabilidade em sistemas dispersos. De acordo com Bezerra (2012), estes surfactantes podem ser classificados em: Surfactantes aniônicos, catiônicos e anfóteros. [18] 
- Surfactantes não iônicos: eles não possuem carga em suas moléculas, mas apresentam uma parte lipofílica e outra hidrofílica que se solubiliza em água, ligando-se através de pontes de hidrogênio (Borsato, 2004). Possuem algumas características particulares que são compatíveis quimicamente com a maioria dos outros tensoativos, e suas propriedades são pouco afetadas pelo $\mathrm{pH}$.

Este tipo de surfactantes geralmente contém um grupo polar formado a partir de algum poliéter ou polihidróxilo, sendo o mais comum o tipo de poliéter composto por unidades de oxietileno. $\mathrm{O}$ processo industrial conhecido como etoxilação consiste na adição do óxido de etileno, usualmente em condições alcalinas, ácidos graxos, fenóis, aminas e alguns álcoois, para a obtenção de agentes de superfície ativa. Os surfactantes não iônicos mais importantes são aqueles produzidos da etoxilação de álcoois, devido a sua forte capacidade de detergência e sua habilidade para estabilizar diferentes tipos de emulsões.

\subsubsection{2 \\ Propriedades dos Tensoativos}

Na recuperação melhorada de petróleo com surfactantes, é importante conhecer as propriedades dos tensoativos e entre as principais propriedades temos:

- Micelização: quando um surfactante é adicionado a um sistema bifásico, tende a se concentrar na interface. Inicialmente, o aumento da concentração de surfactante é acompanhado pela diminuição da tensão interfacial. A interface aceita moléculas de surfactante até atingir uma concentração máxima, a partir daí, as moléculas de surfactante adicionadas vão se dispersando no interior da fase contínua em forma livre.

O aumento da concentração de tensoativos tende a promover a formação de estruturas chamadas micelas, em que as moléculas se agrupam pelas suas extremidades hidrofóbicas. Essa configuração 
se forma naturalmente por ser mais estável da que a presença de moléculas livres na solução.

A menor concentração de tensoativos em que é observada a formação de micelas é denominada concentração micelar crítica (CMC) que também corresponde ao valor mínimo da tensão interfacial. A determinação da CMC é feita experimentalmente medindo-se a tensão interfacial para diversas concentrações do surfactante até atingir um valor de tensão constante. A capacidade máxima de surfactante a se adicionar ao sistema, depende da sua solubilidade na fase contínua.

Existe uma condição limite quando se incrementa a concentração de surfactante, a partir da qual, não é possível obter uma maior redução da energia livre de superfície. Geralmente, esse limite é atingido quando o fenômeno de formação das micelas em solução inicia espontaneamente.

A concentração de surfactante no início do fenômeno de formação das micelas é considerada um ponto de referência, a partir da qual é observada uma mudança drástica nas propriedades físico-químicas do surfactante. A concentração micelar crítica é única para cada surfactante e é função da temperatura, da natureza do surfactante e das impurezas presentes na mistura.

Preston (1948), através de testes experimentais representou graficamente a concentração micelar crítica (CMC) do Lauril Sulfato de sódio (surfactante aniônico). Ele observou uma pequena faixa de concentração, na qual, a maioria das propriedades físico-químicas apresentaram uma mudança abrupta, conforme mostrado na Figura 2-10. 


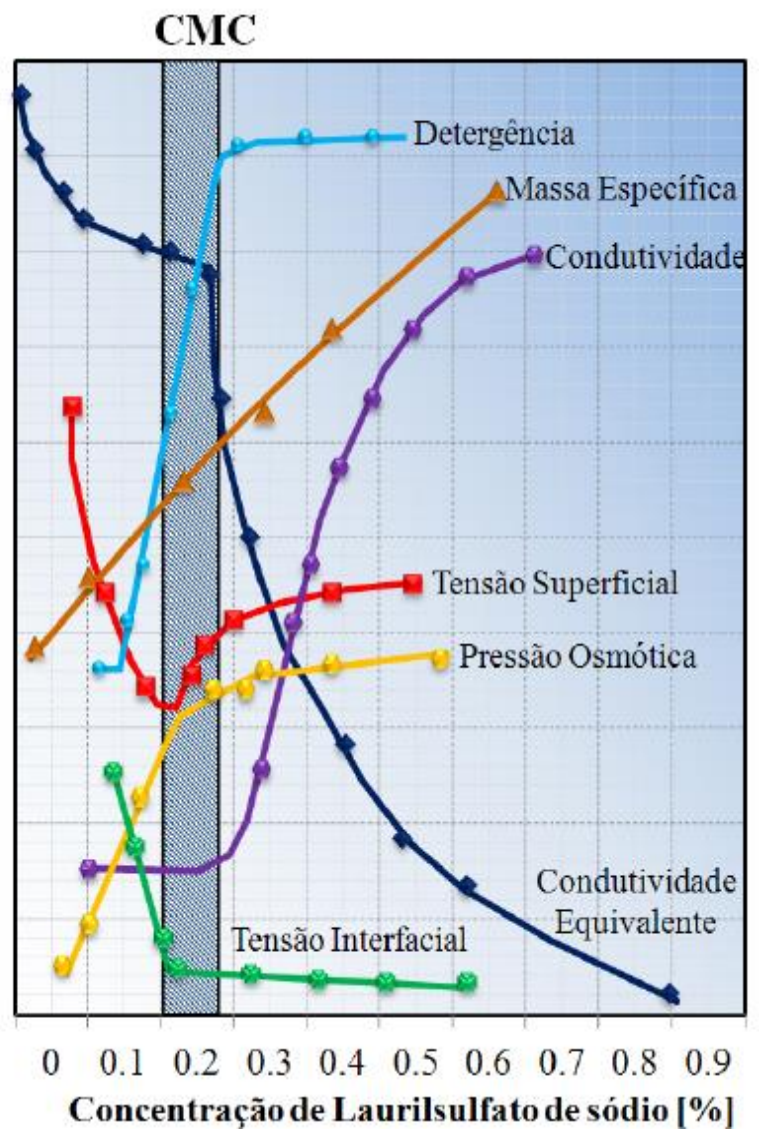

Figura 2-10: Propriedades físicas do Laurilsulfato de Sódio. [2]

Em 2000, Schramm apresentou alguns dos métodos comuns para a medição da concentração micelar crítica:

- Espectroscopia UV/visível;

- Espectroscopia de infravermelho;

- Espectroscopia de fluorescência;

- Espectroscopia NMR;

- Técnicas de dispersão;

- Medição de Condutividade Elétrica;

- Calorimetria e;

- Medição da Tensão Superficial

Neste trabalho, foi determinada a CMC medindo a tensão interfacial em função da variação da concentração de surfactante, a $40^{\circ} \mathrm{C}$. 
- Salinidade: durante o uso de surfactantes como método de recuperação avançada de óleo, o sistema deve manter-se quimicamente estável para diminuir a tensão interfacial, e manter uma baixa taxa de adsorção nas condições de temperatura e pressão, determinadas.

A instabilidade gerada na mistura é o resultado da redução da solubilidade do surfactante na salmoura, devida à alta concentração de eletrólitos. O comportamento de fases dos sistemas surfactanteóleo-água é analisado graficamente através de diagramas ternários de pseudo-componentes, sendo o surfactante representado no topo, o óleo no ápice direito e a salmoura no ápice esquerdo.

- Winsor Tipo II: para sistemas de baixa salinidade Tipo II (-), a solubilidade do surfactante é maior na fase aquosa. Esse tipo de ambiente caracteriza-se pela existência no máximo de duas fases. As fases formadas são óleo puro e uma microemulsão que contém salmoura, surfactante e uma pequena quantidade de óleo solubilizado. Para sistemas de alta salinidade, o ambiente característico é chamado de Ambiente Tipo II (+). Nesse caso também são formadas no máximo duas fases, uma salmoura de alta salinidade e uma microemulsão que contém óleo, surfactante e uma pequena quantidade de salmoura.

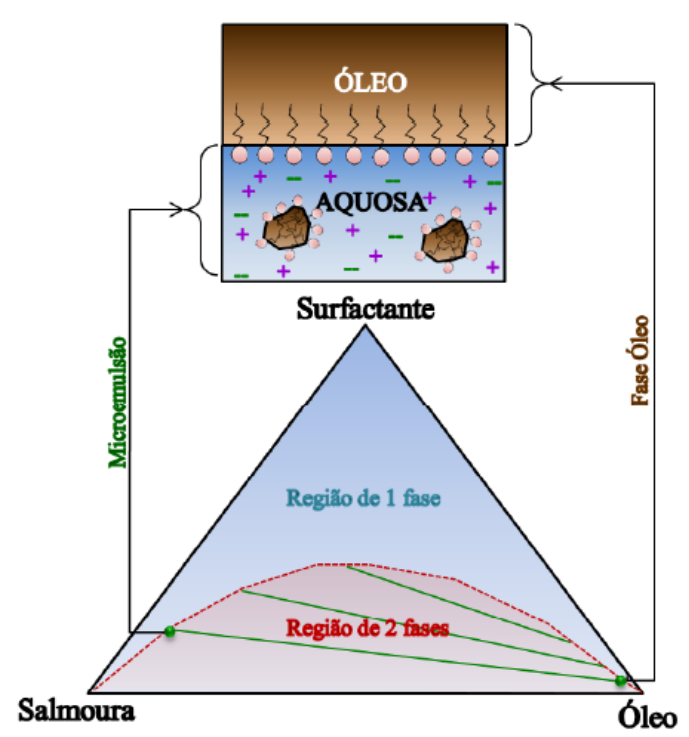

Figura 2-11: Diagrama de fases para o ambiente Tipo II(-). [2] 
- Winsor Tipo III: para sistemas de salinidade intermediária, o ambiente característico é chamado de Ambiente Tipo III, no qual pode existir três fases em equilíbrio, como mostrado na Figura 2-12. Estes sistemas caracterizam-se pela geração de tensões interfaciais mais baixas, sendo esta a condição ótima para o processo de injeção de surfactantes. Os diagramas ternários para os pseudocomponentes evidenciam uma região de uma fase localizada na parte superior, duas regiões de duas fases e uma região de três fases na parte inferior (região de baixas concentrações de surfactante) formando um triângulo.

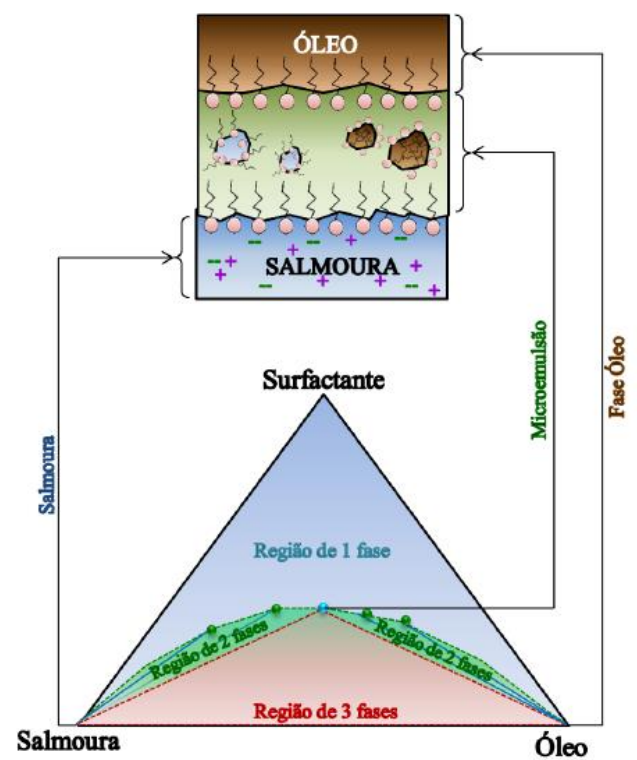

Figura 2-12: Diagrama de fases para o ambiente Tipo III. [2]

Considerando três possíveis fases no sistema, existirão dois tipos de interfaces: a interface entre a fase aquosa e a fase da microemulsão, e a interface entre a fase oleosa e a fase da microemulsão. A tensão da interface óleomicroemulsão $\sigma_{\mathrm{mo}}$ decresce de forma apreciável em função da salinidade, por causa do aumento da solubilidade do surfactante na fase oleosa nessa direção. Consequentemente, o efeito contrário ocorre com a tensão da interface águamicroemulsão $\sigma_{\mathrm{mw}}$, ou seja, a solubilidade dos surfactantes será maior quando a concentração de eletrólitos dissolvidos é menor promovendo a uma menor tensão interfacial.

As curvas da Figura 2-13 mostram o efeito da variação da salinidade para: o sistema composto de uma mistura de surfactantes com $63 \%$ de dodecil o-xileno 
sulfonato de monoetanolamina (MEAC12OXS) e 37\% de 2-metil-2-butanol (TAA), e um sistema composta de uma fase oleosa com $90 \%$ de Isopar-M (I) e 10\% de Nafta pesada aromática $(\mathrm{H})$.

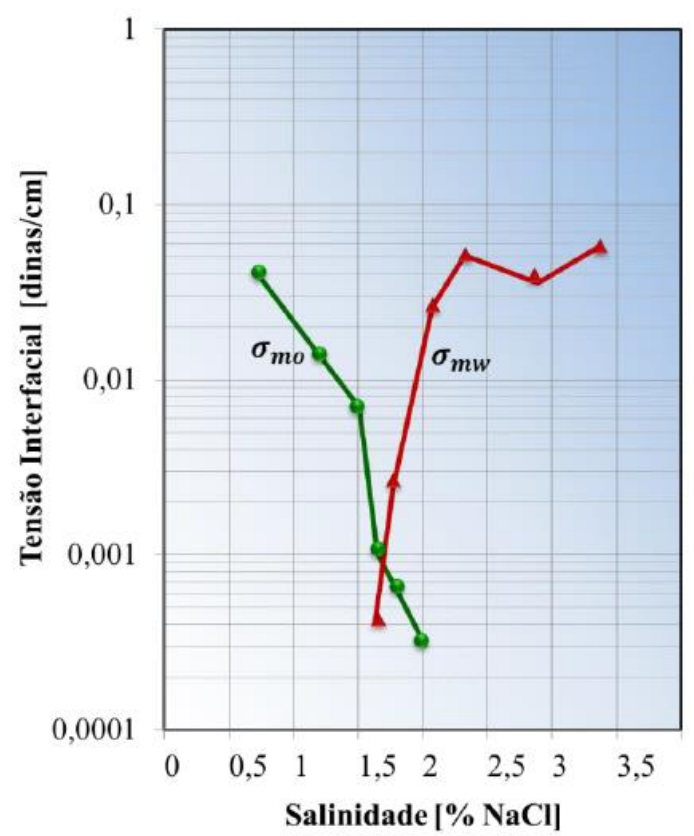

Figura 2-13: Tensão interfacial e Salinidade ótima. [2]

- Parâmetros de Solubilização: o valor de salinidade no qual $\sigma_{\mathrm{mo}}=$ $\sigma_{\mathrm{mw}}$ é chamado de Salinidade Ótima. Tipicamente, a sensibilidade dos equipamentos de medida de tensão interfacial não permite fazer uma medição representativa da propriedade no ponto de salinidade ótima (Green e Willhite, 1998). Usualmente a salinidade ótima é determinada através do cálculo dos parâmetros de solubilização.

Healy e Reed (1974) definiram os parâmetros de solubilização do óleo e da água como a razão entre o volume de cada fase (óleo e água) e o volume de surfactante contido na fase da microemulsão, sem incluir o volume de co-surfactante.

Através de testes de comportamento de fases é possível obter valores dos parâmetros de solubilização $\left(P_{o}, P_{w}\right)$ e assim, obter valores aproximados da tensão interfacial. Os testes são levados a cabo em recipientes de vidro a uma razão volumétrica 1:1 preparando, soluções com óleo e água a diferentes concentrações de surfactante, com o fim de observar o comportamento da mistura em uma faixa de salinidade, ou concentração de algum tipo de eletrólito, a uma temperatura definida. A variação da salinidade modifica o comportamento interfacial e a fase 
da microemulsão observada, desde o Ambiente tipo II(-), que é característico de salinidades baixas, até o Ambiente tipo $\mathrm{II}(+)$, próprio de salinidades altas, passando pelo Ambiente tipo III que é um ambiente de transição no qual geralmente encontra-se a Salinidade Ótima.

Os volumes das fases são medidos constantemente, observando-se também a aparência das fases e o tempo de estabilização. A partir dos volumes medidos são determinados os volumes de surfactante e de óleo na microemulsão $\left(V_{o}\right.$ e $\left.V_{w}\right)$ e, posteriormente os parâmetros de solubilização $\left(P_{\circ}\right.$ e $\left.P_{w}\right)$. As tensões interfaciais podem ser calculadas utilizando-se as equações a seguir de Chun-Huh e Huh, 1979:

$$
\begin{gathered}
\sigma_{m o}=\frac{0,3}{P_{o}^{2}} \\
\sigma_{m o}=\frac{0.3}{P_{w}^{2}}
\end{gathered}
$$

Usualmente, os valores da salinidade ótima obtidos a partir da análise dos parâmetros de solubilização das fases $V_{o} / V_{s}$, e da medição da tensão interfacial $\sigma_{\mathrm{mo}}=\sigma_{\mathrm{mw}}$ são próximos para a maioria dos surfactantes (Green e Willhite, 1998). Assim, é possível determinar a salinidade ótima através de medições dos parâmetros de solubilidade sem medir as tensões interfaciais, conforme mostrado na Figura 2-14

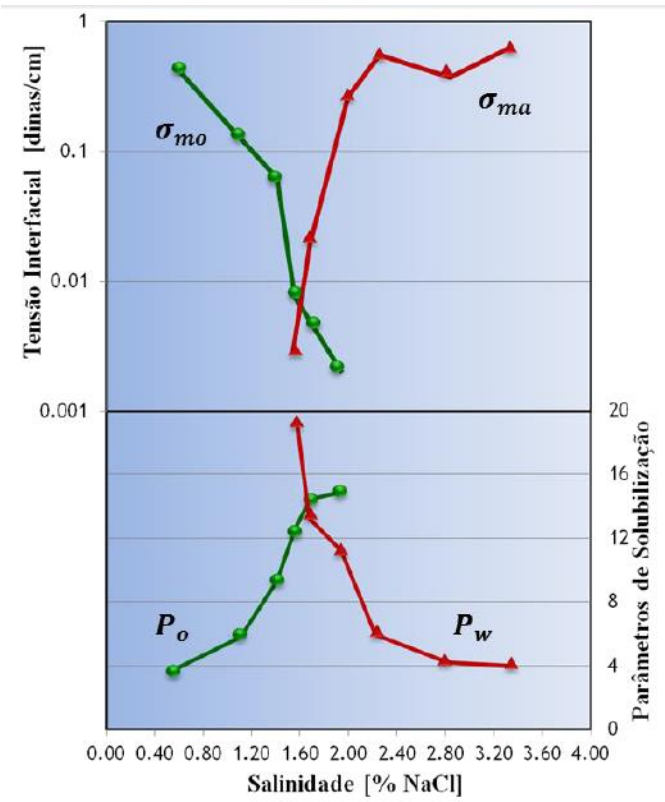

Figura 2-14: Parâmetros de solubilização e salinidade ótima. [2] 


\section{2 \\ Recuperação avançada de petróleo}

Há muita confusão em torno do uso dos termos EOR (Enhanced Oil Recovery) e IOR (Improve Oil Recovery). A Figura 2-15 mostra estes em termos dos métodos de recuperação de óleo, tal como definido pela Sociedade de Engenheiros de Petróleo (SPE). A recuperação primária e/ou secundária (recuperação convencional) tem como objetivo recuperar o óleo móvel do reservatório e a recuperação terciária (EOR) o óleo residual (óleo que não pode ser produzido por as forças capilares e viscosas).

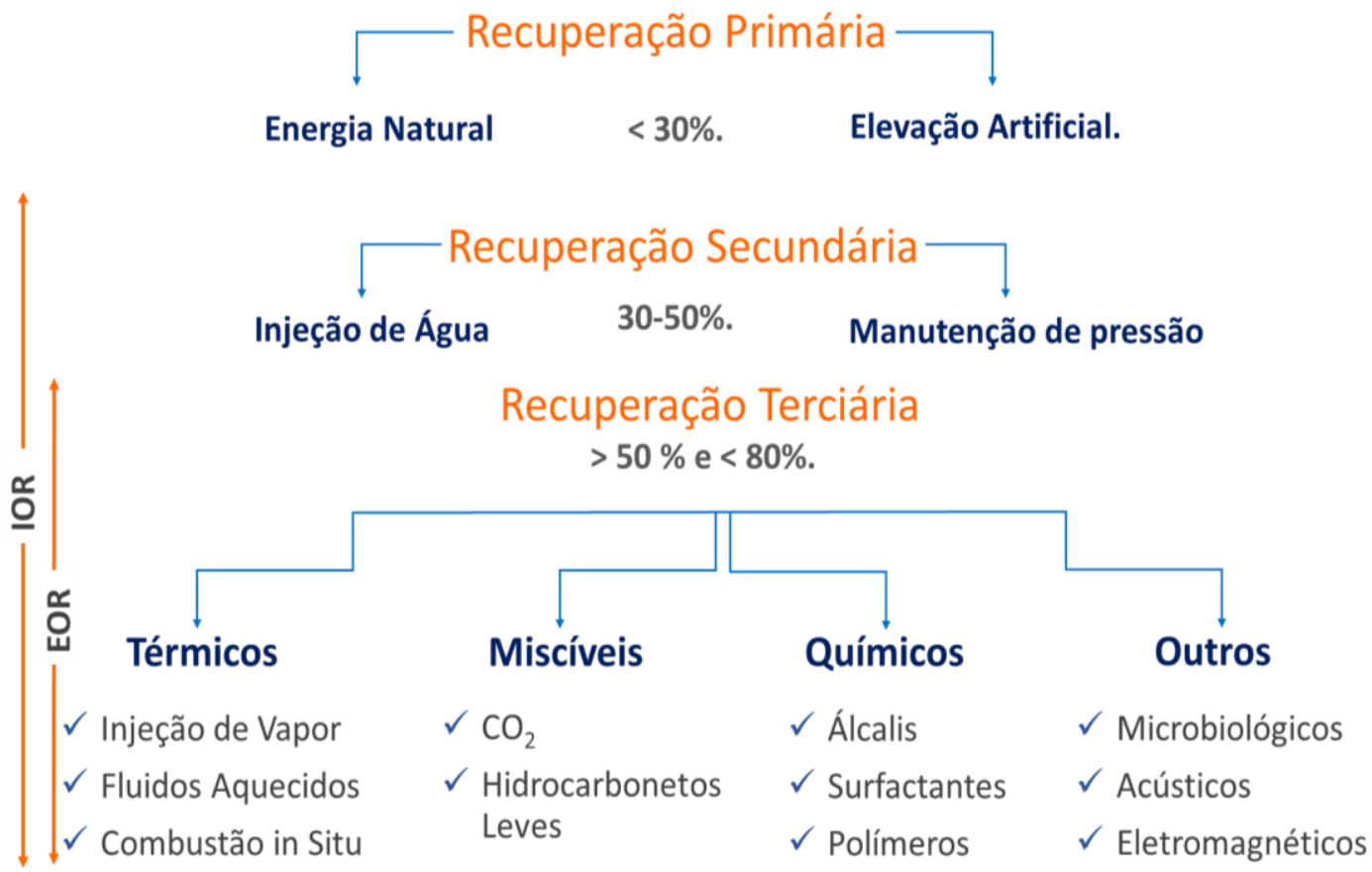

Figura 2-15: Classificação dos métodos EOR/IOR. [19]

Os métodos de recuperação primária, secundária e terciária (EOR) seguem uma progressão natural da produção de petróleo desde o início até um ponto onde não é mais economicamente viável produzir o petróleo do reservatório. A recuperação de óleo, especialmente por técnicas EOR, está fortemente associada ao preço do petróleo e a economia em geral. Em média, o fator de recuperação em todo o mundo a partir de métodos convencionais de recuperação é aproximadamente um terço do óleo inicialmente alojado no espaço poroso (OOIP). Isto implica que a meta para EOR é desafiante (2/3 dos recursos base). A optimização do fator de recuperação pode ser alcançada através da 
implementação de tecnologias avançadas IOR utilizando práticas de gestão do reservatório e tecnologias EOR. [19]

O fator de recuperação RF é definido segundo a equação (2.19):

$$
R F=\frac{N_{p}}{N}=E_{D} \times E_{v o l}=E_{D} \times E_{V} \times E_{A}
$$

em que Np são as reservas produzidas, $\mathrm{N}$ é o total das reservas no reservatório, $E_{D}, E_{v o l}, E_{v}$ e $E_{A}$ são as eficiências: microscópicas de deslocamento, volumétrica, vertical e areal, respectivamente.

- Eficiência microscópica de deslocamento $\left(E_{D}\right)$ : é a fração de óleo que foi deslocado da zona varrida pelo fluido deslocante. Este parâmetro é uma função da tensão interfacial fluido-fluido e rochafluido, volume do fluido injetado, permeabilidade relativa, viscosidade e volume injetado, principalmente. $A E_{D}$ é definida pela equação (2.20)

$$
E_{D}=\frac{\text { Volume de òleo deslocado }}{\text { Volume de òleo contactado }}=\frac{S_{o i}-S_{o r}}{S_{o i}}
$$

- Eficiência Volumétrica ( $\left.E_{\mathrm{vol}}\right)$ : relação do volume invadido pelo volume do reservatório pode ser definida pela equação (2.21).

$$
\mathrm{E}_{\mathrm{vol}}=\mathrm{E}_{\mathrm{A}} \times \mathrm{E}_{\mathrm{V}}
$$

O aumento da eficiência de deslocamento $E_{D}$ leva à produção do óleo que permanece preso nas partes do reservatório que já foram varridas pelo fluido deslocante (diminuição da saturação de óleo residual, $\mathrm{S}_{\text {or }}$ ).

O aumento da eficiência de deslocamento volumétrico pode ser obtida pela redução da tensão interfacial, como já foi discutido anteriormente, e a aplicação de tecnologias de bloqueio de poro ou redução da mobilidade da fase aquosa. 


\subsection{1 Injeção de Água e Razão de Mobilidade}

A injeção de água é o método mais utilizado na recuperação secundária de petróleo no mundo. Entretanto, o fator de recuperação pode ser afetado pelas altas razões de mobilidade. A razão de mobilidade é definida pela equação (2.22)

$$
M=\frac{K_{\mathrm{rw}} @ S_{\mathrm{or}}}{K_{\mathrm{ro}} @ S_{\mathrm{wc}}} \times \frac{\mu_{\mathrm{o}}}{\mu_{\mathrm{w}}}
$$

em que $S_{\text {wi e }}$ a saturação de água inicial no reservatório, $S_{\text {or }}$ é a saturação de óleo residual (imóvel) após a injeção de água, $\mathrm{K}_{\mathrm{rw}} @ \mathrm{~S}_{\text {or }}$ é a permeabilidade relativa da água na saturação de óleo residual, e $\mathrm{K}_{\mathrm{ro}} @ \mathrm{~S}_{\mathrm{wc}}$ é a permeabilidade relativa do óleo na saturação de água inicial, $\mu_{w}$ e $\mu_{o}$ são as viscosidades da água e do óleo respectivamente, em condições de reservatório.

Razões de mobilidade maiores que 1 , indicam que a água é mais móvel que o óleo no reservatório, e grandes volumes de água serão produzidos prematuramente.

As heterogeneidades do reservatório, tais como, a existência de regiões com menor porosidade, falhas geológicas que isolam partes do reservatório e caminhos de alta permeabilidade, prejudicam o varrido volumétrico do reservatório e potencializam à formação das digitações viscosas. A Figura 2-15 mostra a formação de digitações viscosas (fingering) em um arenito Bentheimer, saturado com petróleo viscoso e submetido à injeção de água. A trajetória da água injetada (tons de branco) é mostrada em função do volume cumulativo injetado. 


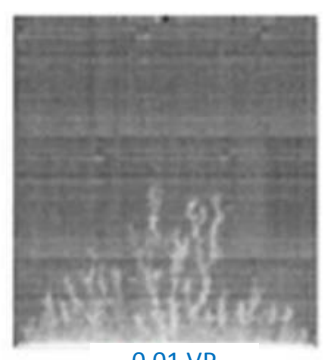

$0.01 \mathrm{VP}$

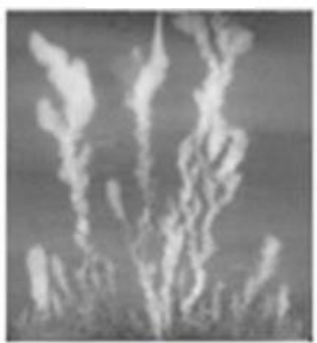

0.14 VP

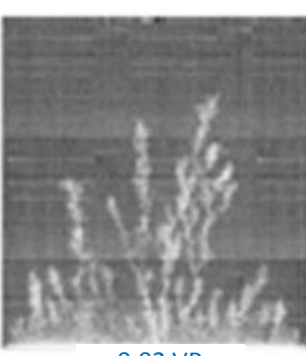

$0.02 \mathrm{VP}$

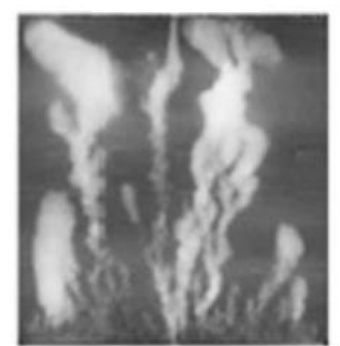

$0.53 \mathrm{VP}$

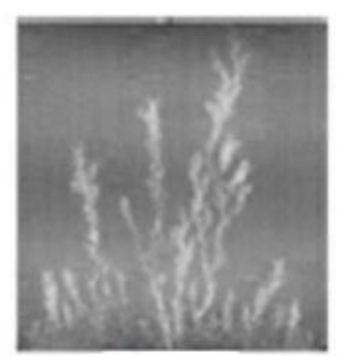

$0.04 \mathrm{VP}$

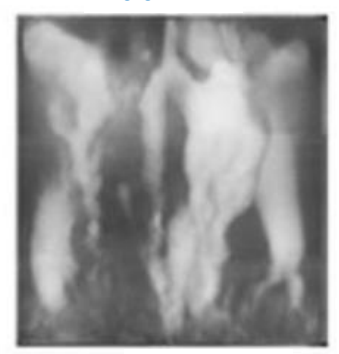

$2.3 \mathrm{VP}$

Figura 2-16: Formação de digitação viscosa em bloco de arenito saturado com óleo viscoso submetido à injeção de água pela face inferior. [14]

Os efeitos de molhabilidade influenciam a saturação de óleo residual no reservatório. Em rochas molhadas preferencialmente pelo óleo, o óleo fica aderido às paredes dos poros, levando a baixos fatores de recuperação. Nesses casos, existem aditivos químicos inversores de molhabilidade que podem incrementar significativamente a recuperação de óleo.

A tensão interfacial entre as fases dificulta o deslocamento do óleo através dos poros. A diminuição da tensão interfacial é obtida pela adição de surfactantes na água de injeção.

Os reservatórios com distribuição de tamanhos de poros mais uniforme são menos propensos à formação de caminhos preferenciais na injeção de água. O resultado é um varrido mais uniforme do reservatório com maiores produções acumuladas de óleo.

Os efeitos gravitacionais são importantes em reservatórios de maior espessura, onde a água de injeção se desloca para a base do reservatório e desloca a coluna de óleo verticalmente, para cima na direção dos poços produtores. Esse efeito, também depende da relação entre as permeabilidades verticais e horizontais. Nos reservatórios de menores espessuras, a água de injeção desloca horizontalmente o óleo na direção dos poços produtores com maior risco de formação de digitações viscosas.

A distribuição do óleo residual na rocha-reservatório é explicada pelos modelos conceituais de poro-duplo e de quebra de gotas. 


\subsection{2}

\section{Modelo de Poro Duplo}

O modelo doublet pore (1959) fornece uma visão qualitativa da posição do óleo residual após a passagem da frente de água. Assumindo-se as seguintes hipóteses:

- Escoamento de Hagen-Pouseille nos poros, idealizados como um feixe de capilares paralelos;

- Deslocamento dos fluidos a baixa velocidade tornando o processo quase-estático;

- Rocha molhável à água e;

- A presença da interface não perturba o fluxo nos capilares.

Considere um meio poroso hipotético composto apenas por duas classes de diâmetros de poros: largos e estreitos. Durante o deslocamento dos fluidos, a interface água-óleo se desloca mais rapidamente nos poros estreitos devido ao maior nível de pressão capilar. A consequência é que a água de injeção atinge a saída comum aos poros mais rapidamente por esse caminho, conforme ilustrado na Figura 2-17. Quando a água atinge esse ponto, ocorre uma invasão parcial dos poros largos e o consequente bloqueio de parte do óleo nessa classe de poros (bypass de gotas). A gota se encontra presa pela ação da pressão capilar aplicada em suas duas extremidades. Esse modelo simples permite concluir que:

- O óleo residual após a injeção de água se encontra predominantemente nos poros de menor diâmetro;

- A diminuição das forças capilares pode provocar uma diminuição da saturação de óleo residual na rocha, pois a diferença de velocidade de avanço da frente nos dois poros será menor.

Segundo Rosa et al. (2006), esse mecanismo é responsável por cerca de $60 \%$ a $90 \%$ de todo o óleo residual após a injeção de água. A parcela restante fica em zonas ultrapassadas pela água de injeção e em área isoladas do reservatório. 


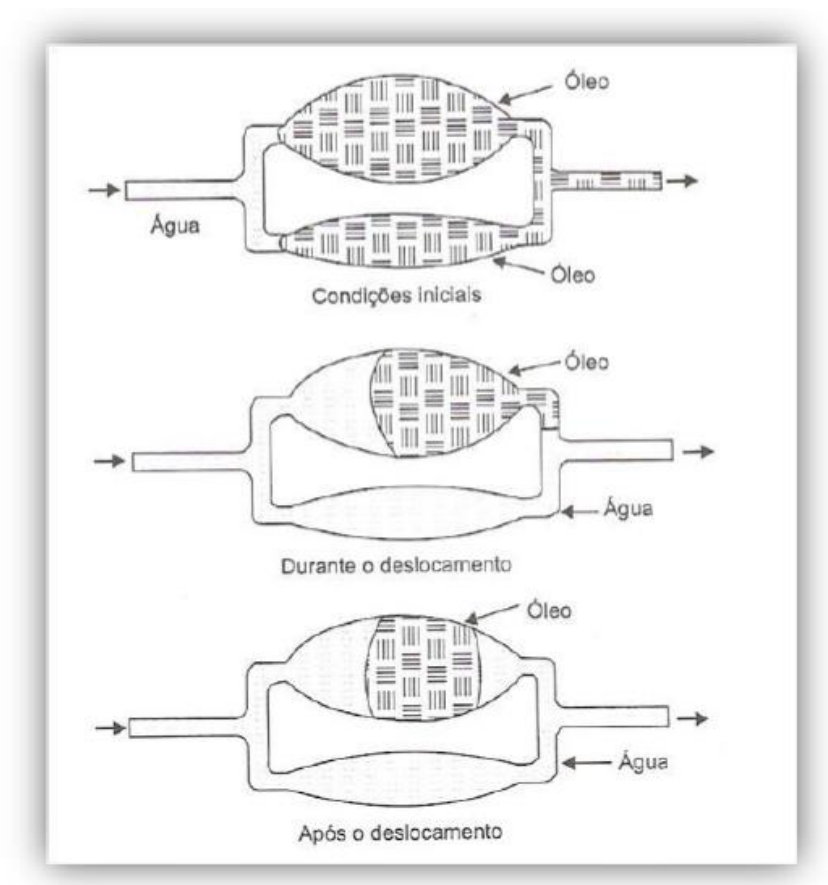

Figura 2-17: Representação esquemática do modelo de poro duplo. [14]

\subsection{3}

\section{Fenômeno de Quebra de Gota}

O fenômeno de quebra de gotas (snap-off) também considera o meio poroso como um conjunto de capilares com a fase molhante (geralmente a água) envolvendo as paredes dos tubos (grãos de rocha).

A pressão capilar é calculada levando em conta geometrias típicas das gargantas de poro, em cada garganta é calculado o balanço das forças aplicadas. As gotas de óleo são retidas sempre que o valor da pressão capilar à jusante é maior que o da pressão ao montante da gota. O resultado é uma distribuição de gotas de óleo residual no reservatório devido ao aprisionamento capilar.

O escoamento da gota é condicionado pelo balanço entre as forças viscosas e capilares. Quando a fase molhante é embebida no meio poroso (e.g. injeção de água em arenitos) tende a fluir ao longo das paredes do poro durante 0 deslocamento da fase não-molhante. A ocorrência de bypass ou snap-off é principalmente determinada pela razão entre o diâmetro da garganta Dt e o diâmetro do poro Dp.

Para razões de aspectos Dp/Dt próximas de 1, a fase não-molhante é essencialmente deslocada pela fase molhante. Entretanto, para poros com razões de aspecto altas $(D p / D t>2)$, a fase molhante tende a se movimentar próxima da 
parede e acaba por formar um anel em torno da gota da fase não-molhante. O bloqueio capilar se estabelece quando a fase molhante atinge a extremidade oposta do poro. O snapoffé mais intenso para pequenos ângulos de contato entre a fase molhante e a parede do poro. A Figura 2-18 representa o fenômeno descrito.

(a) Injeção da Fase Molhante $D p / D t \approx 1$

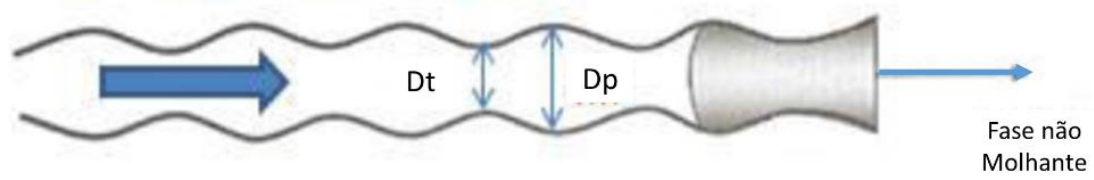

(b) Injeção da Fase Molhante Dp/Dt Grande

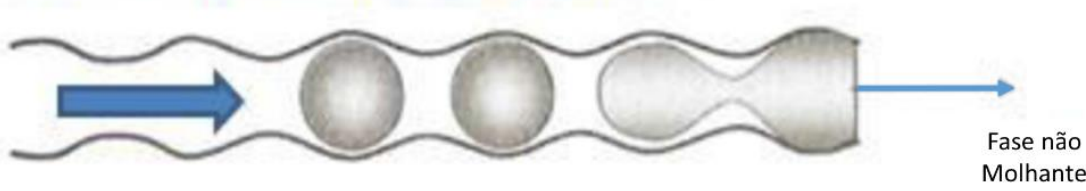

Figura 2-18: Representação do fenômeno do snap-off em um poro. [14]

Em um resenvatório de petróleo, os poros são distribuídos em diversas classes de tamanho e a saturação de óleo residual depende da relação entre as forças viscosas e as forças capilares. Na realidade, o fenômeno observado é uma combinação dos efeitos descritos pelos modelos descritos anteriormente, conforme esquematizado na Figura 2-19.

(a) Stable Displacement ( No trapping)
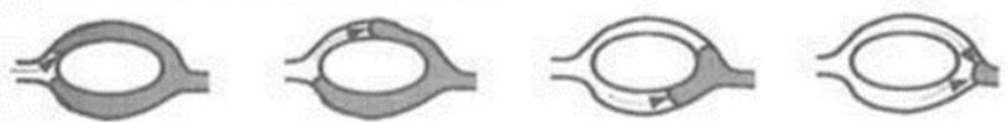

(b) Trapping Due to By-Passing
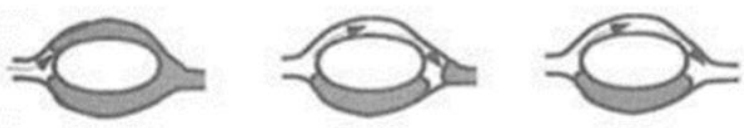

(c) Trapping Due to Both By-Passing and Snap-Off
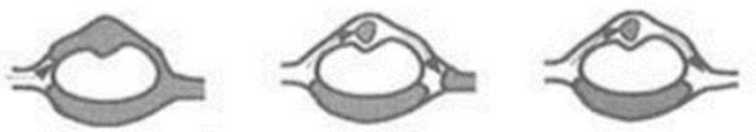

Figura 2-19: Mecanismos de formação da saturação de óleo remanente. [14] 
A partir dos fenômenos mencionados anteriormente, pode se afirmar que a redução da saturação de óleo remanente em um reservatório envolve as seguintes ações no nível microscópico:

- Redução da tensão interfacial;

- Bloqueio de poros já varridos pela fase deslocante, e o redirecionamento do fluxo no meio poroso. 


\section{3 \\ Experimento}

A etapa experimental dos testes de deslocamento foi realizada implementando a metodologia de Engelke (2012) [20], em um equipamento modelo CFS-830-SS Core Flooding System fabricado pela TEMCO, instalado no Laboratório de Microhidrodinâmica e Escoamento em meios porosos da PUC-Rio. Os testes foram efetuados visando analisar a influência do comportamento de fases, a tensão interfacial e salinidade na eficiência dos processos de deslocamento.

Esta seção irá descrever o equipamento e o procedimento experimental adotado para estudar o efeito da salinidade da água e concentração de surfactante no processo de deslocamento de um óleo mineral.

Os testes de deslocamento ou coreflooding foram levados a cabo usando amostras de arenito de alta permeabilidade de Bentheimer, soluções salinas com e sem surfactante não iónico Álcool Laurílico Etoxilado- 8EO (L80) e óleo mineral, sob condições de temperatura, pressão de confinamento e vazão constantes.

No total foram utilizadas 6 amostras de arenito, para um total de 8 experimentos, fato pelo qual algumas das amostras foram submetidas a um processo de limpeza para restaurar as condições de porosidade, permeabilidade e molhabilidade e concluir os experimentos, como será descrito mais adiante.

\section{1}

\section{Descrição do Dispositivo Experimental}

O dispositivo experimental utilizado nos testes é apresentado na Figura 3-1 como um esquema simplificado do arranjo experimental. As letras $O$ e $A$ significam respectivamente óleo, e solução salina. 


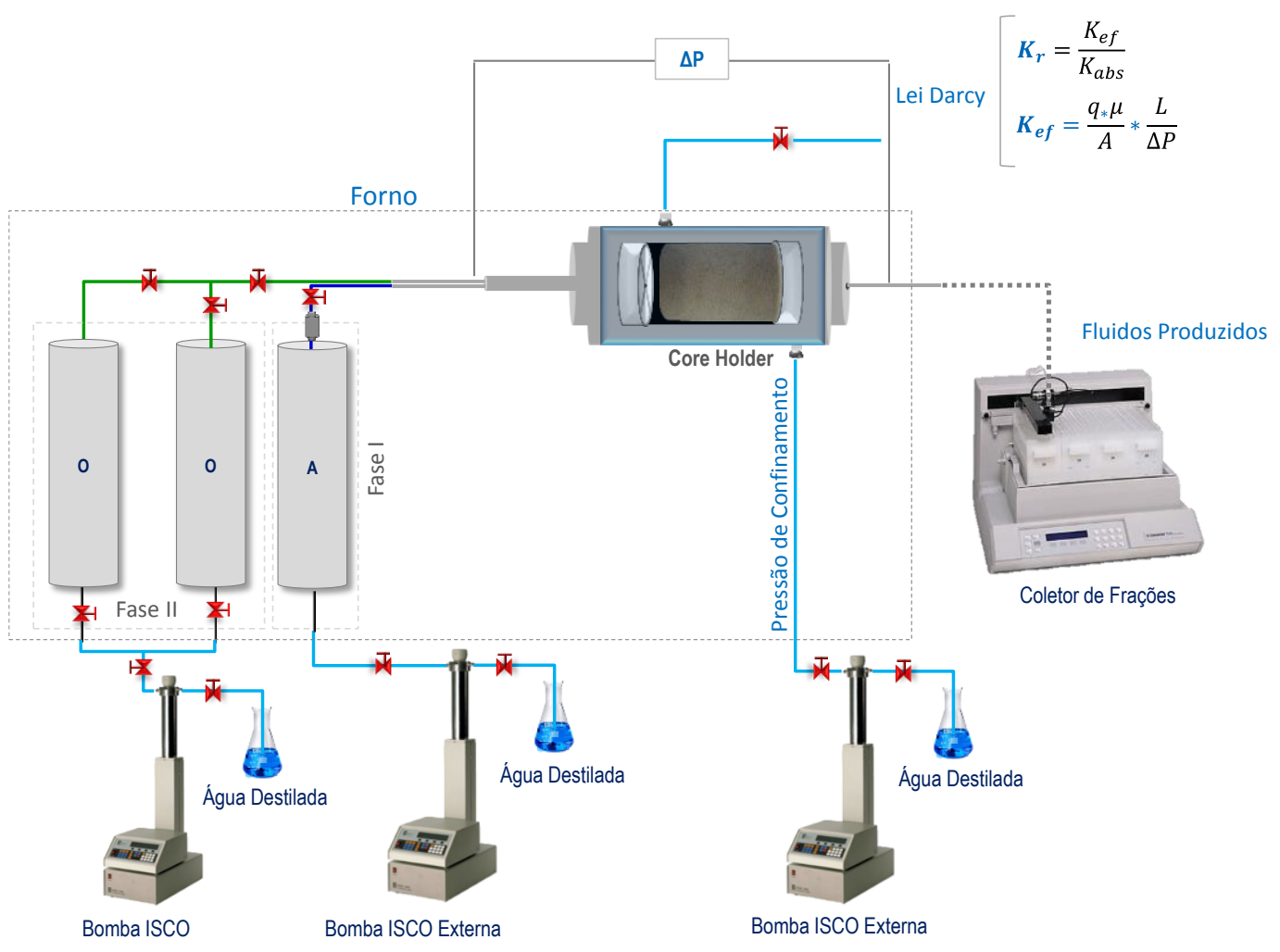

Figura 3-1: Esquema simplificado do experimento.

A Tabela 3-1 apresenta os detalhes técnicos de alguns dos componentes da Figura 3-1.

Detalhes Técnicos Bancada Experimental

\begin{tabular}{cccc}
\hline Quantidade & Componente & Fabricante & Modelo \\
\hline \hline 1 & Forno & Despatch & LBB2-18-1 \\
3 & Transductores de Pressão & Honeywell & TJE \\
2 & Transdutores de Pressão & Validyne & DP360-60 \\
1 & Transdutores de Pressão & Validyne & DP363-40 \\
3 & Bombas de seringa & Teledyne ISCO & 500-DX \\
1 & Coletor de frações & Gilson & FC 204 \\
1 & Computador & Dell & Intel Pentium Dual 2.40 \\
& & & GHz
\end{tabular}

Tabela 3-1: Tabela com detalhes técnicos de cada componente da bancada experimental.

A seguir, será feita uma descrição do equipamento tal qual foi utilizado, quer dizer, incluindo todas as mudanças realizadas relação ao seu formato original, apresentado na Figura 3-2. 


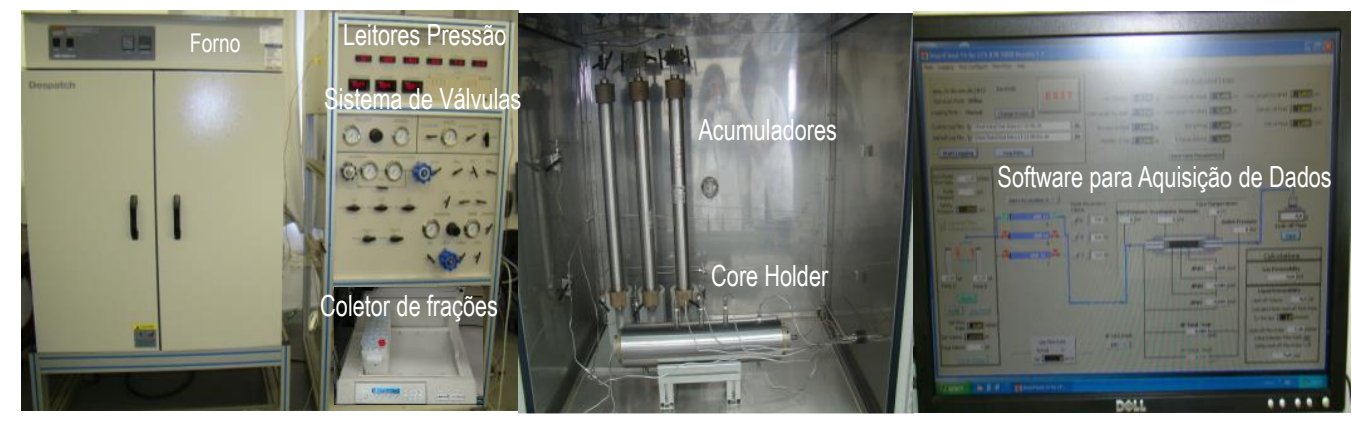

Figura 3-2: Equipamento Original, Core Flooding System - modelo CFS-830-SS.

O sistema usado é composto principalmente por:

- Um porta amostra (core holder), fabricado pela LABCONTE no Brasil, onde será depositada e submetida a 2300 psi de pressão de confinamento a amostra de rocha, indicado pelo número 1 na Figura 3-3. A escolha de não utilizar o original feito pela TEMCO (Figura 3-2) foi pela grande simplicidade no manuseio do core holder escolhido.

- Três acumuladores (cilindros) tipo pistão feito parcialmente de aço inox, onde são colocados os fluidos a serem injetados no core holder. Dois deles para armazenar o óleo e outro para a solução salina, indicados pelo número 2 na Figura 3-3.

- Duas bomba ISCO externas, uma responsável pela injeção da solução salina de um dos acumuladores, e outra pela injeção da água destilada na câmara mais externa do core holder para aplicar a pressão de confinamento.

- Uma bomba ISCO, responsável por injetar óleo dentro dos outros dois acumuladores

- Cinco transdutores de pressão Validyne, são responsáveis por medir cinco diferenciais de pressão. Destes apenas três foram utilizados (Placas 12,5, 125 e 1250 Psi).

- Três transdutores de pressão Honeywell, responsáveis por medir a pressão de confinamento, a pressão de entrada e a pressão de saída do fluido do core holder. Destes apenas um foi utilizado, os outros dois foram utilizados apenas para conferir valores medidos quando necessário. 
- Um sensor de temperatura, usado para medir a temperatura dentro do core holder original, utilizado para medir a temperatura dentro do forno.

- Linhas de $1 / 8$ de polegadas e válvulas: responsáveis pelo transporte dos fluidos no sistema

- Um Filtro 0,5 $\mu \mathrm{m}$, na saída do acumulador das soluções salinas, para impedir a passagem de óxido de ferro.

- Um forno, usado para operar com temperaturas altas.

- Coletor de frações, equipamento usado para coletar pequenos volumes dos fluidos produzidos em tubos de plástico. Seu controle é feito por tempo e foram usados tubos de $15 \mathrm{ml}$.

- Um computador, recebe os dados medidos no sistema, processaos, gerando tabelas e gráficos.

A Figura 3-3 mostra uma visão geral do porta amostra e dos acumuladores.

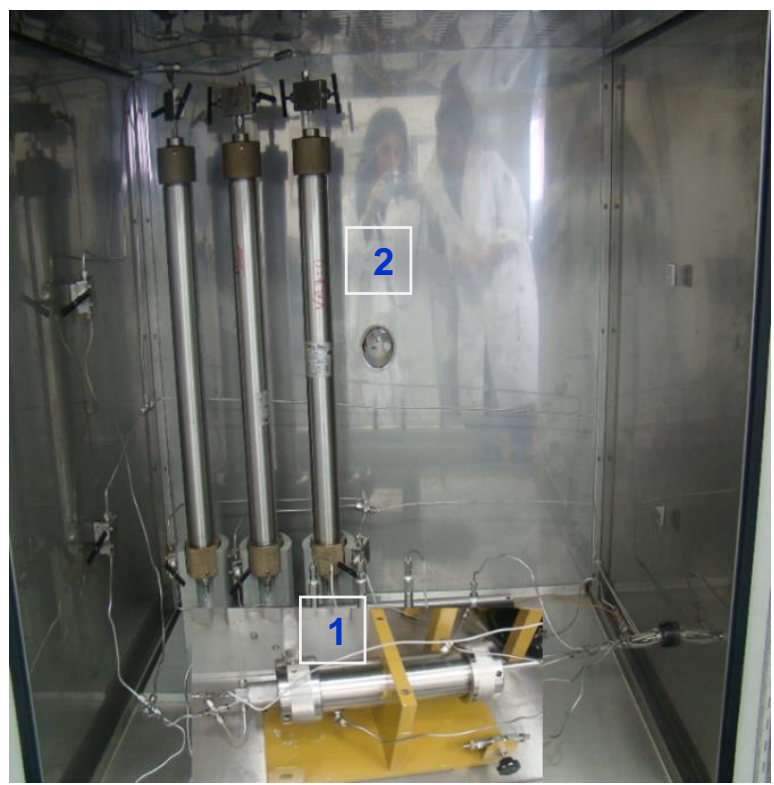

Figura 3-3: Visão geral do arranjo experimental, dentro do forno.

\section{2}

\section{Procedimento Experimental}

As permeabilidades foram medidas para cada fase neste trabalho, utilizando a Lei de Darcy em regime permanente. Todas as fases foram injetadas a vazões 
constantes até o equilíbrio ser atingido e o diferencial de pressão medido. Todas as medidas realizadas no meio poroso foram feitas a $40^{\circ} \mathrm{C}$ e uma pressão de confinamento de 2300 psig.

Uma vez selecionada a amostra a ser utilizada, o seguinte procedimento era seguido:

1. O peso da amostra seca foi medido em gramas em uma balança com precisão de três casa decimal (fabricante OHAUS).

2. Em seguida a amostra foi colocada em um béquer com a solução salina escolhida. O nível de solução colocada no béquer é até aproximadamente $1 \mathrm{~cm}$ abaixo da altura da amostra, como mostrado na Figura 3-4. E importante deixar a parte superior em contato com o ar para ter um caminho de escape para o ar deslocado.

3. Para ter certeza que todo ar é deslocado, utiliza-se uma bomba de vácuo para reduzir a pressão da fase gasosa. A Figura 3-4 mostra a bomba utilizada na saturação da amostra, conectada a um recipiente capaz de vedar a entrada de ar, que, com a bomba de vácuo, pode ser despressurizado. A pressão do recipiente foi reduzida até um valor de aproximadamente $-670 \mathrm{mmHg}$. A Figura 3-4 mostra a amostra de rocha dentro deste recipiente com a bomba de vácuo ligada. Na Figura 3-4, percebe-se a formação de bolhas ao redor da amostra, o que significa a saída do ar da parte de baixo da amostra e, ainda, que a parte superior da amostra passa a ter um aspecto úmido, resultado do efeito de capilaridade, que faz a solução alcançar o topo da amostra. A amostra foi mantida no recipiente com a bomba ligada por, aproximadamente, 30 minutos. Após isso, o recipiente foi mantido despressurizado por cerca de 15 horas. Neste momento, a bomba era novamente ligada por cerca de 10 minutos e verificava-se se ainda existiam bolhas de ar saindo da amostra. Caso positivo, a amostra permanecia no recipiente e a cada uma hora a bomba era ligada por mais 10 minutos. A partir do momento em que não saísse mais ar da amostra, a mesma estava completamente saturada e pronta para ser retirada do recipiente.

4. Após esta etapa, a amostra foi novamente pesada. Ao se retirar a amostra do recipiente com a solução salina e, antes de ser pesada, a mesma foi levemente seca com um papel para retirar o excesso de fluido da borda. Desta forma, é possível calcular seu volume poroso levandose em conta a massa específica da solução salina, medida no Laboratório de Caracterização de Fluidos na PUC-Rio. Percebe-se que 
o peso é maior que o visto na Figura 3-4 (4), quando foi pesada antes de ser saturada. Vale ressaltar que foi utilizada a mesma balança.

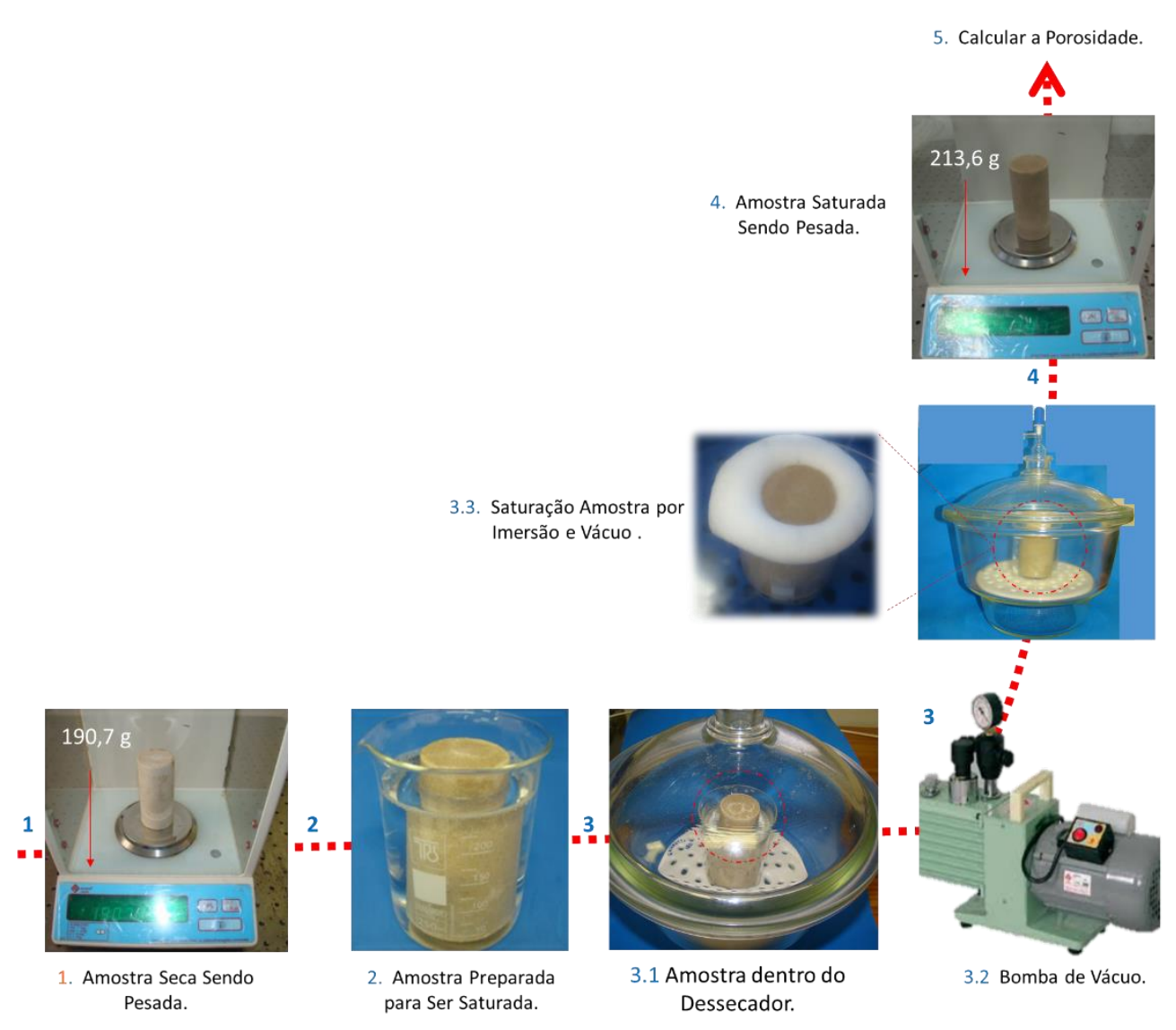

Figura 3-4: Esquema de saturação das amostras.

O passo seguinte foi instalar a amostra saturada no core holder e montar o equipamento. Uma observação importante é que antes do equipamento estar montado foi necessário preencher completamente todas as linhas com água destilada, solução salina ou óleo (dependendo da linha). Isto é importante para que não exista nenhuma bolha de ar ou algum outro fluido indesejado nas linhas, o que pode prejudicar as medidas e/ou o andamento do experimento. Neste instante, a amostra foi confinada com água destilada à pressão desejada (2300 psi).

O primeiro fluido a ser injetado foi a própria solução salina. O objetivo de tal injeção é determinar a permeabilidade absoluta da rocha. Foi medido o diferencial de pressão para seis ou sete diferentes vazões após de atingir o regime permanente, ou, em outras palavras, após o diferencial de pressão estar estabilizado. A partir disso, foi possível calcular a inclinação da reta cuja abscissa é a vazão e ordenada é o diferencial de pressão. Tendo como base a Lei de Darcy 
unidimensional, a permeabilidade absoluta da rocha foi determinada. A Figura 3-5 apresenta um esquema qualitativo do cálculo realizado.

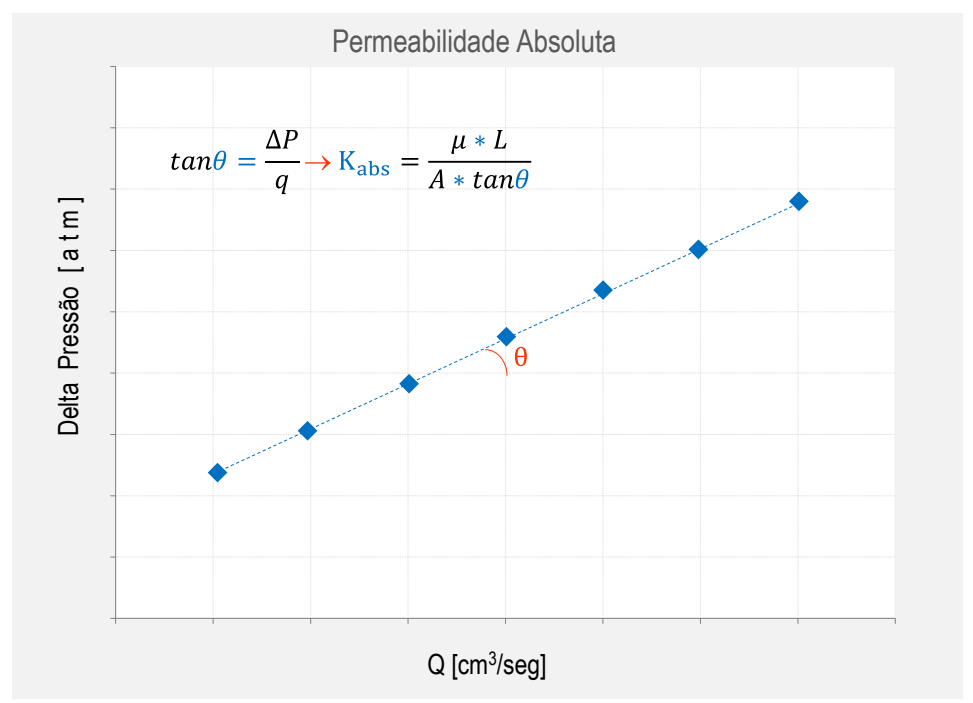

Figura 3-5: Esquema Indicando como calcular a permeabilidade absoluta.

Em seguida, foi iniciada a injeção de óleo (drenagem) a uma vazão constante de $0,24 \mathrm{ml} / \mathrm{min}$, até finalizar a produção de água. Neste ponto, o experimento alcançou o regime permanente (volume injetado de óleo = volume produzido de óleo) e pode-se calcular a saturação de água conata (Equação 3.1) e, a permeabilidade efetiva máxima do óleo com a lei de Darcy (lembrando que: $\left.k_{\text {rel }}=k_{e f} / k_{\text {abs }}\right)$.

$$
\forall_{f i}=\forall_{f p}-\forall_{f m}
$$

em que $\forall_{f i}$ é o volume inicial da fase na amostra de rocha, $\forall_{f p}$ é o volume produzido da fase e $\forall_{f m}$ é o volume da fase nas linhas de produção e injeção, injetado durante o drenagem ou embebição.

Tendo encontrado o primeiro ponto da curva de permeabilidade relativa do óleo (permeabilidade relativa do óleo a saturação de água conata), o processo de embebição é iniciado injetando-se a solução salina a vazão constante de 0.24 $\mathrm{ml} / \mathrm{min}$. No momento em que se atinge o regime permanente a produção de óleo é zero, a amostra de rocha está com uma saturação residual de óleo e o último ponto da curva de permeabilidade relativa é medido (permeabilidade relativa da água a saturação de óleo residual). Os procedimentos anteriormente descritos foram utilizados em cada um dos testes realizados. A Figura 3-6 apresenta um 
esquema deste procedimento. O subescrito " 0 " indica óleo e o subescrito " $w$ " indica a solução salina
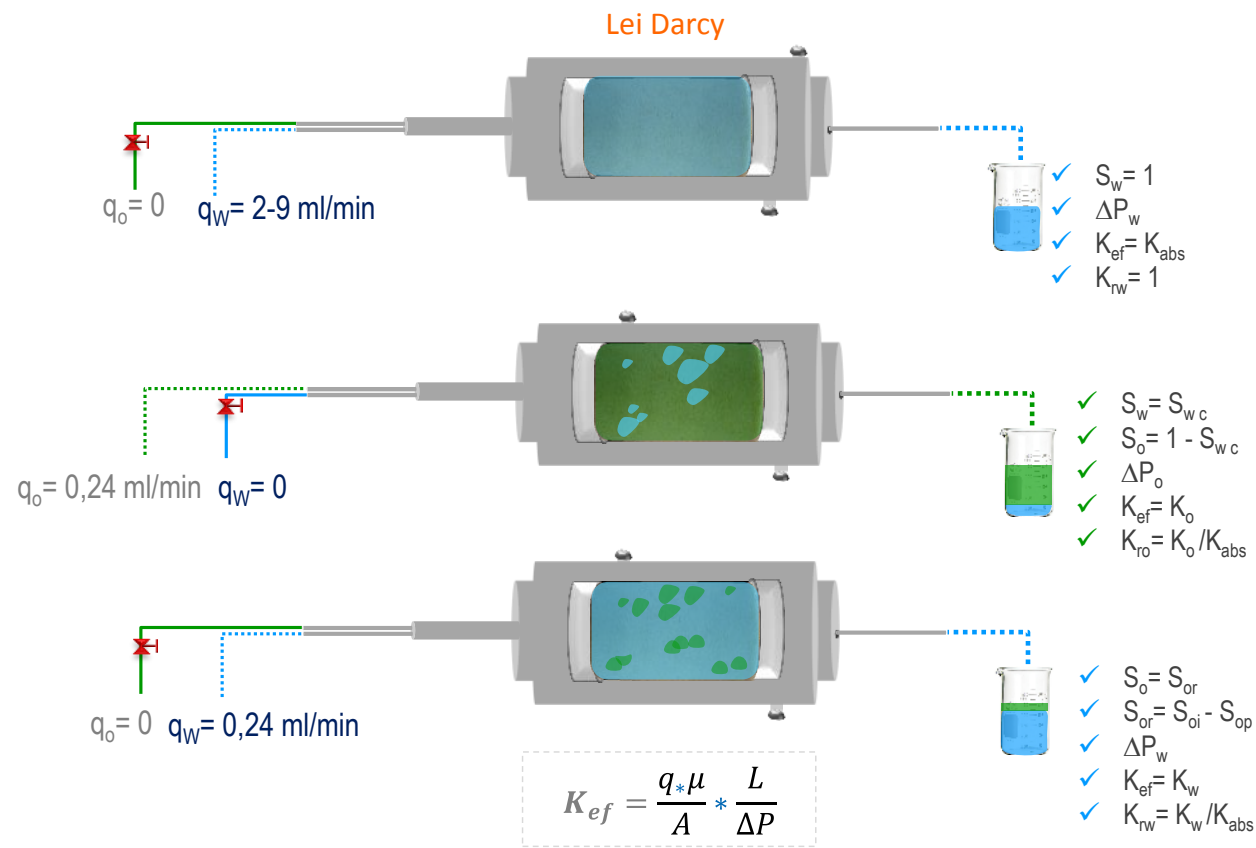

Figura 3-6: Esquema do Procedimento para Medir a Permeabilidade Relativa.

\section{3 \\ Amostra de Rocha}

A amostra de rocha escolhida para realizar este trabalho foi um arenito de Bentheimer. Duas amostras grandes de Bentheimer foram dividida em cinco partes, logo heterogeneidade, porosidade e permeabilidade absoluta devem ter variações mínimas entre as duas amostras. No total foram utilizadas seis amostras. A Figura 3-7 apresenta uma das amostras tendo seu diâmetro medido por um paquímetro com precisão de $0,5 \mathrm{~mm}$. 


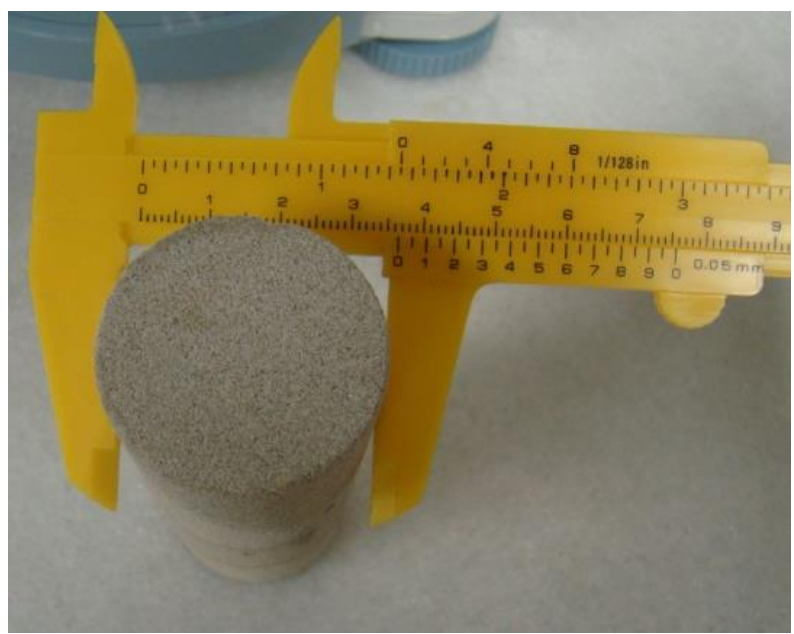

Figura 3-7: Amostra de Bentheimer medida com um paquímetro

\begin{tabular}{ccc}
\hline Mineral & Fórmula Molecular & Conteúdo $[ \pm 0,1 \%]$ \\
\hline \hline llita / Esmectita & - & TR \\
Ilita+Mica & $\left(\mathrm{K}, \mathrm{H}_{3} \mathrm{O}\right)(\mathrm{Al}, \mathrm{Mg}, \mathrm{Fe})_{2}(\mathrm{Si}, \mathrm{Al})_{4} \mathrm{O}_{10}\left[(\mathrm{OH})_{2},\left(\mathrm{H}_{2} \mathrm{O}\right)\right]$ & 3,2 \\
Caulinita & $\mathrm{Al}_{2} \mathrm{Si}_{2} \mathrm{O}_{5}(\mathrm{OH})_{4}$ & 0,0 \\
Clorite & $\mathrm{ClO}_{2}^{-}$ & 0,0 \\
Quartzo & $\mathrm{SiO}_{2}$ & 90,6 \\
Feldspato Potássico & $\mathrm{KAlSi}_{3} \mathrm{O}_{8}$ & 4,6 \\
Plagióclase & $\mathrm{NaAlSi}_{3} \mathrm{O}_{8}-\mathrm{CaAl}_{2} \mathrm{Si}_{2} \mathrm{O}_{8}$ & 0,0 \\
Calcita & $\mathrm{CaCO}_{3}$ & 0,6 \\
Dolomite & $\left.\mathrm{CaMg}_{3} \mathrm{CO}_{3}\right)_{2}$ & 0,0 \\
Siderite & $\mathrm{FeCO}_{3}$ & 1,0 \\
Pirita & $\mathrm{FeS}_{2}$ & $\mathrm{TR}$ \\
TR $=$ Trace amounts (vestígios) &
\end{tabular}

Tabela 3-2: Composição mineral do arenito de Bentheimer, obtidos a partir de XRD (Standard X-Ray Diffraction). [21]

$\mathrm{Na}$ Tabela 3-2, é apresentada a composição mineral de amostras de Bentheimer, e na Figura 3-8 a sua distribuição de tamanho de garganta de poro (PSD - Pore Size Distribution), a qual, segundo é bastante homogéneo. A média do raio de garganta de poro, estimada foi $11,9 \mu \mathrm{m}$. 


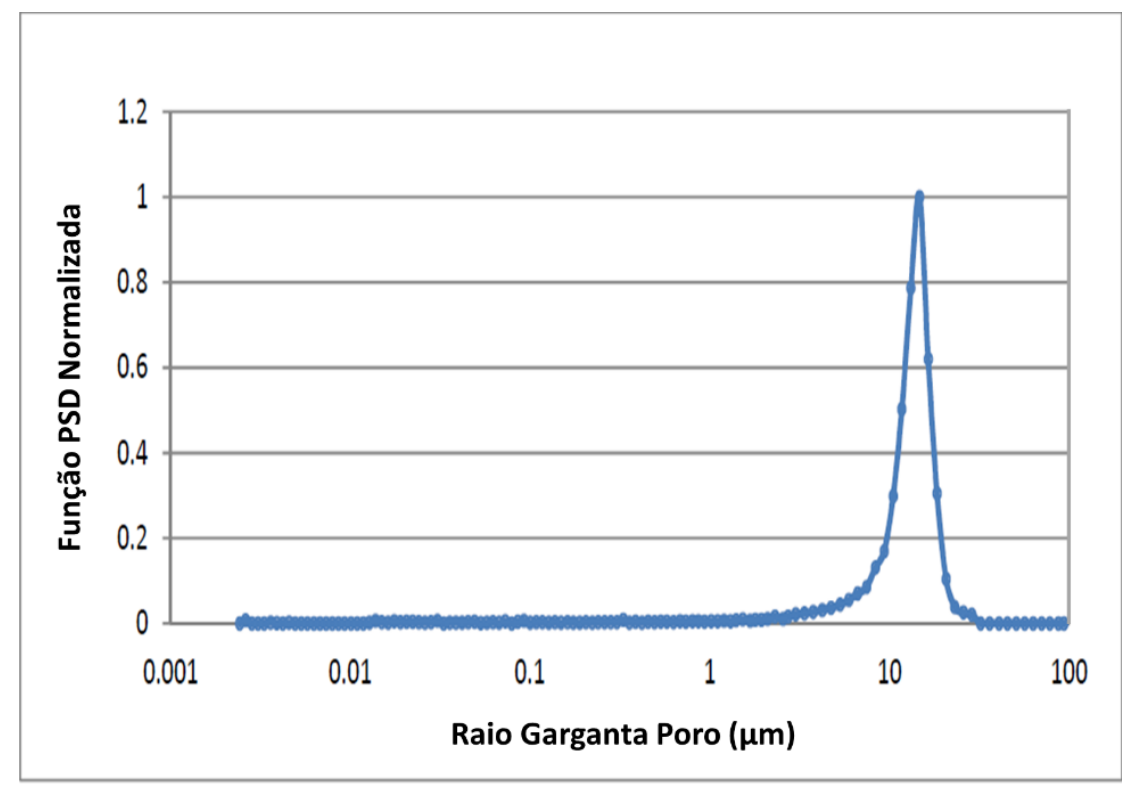

Figura 3-8: PSD Arenito Bentheimer baseado na Injeção Padrão de Mercúrio. [21]

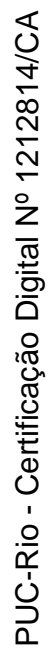

A Tabela 3-3 apresenta o resumo dos testes aos quais foram sometidas a amostras

\begin{tabular}{|c|c|c|c|}
\hline \multicolumn{4}{|c|}{ Amostras Utilizadas nos Testes de Deslocamento } \\
\hline Amostra & Perm. Absoluta & Drenagem & Embebição \\
\hline \multirow{2}{*}{$\mathrm{A} 31$} & $\mathrm{NaCl} 15$ & DK7 & $\mathrm{NaCl} 24$ \\
\hline & Água do Mar (AMS) & DK7 & AMS \\
\hline A32 & $\mathrm{NaCl} 15+\mathrm{L} 80$ & DK7 & $\mathrm{NaCl} 15+\mathrm{L} 80$ \\
\hline \multirow{2}{*}{ A33 } & $\mathrm{NaCl} 33+\mathrm{L} 80$ & DK7 & $\mathrm{NaCl} 33+\mathrm{L} 80$ \\
\hline & $\mathrm{NaCl} 33$ & DK7 & $\mathrm{NaCl} 33$ \\
\hline \multirow{2}{*}{ A35 } & $\mathrm{AMS}+\mathrm{L} 80$ & DK7 & $\mathrm{AMS}+\mathrm{L} 80$ \\
\hline & $\mathrm{NaCl} 15$ & DK7 & $\mathrm{NaCl} 15$ \\
\hline \multirow{2}{*}{ A53 } & AMS + L80 & DK7 & AMS +L80 \\
\hline & $\mathrm{NaCl} 24$ & DK7 & $\mathrm{NaCl} 24$ \\
\hline \multirow{2}{*}{ A55 } & AMS & DK7 & AMS \\
\hline & $\mathrm{NaCl} 24+\mathrm{L} 80$ & DK7 & $\mathrm{NaCl} 24+\mathrm{L} 80$ \\
\hline
\end{tabular}

Tabela 3-3: Testes realizados nas amostras de Bentheimer.

A terminologia utilizada Tabela 3-3 corresponde a:

- DK7: Óleo mineral Drakeol 7;

- $\quad \mathrm{NaCl} 15:$ Solução com $15 \mathrm{~g} / \mathrm{l} \mathrm{NaCl}$; 
- $\mathrm{NaCl} 15$ + L80 - Solução com 15 g/l NaCl e surfactante Ultrol L80;

- $\mathrm{NaCl} 24$ : Solução com 24,53 g/l NaCl;

- $\mathrm{NaCl} 15$ + L80 - Solução com 24,53 g/l NaCl e surfactante Ultrol L80;

- $\mathrm{NaCl} 33:$ Solução com 33,94 g/l NaCl;

- $\mathrm{NaCl} 15$ + L80 - Solução com 33,94 g/l NaCl e surfactante Ultrol L80;

- AMS: Solução água do mar sintética e;

- $\mathrm{AMS}+$ L80 - Solução com água do mar sintética e surfactante Ultrol L80.

Vale mencionar que aqueles testes ressaltados na Tabela 3-3, foram descartados devido a interrupções na injeção por falta de energia elétrica no laboratório, coleta de dados, entre outros.

\section{4}

\section{Fase Aquosa}

Uma solução de água deionizada com surfactante e sal foi preparada para ser utilizada como fase deslocante. A seguir serão explicadas a escolha das diferentes salinidades e surfactante.

\subsection{1 \\ Salinidade}

A importância da presença do sal na solução a ser injetada é para evitar o inchamento da parcela de argila presente na amostra de rocha. De forma geral, as amostras de Bentheimer possuem aproximadamente 3,2 por cento de argila em sua composição [21]. Estes minerais (caolinita, ilita e clorita) fazem parte de um grupo conhecido por causarem danos de permeabilidade a formação. Uma redução na concentração de íons (salinidade) no fluido em contato com a argila provoca uma migração da água para as camadas de argila, provocando o inchamento da mesma (Atwood, 1964).

Caso haja o inchamento da argila, a permeabilidade da amostra é capaz de reduzir até uma ordem de grandeza. Este fato foi verificado no trabalho de Engelke (2012) [20], pelo qual com base nos resultados dele foi escolhido para trabalhar o $\mathrm{NaCl}$ (cloreto de sódio) com 1,5\% em peso (ou seja, $15 \mathrm{~g} / \mathrm{L}$ ), que durante seus testes não apresentou qualquer tipo de problema em relação a indícios de 
inchamento em amostras de Bentheimer e ou afinidade com os surfactantes aqui testados.

Como o objetivo deste trabalho é avaliar o efeito da concentração do sal na recuperação de óleo, foi decidido também trabalhar com água sintética de mar, a qual tem a presença de diferentes íons em sua composição, como é apresentado na Tabela 3-4. As outras duas salinidades selecionadas correspondem à concentração de $\mathrm{NaCl}$ presente na água do mar $24,54 \mathrm{~g} / \mathrm{l}$ e ao total de sólidos dissolvidos (TDS) da água do mar, 33,94 g/l, este último valor foi definido com a finalidade de observar o efeito da presença dos íons na recuperação de óleo.

\begin{tabular}{cc}
\hline Salt & Concentration $[\mathrm{g} / \mathrm{l}]$ \\
\hline $\mathrm{NaCl}$ & 24,53 \\
$\mathrm{MgCl}_{2}$ & 5,20 \\
$\mathrm{Na}_{2} \mathrm{SO}_{4}$ & 4,09 \\
$\mathrm{CaCl}$ & 1,16 \\
$\mathrm{KCl}$ & 0,695 \\
$\mathrm{NaHCO}$ & 0,201 \\
$\mathrm{KBr}_{3}$ & 0,101 \\
$\mathrm{H}_{3} \mathrm{BO}{ }_{3}$ & 0,027 \\
$\mathrm{SrCl}$ & 0,025 \\
$\mathrm{NaF}$ & 0,003 \\
$\mathrm{Ba}\left(\mathrm{NO}_{3}\right)_{2}$ & 0,0000994 \\
$\mathrm{Mn}\left(\mathrm{NO}_{2}\right)_{2}$ & 0,0000340 \\
$\mathrm{Cu}\left(\mathrm{NO}_{3}\right)_{2}$ & 0,0000308 \\
$\mathrm{Zn}\left(\mathrm{NO}_{3}\right)_{2}$ & 0,0000096 \\
$\mathrm{~Pb}\left(\mathrm{NO}_{3}\right)_{2}$ & 0,0000066 \\
$\mathrm{AgNO}$ & 0,00000049
\end{tabular}

Tabela 3-4: Composição da água do mar sintética. [22]

Outro sal que foi testado mas que apresentou problemas com um surfactante foi o cloreto de potássio $(\mathrm{KCl})$, como será apresentado a seguir. 


\subsection{2 Surfactante}

Tendo definido o sal e suas concentrações, o próximo passo foi definir o surfactante a ser usado. As moléculas do surfactante possuem duas regiões distintas, uma com afinidade à água e outra com afinidade ao óleo. Desta forma, o surfactante se localiza na interface água-óleo, provocando a redução da tensão interfacial e facilitando a formação de gotas de óleo (ou água, dependendo da característica do surfactante) no meio contínuo. Existem diferentes características de surfactantes que fazem dele adequado para diversas aplicações, porém este estudo não será o escopo deste trabalho.

Conforme já foi explicado, o surfactante tem a capacidade de diminuir a tensão interfacial entre água e óleo. Porém não é qualquer surfactante que é capaz de manter a emulsão estável. Isto depende da afinidade entre o óleo e o surfactante e a única forma de saber isso é realizando testes de estabilidade com vários surfactantes e com a concentração de óleo que é planejada usar na emulsão, assim como a concentração de sal da solução.

Desta forma, uma análise de afinidade do óleo com o surfactante foi realizada para a concentração de sal já definida e com uma concentração de óleo de $30 \%$. Esta será a concentração de óleo usada inicialmente. Mesmo com uma pequena variação de concentração, como ocorrerá no trabalho, o surfactante selecionado não deve apresentar problemas. Esta afinidade foi medida através da distribuição do tamanho de gotas. Se esta distribuição se mantivesse estável, significaria que o surfactante teria afinidade com o óleo. Os surfactantes testados com suas respectivas concentrações foram:

- SDS (dodecil sulfato de sódio) - 3,45 g/L (1,5 x CMC)

- Steol CS-230 da Stepan - 0,179 mL/L

- Steol CS-330 da Stepan - 1,35 mL/L

- Ultrol L80 da Oxiteno - 3,45 g/L

A escolha das concentrações foi definida de acordo com a concentração micelar crítica (CMC) para os surfactantes cujas CMCs eram conhecidas, caso do SDS, CS-230 e do CS-330. Para este trabalho, foi definido como a concentração ideal àquela equivalente a 1,5 vezes a $\mathrm{CMC}$ (isto será melhor explicado ao final deste tópico). No caso do Steol CA-330, como não tínhamos sua $\mathrm{CMC}$, foi escolhida uma concentração sugerida em outros trabalhos. No caso do Ultrol L80, 
como não existia qualquer referência sobre qual concentração usar, foi escolhida a mesma concentração do SDS, que, acreditava-se, seria mais alta que sua CMC.

Foram preparadas $600 \mathrm{~mL}$ das soluções testadas em um béquer de 1000 $\mathrm{mL}$ e, em seguida, foi adicionado $30 \%$ de óleo em volume. Para cada uma das velocidades de 6500, 9500 e $13500 \mathrm{rpm}$ durante os primeiros 10 segundos do minuto de mistura foi adicionado $1 / 3$ do volume total de óleo. O equipamento utilizado para criar as emulsões foi o Ultra-Turrax T25 (Figura 3-10), que utiliza o princípio de cisalhamento. Após cada uma ter sido preparada, ela foi dividida em 1 béquer de $600 \mathrm{ml}$ uma proveta de $100 \mathrm{ml}$ e um porta amostras, conforme amostrado na Figura 3-9. A primeira análise de distribuição de tamanho de gotas $(\mathrm{t}=0)$ foi realizada logo após o preparo da mistura no béquer de $1000 \mathrm{ml}$, as demais análises foram realizadas colhendo-se a amostra do béquer de $600 \mathrm{ml}$

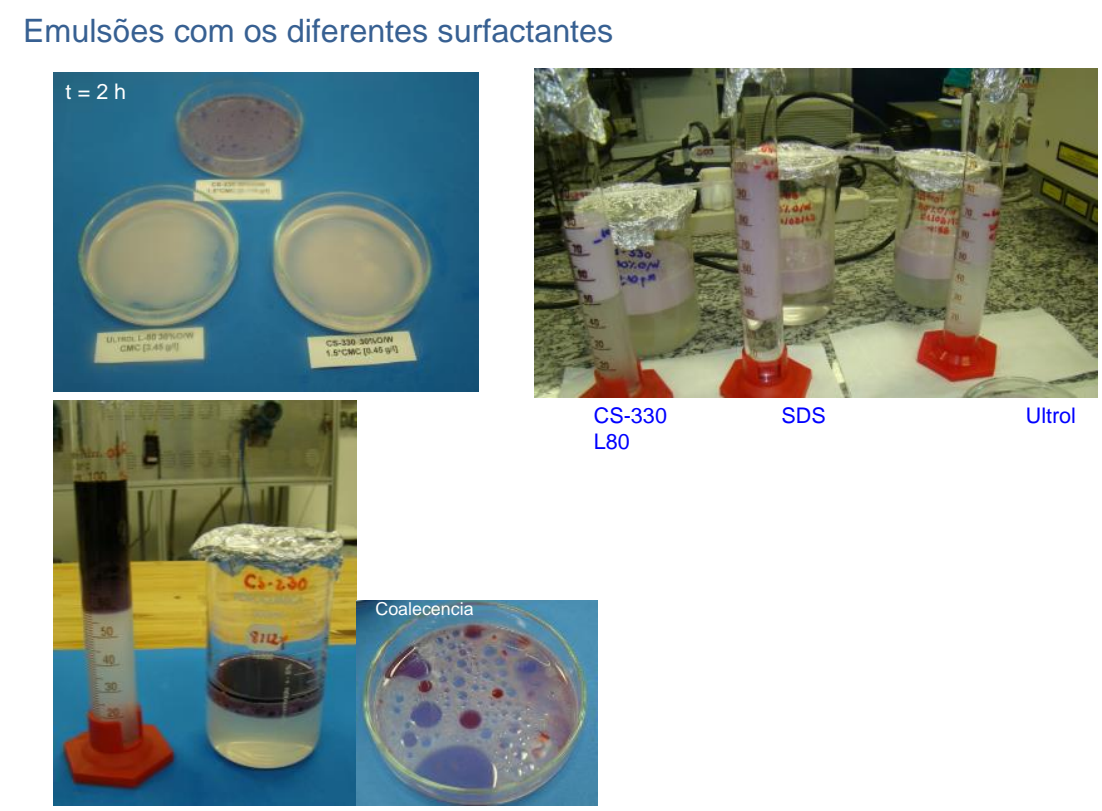

Figura 3-9: Emulsões com os diferentes surfactantes.

O motivo de se colocar um volume pequeno em um béquer grande foi o de diminuir o efeito da densidade. As gotas de óleo, por serem menos densas, sobem e se mantém na parte superior do béquer. Mesmo em uma emulsão estável, as gotas se mantêm compactadas no topo da solução. Ao manter uma altura pequena de solução este efeito é minimizado.

As análises de distribuição de tamanho de gotas foram realizadas utilizando o Mastersizer 2000 da Malvern (Figura 3-11), que utiliza o princípio da difração da luz para a determinação da distribuição do tamanho de gota. 


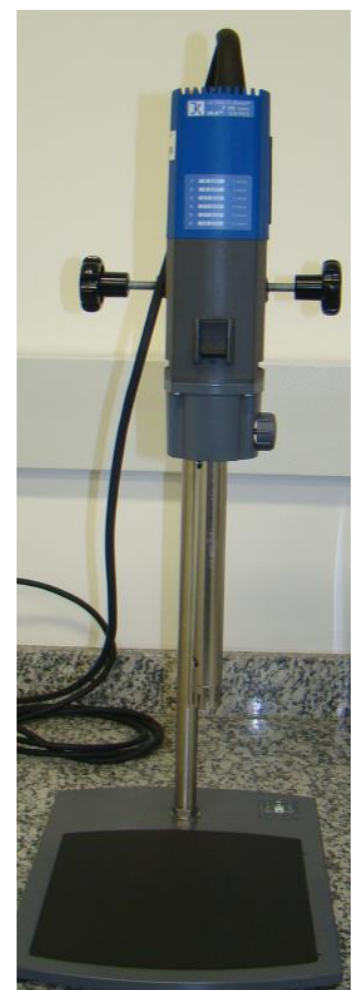

Figura 3-10: Emulsão sendo criada com o Ultra-Turrax T25.

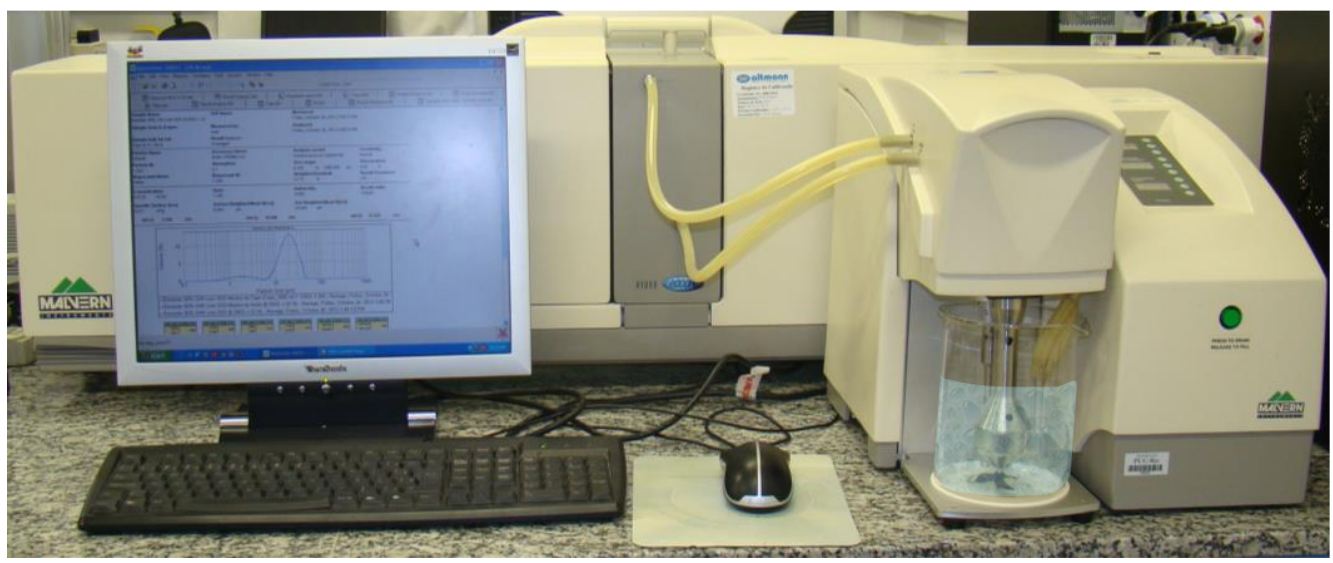

Figura 3-11: Foto do Mastersizer 2000 da Malvern.

O Ultrol L80 e o CS-330 foram os surfactantes que apresentaram melhor estabilidade das emulsões. No entanto, com a finalidade de ter uma comparação direta com o trabalho Engelke (2012), foi definido trabalhar com o Ultrol L80. A distribuição do tamanho de gotas para o Ultrol L80 e o CS-330 é apresentado na Figura 3-12. Como se pode verificar, a emulsão se mantém estável para um tempo de até 8 dias. 
Ultrol L-80

Repetibilidade

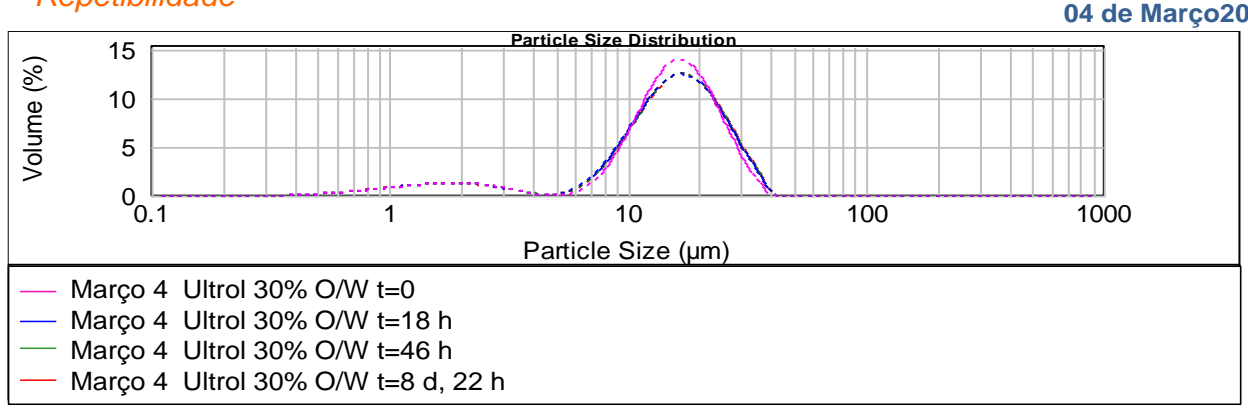

14 de Março2013

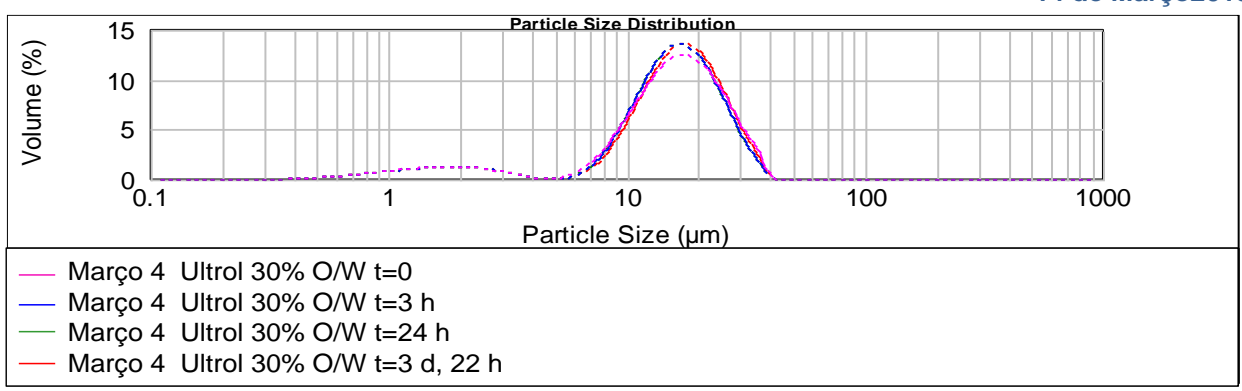

CS-330

Repetibilidade

04 de Março2013

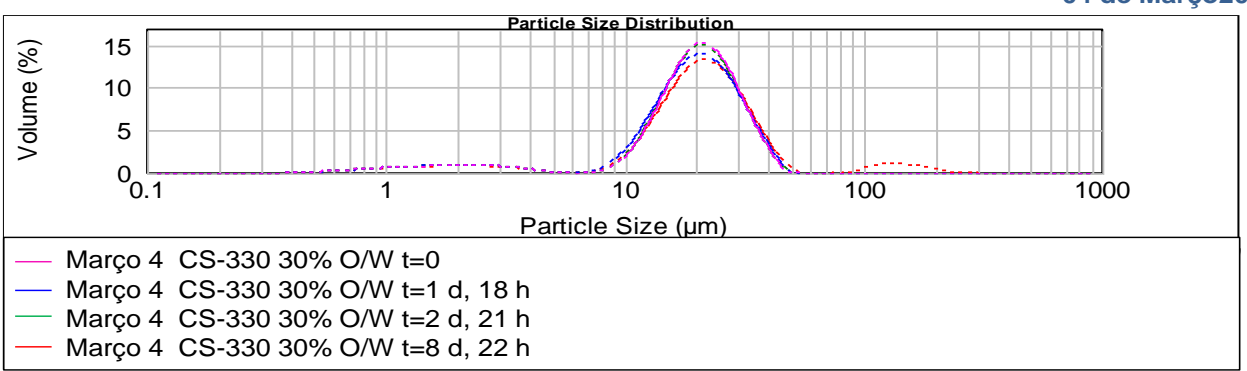

14 de Março2013

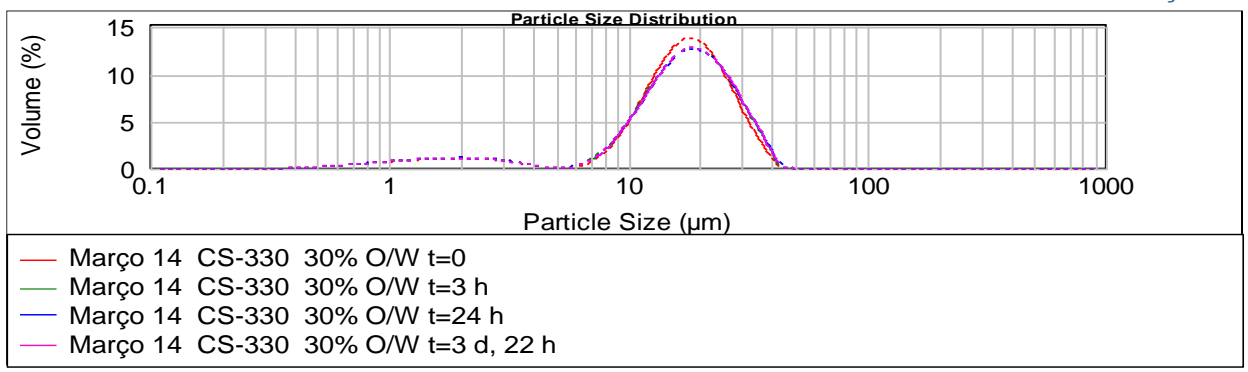

Figura 3-12: Testes de estabilidade e repetibilidade das soluções com água do mar e Ultrol L80 e CS-330.

Apenas para efeitos comparativos, a Figura 3-13 apresenta a distribuição de gotas para a solução feita com SDS além das imagens do efeito ao colocar este surfactante em uma solução de água do mar com SDS (Dodecil Sulfato de Sódio), 
a mesma ficava quase que imediatamente esbranquiçada, o que significa que este sal não possui afinidade com o surfactante, como será apresentado a seguir.

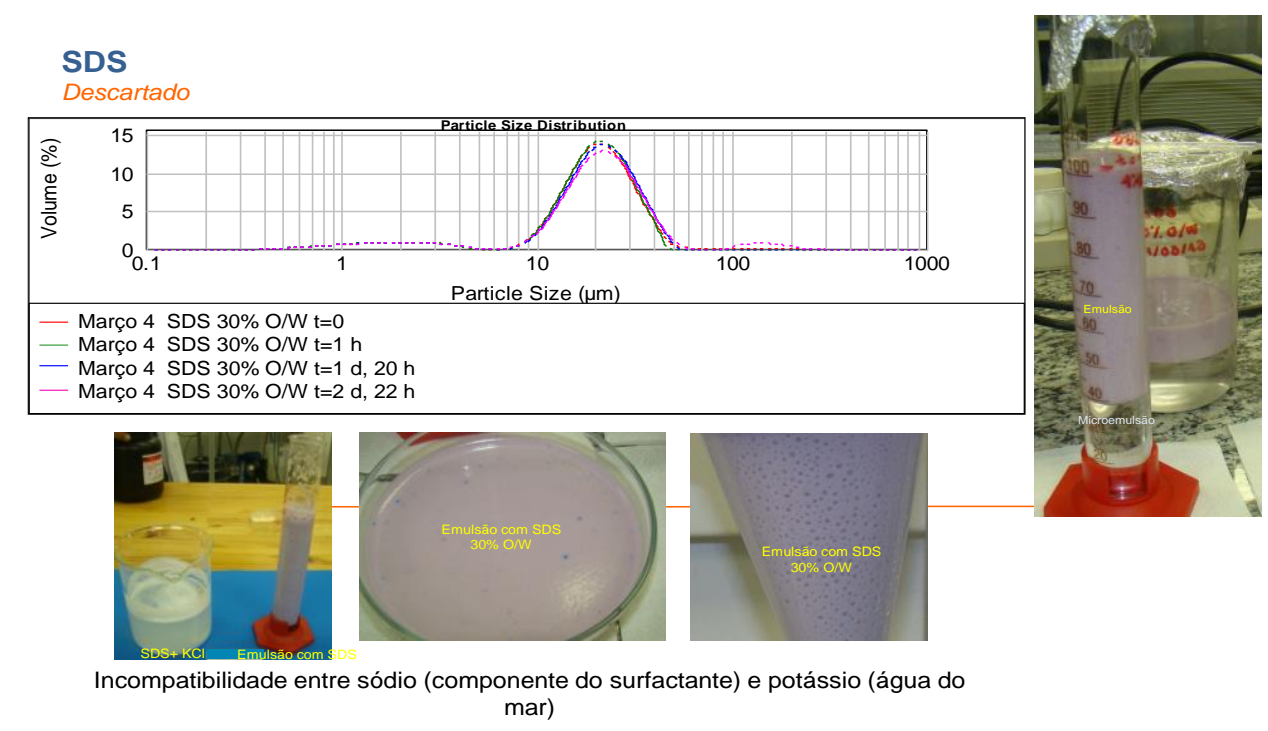

Figura 3-13: Distribuição do tamanho de gotas para a solução com o SDS.

\section{5 \\ Tensão Interfacial e Concentração Micelar Critica}

Tendo definido o surfactante, é importante conhecer as tensões interfaciais do óleo-solução salina e a Concentração Micelar Crítica (CMC) do mesmo. Uma das formas de obter o valor da CMC é medir a tensão superficial de soluções de surfactante em uma faixa de concentração de surfactante e observar o seu comportamento. O equipamento utilizado para fazer issas medições a temperatura de $40^{\circ} \mathrm{C}$ foi o Tensiômetro Tracker da Teclist. (Figura 3-14).

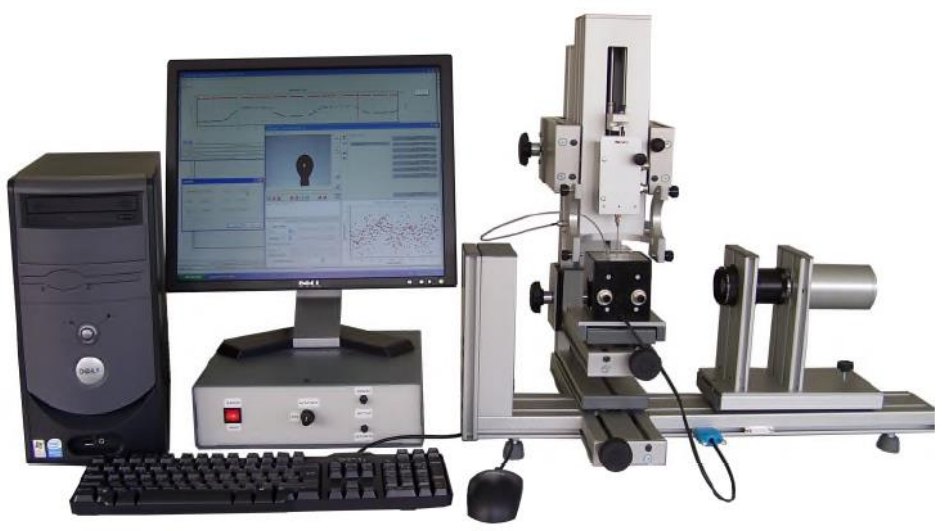

Figura 3-14: Tensiômetro Tracker da Teclist. 


\subsection{1}

\section{Gota Pendente}

O método da gota pendente consiste na determinação do perfil de uma gota pendente de um líquido suspenso em um outro líquido mais denso. O perfil da gota, quando está em equilíbrio mecânico, é determinado por um balanço entre a força de gravidade e as forças de superfície, e pode ser descrito por uma equação diferencial que não possui soluções analíticas (Equações 3.2, 3.3, 3.4 e 3.5) [23]:

$$
2+\mathrm{B} \frac{\mathrm{z}}{\mathrm{a}}=\frac{1}{\frac{\mathrm{R}_{1}}{\mathrm{~A}}}+\frac{\sin \phi}{\frac{\mathrm{x}^{5}}{\mathrm{a}}}
$$

onde

$$
\mathrm{B}=\frac{\mathrm{a}^{2} \Delta \rho g}{\gamma}
$$

e

$$
\begin{aligned}
& \mathrm{R}_{1}=\frac{\mathrm{ds}}{\mathrm{d} \phi} \frac{\left\{1+\left(\frac{\mathrm{dz}}{\mathrm{dx}}\right)^{2}\right\}^{\frac{3}{2}}}{\frac{\mathrm{d}^{2} \mathrm{z}}{\mathrm{d}^{2} \mathrm{x}}} \\
& \sin \phi=\frac{\frac{\mathrm{dz}}{\mathrm{dx}}}{\left\{1+\left(\frac{\mathrm{dz}}{\mathrm{dx}}\right)^{2}\right\}^{\frac{1}{2}}}
\end{aligned}
$$

$\Delta \rho$ é a diferença de densidade dos dois líquidos em contato, $g$ é a aceleração gravitacional, $\gamma$ é a tensão interfacial, a é o raio de curvatura no ápex da gota, $x$, $z$, $\phi$ são as coordenadas definidas como na Figura 3-15 e $\mathrm{R}_{1}$ é o raio de curvatura no ponto $x, y$. [23] 


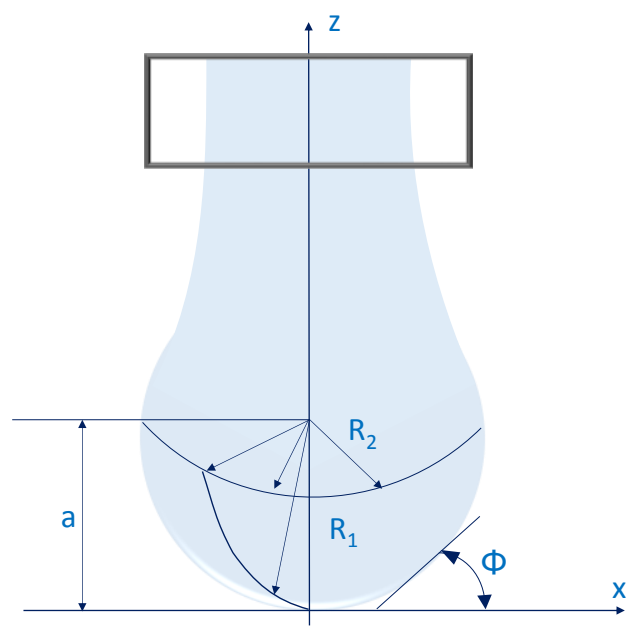

Figura 3-15: Geometria de uma gota pendente. [23]

O aparelho da Figura 3-14 é baseado no método da gota pendente é composto de: $\mathrm{i}$

1. uma câmara experimental aquecida onde a gota é formada;

2. um sistema óptico para iluminar e capturar a imagem da gota e;

3. um sistema de aquisição de dados com um computador para inferir a tensão interfacial a partir do perfil da gota.

A Figura 3-16 apresenta um esquema do aparelho. Os diferentes componentes do aparelho são montados sobre uma mesa com amortecedores de vibração. É muito importante que os ensaios sejam realizados neste tipo de mesa para se evitar a separação da gota. O sistema de iluminação consiste em uma lâmpada e fibra óptica. O comprimento de onda da luz pode ser modificado usando-se filtros quando a gota e a matriz têm o mesmo índice de refração para um dado comprimento de onda. O sistema de visualização da gota é composto de um sistema óptico que aumenta a imagem da gota e a projeta em um equipamento de digitação de imagens. Uma câmara de vídeo é acoplada ao sistema óptico levando a imagem até a digitalizador residente no computador. A câmara experimental é composta de um vaso de secção quadrada de aço inoxidável, aquecido eletricamente, no qual um cilindro em cobre é inserido. Uma célula de vidro, do mesmo tipo utilizada em espectroscopia UV, é inserida no cilindro de cobre. Nessa célula é inserido um fluido de menor densidade. Duas janelas de vidro, em dois lados opostos da câmara experimental, permitem a iluminação e visualização da gota. Um controlador de temperatura com precisão de $\pm 0.5^{\circ} \mathrm{e}$ é usado para manter constante a temperatura dos fluidos. O dispositivo de inserção consiste em uma seringa especialmente projetada para evitar problemas de 
capilaridade e de separação da gota (alongamento, pescoço) encontrados por outros pesquisadores. [23]

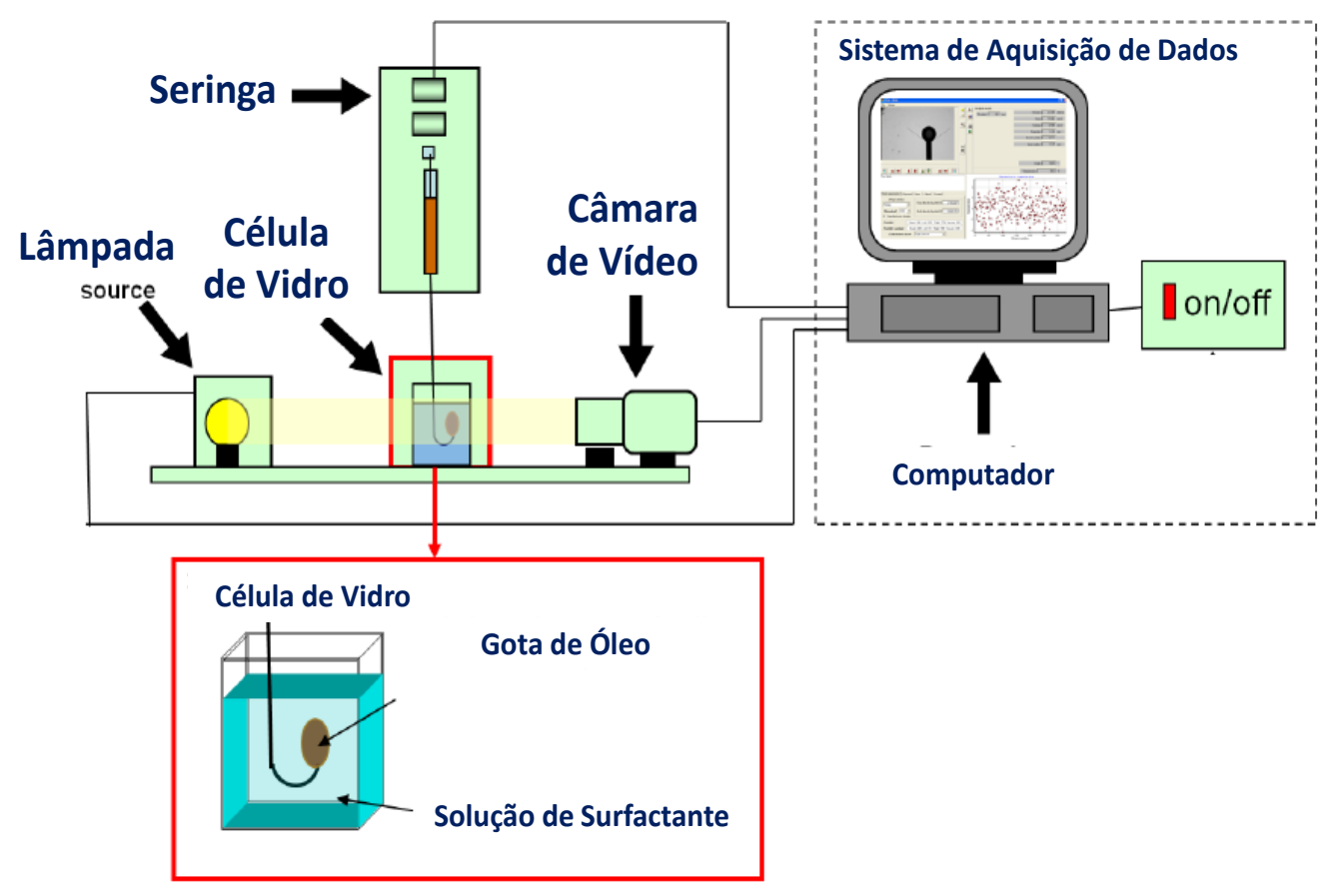

Figura 3-16: Geometria de uma gota pendente. [23]

O fator de forma é obtido a partir do ajuste da imagem tridimensional à equação de Young-Laplace, e para calcular a tensão superficial utiliza-se a Equação 3.3 deduzida de um balanço de forças na gota.

Assim, é obtido o valor da tensão superficial média para cada concentração de surfactante empregada e o desvio padrão entre as medidas significativas (Tensões superficiais calculadas para as imagens das gotas seguindo a forma do modelo de Young-Laplace) das imagens registradas.

A medição da tensão interfacial é feita para várias concentrações do surfactante em estudo, abaixo e acima da CMC teórica. Finalmente, a CMC do surfactante é obtida de uma análise gráfica da variação da tensão superficial com a concentração do surfactante

O protocolo para a determinação da CMC consistiu em duas etapas:

1. Etapa de preparação do teste: foi definida a faixa de concentrações de surfactante, baseado no valor da CMC utilizada na preparação das soluções.

2. Preparação das soluções de surfactante por diluição 
3. Etapa de Medição: enchimento da seringa com ar e a célula com aproximadamente $1 \mathrm{ml}$ de solução, posicionamento da seringa na unidade móvel do tensiômetro, conexão do banho termostático ao tensiômetro à temperatura desejada, dosagem de uma gota de solução até a obtenção da forma da gota desejada e calibração do tensiômetro seguindo o protocolo do equipamento. $O$ cálculo da tensão superficial de cada imagem registrada pelo software. O programa fornece o valor da tensão superficial média e do volume de gota médio calculados com seus respectivos desvios padrão, no momento em que a gota é expulsada. Finalizada esta medida uma nova gota é formada para realização de uma nova medida. Neste caso foram realizadas no mínimo quatro medições para cada solução. As tensões foram medidas da concentração mais baixa à mais alta, e com os resultados obtidos, foi feito um gráfico de tensão superficial em função da concentração do surfactante. A tensão superficial pode ser ajustada utilizando-se duas linhas retas como será apresentado no capitulo 4. Uma das linhas modela o comportamento da tensão antes da concentração micelar crítica (CMC), enquanto a outra linha modela os dados obtidos acima da CMC. A CMC é obtida graficamente a partir do ponto de interseção das retas de ajuste.

O procedimento descrito anteriormente foi repetido variando a concentração de sal, fixando a concentração de surfactante e substituindo a conteúdo da seringa por óleo, para a medição da tensão interfacial.

\section{6}

\section{Propriedades dos Fluidos}

Primeiramente, é importante ressaltar que tanto o óleo quanto a solução salina foram filtrados antes de serem usados, em um filtro com malha de $5 \mu \mathrm{m}$. A densidade e a viscosidade do óleo e das soluções salinas a $40^{\circ} \mathrm{C}$, foram medidas no Laboratório de Caracterização de Fluidos. A viscosidade foi medida usando um viscosímetro Cannon-Fenske que se manteve mergulhado em um banho térmico na temperatura desejada. Já a densidade foi medida através de um picnômetro de $10 \mathrm{ml}$.

A Tabela 3-5, Tabela 3-6 e Tabela 3-7 apresentam a viscosidade e a densidade do óleo Drakeol 7 soluções salinas com e sem surfactantes, 
respectivamente nas temperaturas medidas. A razão de viscosidade $\left(\mu_{\mathrm{o}} / \mu_{\mathrm{w}}\right)$ calculada, para as diferentes soluções na temperatura em que o experimento foi realizado $\left(40^{\circ} \mathrm{C}\right)$, foi aproximadamente 14,71 .

\begin{tabular}{ccc}
\multicolumn{3}{c}{ Drakeol 7} \\
\hline Temperatura $\left[{ }^{\circ} \mathrm{C}\right]$ & $\begin{array}{c}\text { Viscosidade Dinámica } \\
{[\mathrm{cP}]}\end{array}$ & $\begin{array}{c}\text { Densidade } \\
{[\mathrm{g} / \mathrm{cm} 3]}\end{array}$ \\
\hline \hline 20,0 & 22,20 & 0,8467 \\
25,0 & 17,78 & 0,8446 \\
30,0 & 14,50 & 0,8413 \\
40,0 & 10,02 & 0,8338 \\
50,0 & 7,22 & 0,8227
\end{tabular}

Tabela 3-5: Drakeol 7.

\begin{tabular}{ccc}
\multicolumn{3}{c}{ Soluções Salinas com L-80 @ 40C } \\
\hline Soluções & $\begin{array}{c}\text { Viscosidade Dinâmica } \\
\text { [cP] }\end{array}$ & $\begin{array}{c}\text { Densidade } \\
\text { [g/cm3] }\end{array}$ \\
\hline \hline $\mathrm{NaCl} \mathrm{15}$ & 0,68 & 1,0015 \\
$\mathrm{AMS}$ & 0,70 & 1,0177
\end{tabular}

Tabela 3-6: Viscosidade e densidade soluções com L80

Soluções Salinas sem Surfactante @ 40C

\begin{tabular}{ccc}
\hline Soluções & $\begin{array}{c}\text { Viscosidade Dinâmica } \\
{[\mathrm{cP}]}\end{array}$ & $\begin{array}{c}\text { Densidade } \\
{[\mathrm{g} / \mathrm{cm} 3]}\end{array}$ \\
\hline \hline $\mathrm{NaCl} 15$ & 0,66 & 1,0070 \\
$\mathrm{NaCl} 24,53$ & 0,67 & 1,0125 \\
$\mathrm{NaCl} 33,94$ & 0,69 & 1,0180 \\
$\mathrm{AMS}$ & 0,721 & 1,0177
\end{tabular}

Tabela 3-7: Viscosidade e densidade soluções sem surfactante.

\section{7}

\section{Testes de Garrafa}

Nos testes de comportamento de fases, é avaliada a interação entre a fase oleica e a fase aquosa. As fases são misturadas em tubos de $10 \mathrm{ml}$, fechadas e deixadas na temperatura do experimento $\left(40^{\circ} \mathrm{C}\right)$. As misturas foram realizadas às relações óleo-água $80 / 20,65 / 35,50 / 50,35 / 65,20 / 80$ tanta para as soluções sem 
surfactante quanto para as soluções com surfactante L80. Foi decidido também agitar manualmente cada um dos tubos para gerar um pouco de energia mecânica, mantendo-se sempre a mesma forma de agitação para todos os testes, como é apresentado na Figura 3-17. Os tubos foram monitorados constantemente durante um mês para observar possível variações nos volumes e as características das fases.

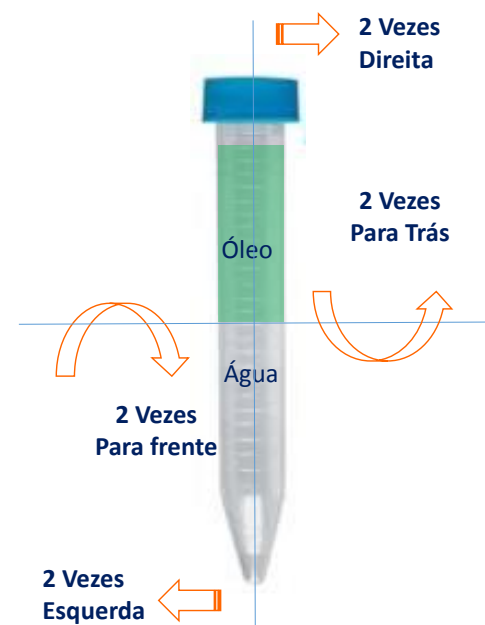

Figura 3-17: Metodologia de agitação das amostras.

\section{8 \\ pH}

$\mathrm{O} \mathrm{pH}$ foi medido utilizando um medidor de $\mathrm{pH}$ Mettler Toledo, à temperatura ambiente. Os resultados serão apresentados no capítulo 4.

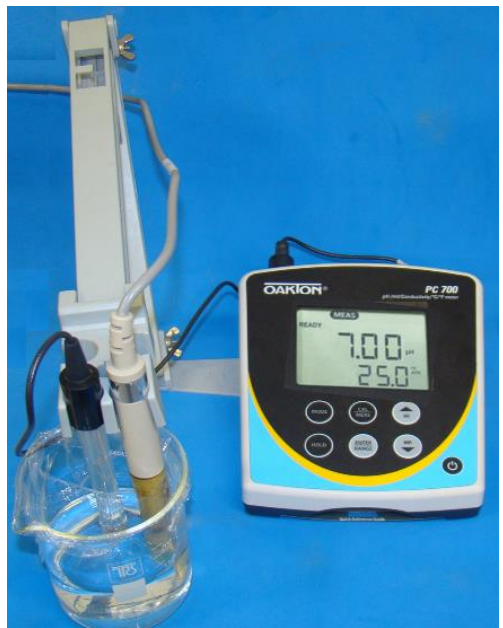

Figura 3-18: Medidor de pH Oakton PC 700. 


\section{9 Limpeza das Amostras}

A restauração das amostras utilizadas nos testes de deslocamento, foi realizada durante quatro dias em um extrator Soxhlet (Figura 3-19). A extração do óleo e resíduos de sal nas amostras foi feita com solventes, lavando continuamente as amostras, até que efluente coletado tornara-se clara. Os solventes utilizados foram acetona e, uma mistura $35 / 75 \mathrm{v} / \mathrm{v}$ de tolueno e metanol respectivamente [24].

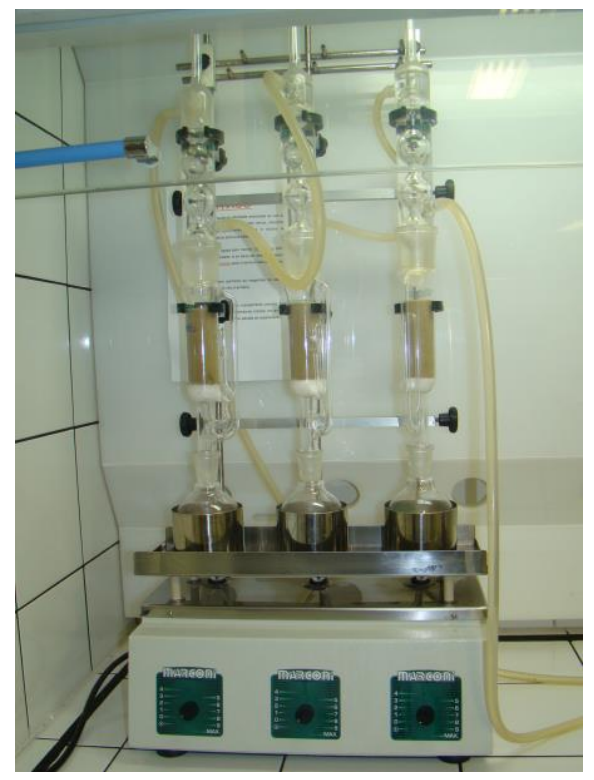

Figura 3-19: Soxhlet para limpeza das amostras.

Das seis amostras utilizadas nos testes de deslocamento, quatro foram reutilizadas: A35, A33, A53 e A55 (ver o capítulo seguinte). Após o processo de restauração, cada uma das amostras foi novamente caracterizada para determinar as suas propriedades petrofísicas (porosidade, permeabilidade, etc.) e continuar com a injeção de outras soluções salinas. 


\section{Resultados}

Neste capítulo apresenta-se um resumo dos experimentos realizados tanto para o escoamento monofásico quanto bifásico.

Os testes foram realizados a temperatura constante de $40^{\circ} \mathrm{C}$, injetando óleo mineral designado como $D K 7$ (Drakeol 7), salmouras com concentrações de 15 até 33,94 $\mathrm{g} / \mathrm{l}$ de $\mathrm{NaCl}$ e água do mar sintética (ASTM-D-1141-98). Além disso, as mesmas soluções foram combinadas com um surfactante não iônico, o L80 (Álcool Laurílico 8 EO ou Ultrol L80), e injetadas mediante testes de deslocamento em seis núcleos de Bentheimer denotados como A31, A32, A33, A35, A53 e A55. Na Figura 4-1, observa-se na primeira coluna a sequência dos testes realizados em cada uma das amostras. A segunda coluna indica as condições de injeção, a terceira coluna o estado de saturação das amostras e finalmente na quarta coluna, os dados obtidos e calculados para os diferentes testes.

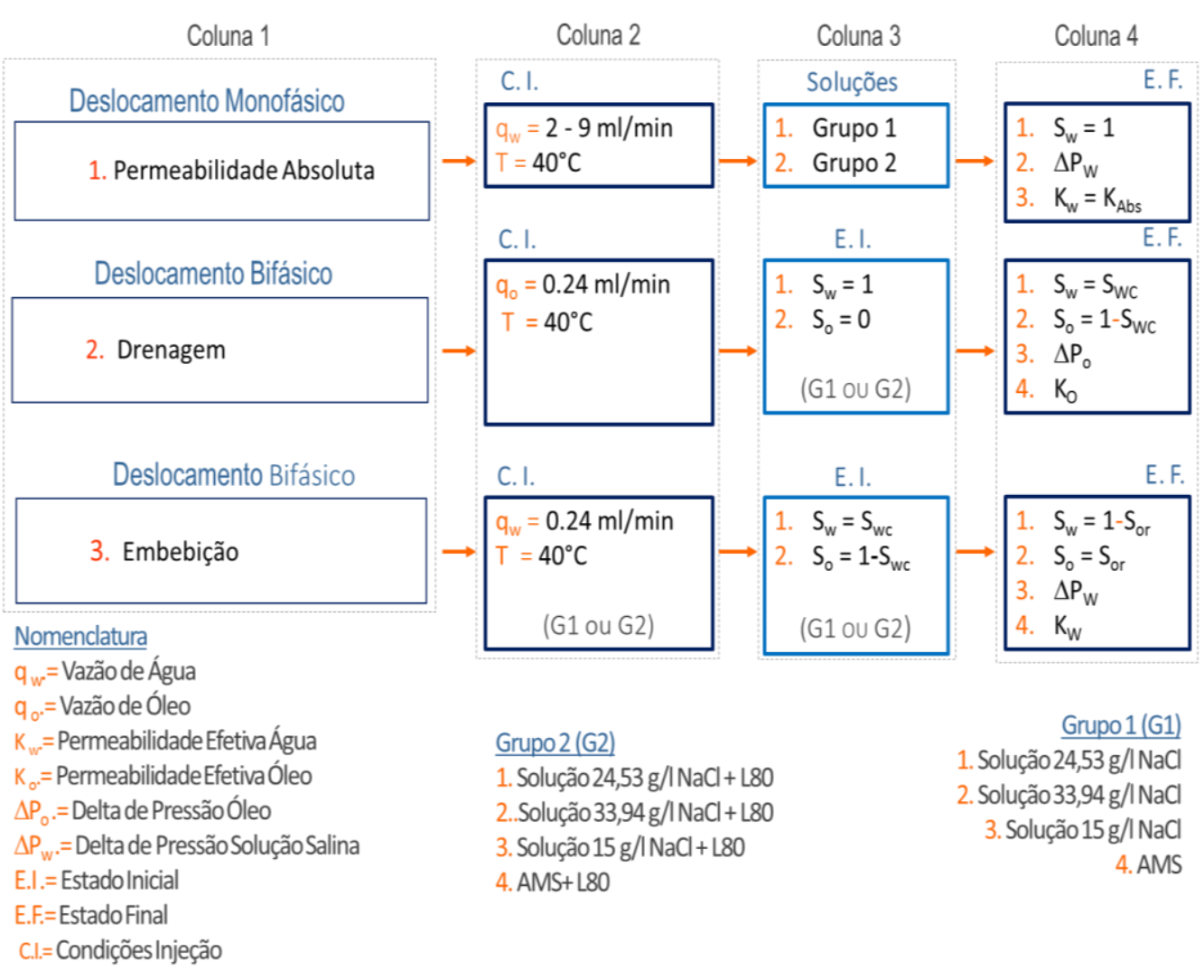

Figura 4-1: Resumos dos experimentos realizados. 
Resultados

O esquema de trabalho mostrado na figura acima, pode-se resumir em três seções:

1. Medição da Permeabilidade Absoluta;

2. Drenagem e;

3. Embebição

Os referidos testes, foram conduzidos mantendo para todos as condições de injeção já especificadas.

\section{1. Porosidade e Propriedades dos Fluidos Injetados}

Para a implementação da metodologia apresentada na Figura 4-1, é necessária caracterizar as amostras de rocha a utilizar em cada teste e os fluidos a serem injetados. Os resultados destas medições se irão apresentar nesta seção.

Para o cálculo da porosidade foi necessário determinar o comprimento e diâmetro das amostras. Os valores calculados são apresentados na Tabela 4-1, e correspondem à média de cada uma destas características físicas. Com esses valores, e o valor da densidade determinado com ajuda de um picnômetro para cada uma das soluções (Tabela 4-2 e Tabela 4-3), e admitindo que a rocha é incompressível, ou seja, sua porosidade a $20^{\circ} \mathrm{C}$ será a mesma que a $40^{\circ} \mathrm{C}$, temperatura sob a qual os testes foram desenvolvidos, o valor da porosidade das amostras foi finalmente determinado.

Propriedades Físicas Amostras de Bentheimer

\begin{tabular}{cccc}
\hline Parâmetro & $\begin{array}{c}\text { Diâmetro } \\
{[\mathrm{cm}]}\end{array}$ & $\begin{array}{c}\text { Comprimento } \\
{[\mathrm{cm}]}\end{array}$ & $\begin{array}{c}\text { Porosidade } \\
\text { [Fração] }\end{array}$ \\
\hline \hline A31 & 3,9 & 9,4 & 0,24 \\
A32 & 3,9 & 9,5 & 0,22 \\
A33 & 3,9 & 9,5 & 0,24 \\
A35 & 3,9 & 9,5 & 0,25 \\
A53 & 3,8 & 9,5 & 0,23 \\
A55 & 3,9 & 9,6 & 0,22 \\
\hline
\end{tabular}

Tabela 4-1: Dados medidos e usados para o cálculo da porosidade. 
Resultados

Soluções $\mathrm{NaCl} @ 40 \mathrm{C}$

\begin{tabular}{ccc}
\hline $\begin{array}{c}\text { Concentração } \\
{[\mathrm{g} / \mathrm{l}]}\end{array}$ & $\begin{array}{c}\text { Viscosidade Dinâmica } \\
{[\mathrm{CP}]}\end{array}$ & $\begin{array}{c}\text { Densidade } \\
{[\mathrm{g} / \mathrm{cm} 3]}\end{array}$ \\
\hline \hline 15 & 0,66 & 1,0070 \\
24,53 & 0,67 & 1,0125 \\
33,94 & 0,69 & 1,0180 \\
AMS & 0,713 & 1,0177 \\
\hline
\end{tabular}

Tabela 4-2: Viscosidade dinâmica e densidade soluções sem surfactante.

Nas Tabela 4-2 e Tabela 4-3 observa-se também os valores calculados da viscosidade dinâmica das soluções que serão utilizados para o cálculo da permeabilidade.

Soluções Salinas com L-80 @ 40C

\begin{tabular}{ccc}
\hline Soluções & $\begin{array}{c}\text { Viscosidade Dinâmica } \\
{[\mathrm{cP}]}\end{array}$ & $\begin{array}{c}\text { Densidade } \\
{\left[\mathrm{g} / \mathrm{cm}^{3}\right]}\end{array}$ \\
\hline \hline $\mathrm{NaCl} \mathrm{15}$ & 0,68 & 1,0015 \\
$\mathrm{AMS}$ & 0,714 & 1,0177
\end{tabular}

Tabela 4-3: Viscosidade dinâmica e densidade soluções com surfactante.

Finalmente, a Tabela 4-4 apresenta a viscosidade dinâmica e densidade do óleo mineral Drakeol 7 a diferentes temperaturas, propriedades que serão utilizadas, também no cálculo da permeabilidade.

Drakeol 7

\begin{tabular}{ccc}
\hline Temperatura $\left[{ }^{\circ} \mathrm{C}\right]$ & Viscosidade Dinâmica $[\mathrm{cP}]$ & Densidade $[\mathrm{g} / \mathrm{ml}]$ \\
\hline \hline 20 & 22,20 & 0,8467 \\
25 & 17,78 & 0,8446 \\
30 & 14,50 & 0,8413 \\
40 & 10,02 & 0,8338 \\
50 & 7,22 & 0,8227
\end{tabular}

Tabela 4-4: Viscosidade dinâmica e densidade soluções com surfactante. 


\section{2.}

\section{Surfactante}

O surfactante não iônico, Ultrol L80 (Álcool Laurílico de oito grupos etoxilados) foi o único utilizado no desenvolvimento desta dissertação. Este surfactante apresenta moléculas com caráter lipofílico, proveniente da cadeia carbônica do álcool de partida, e hidrofílico, resultante da cadeia de óxido de eteno. Estes produtos geralmente não precipitam na presença de íons de dureza de água e são compatíveis com tensoativos aniônicos, catiônicos e não-iônicos mantendo e apresentando estabilidade química e física tanto em meio alcalino como em meio ácido e em diferentes temperatura. [25]

Grupo Polar

(Hidrofílico)

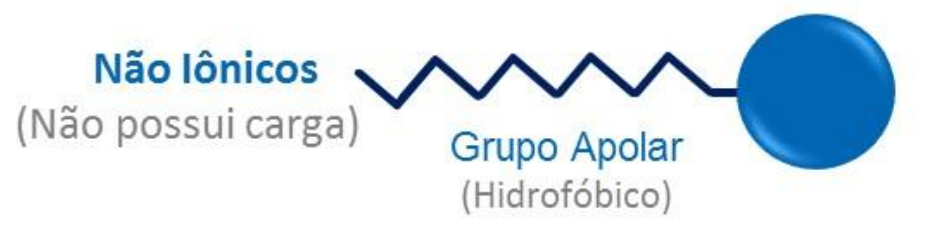

\section{$\mathrm{R}\left(\mathrm{CH}_{2} \mathrm{CH}_{2} \mathrm{O}\right)_{\times} \mathrm{OH}$}

X: Número médio de moles de óxido de eteno (grau de etoxilação)

R: Cadeia carbônica do álcool laurílico.

Figura 4-2: Estrutura química de um surfactante não iônico.

A fórmula química do surfactante L-80, o HLB e temperatura de névoa são apresentados na Tabela 4-5.

Propriedades Surfactante

\begin{tabular}{cc}
\hline \multicolumn{2}{c}{ Caraterísticas do Surfactante Ultrol L80 } \\
\hline \hline Formula Química & $\mathrm{C}_{12} \mathrm{H}_{25}\left(\mathrm{OCH}_{2} \mathrm{CH}_{2}\right)_{8} \mathrm{OH}$ \\
HLB & $12,9 \mathrm{O} / \mathrm{W}$ \\
Temperatura de Névoa & $19^{\circ} \mathrm{C}$ \\
\hline
\end{tabular}

Tabela 4-5: Propriedades do surfactante Ultrol L-80. 


\section{3.}

\section{Tensão Interfacial Óleo-Soluções Salinas}

A tensão interfacial IFT óleo/água foi medida a temperatura constante de $40^{\circ} \mathrm{C}$ para dois sistemas diferentes:

- DK7 + soluções salinas

- DK7 + soluções salinas com L80, (concentração utilizada 1,8 g/l d L80).

A nomenclatura foi definida como $\sigma_{0 / w}$ e $\sigma_{0 / w+L 80}$, respectivamente para os sistemas acima. Na Figura 4-3, pode-se observar que as tensões interfaciais dos sistemas com surfactante foi quase constante para as diferentes soluções salinas, uma vez que para este tipo de surfactante a tensão interfacial não é afetada pela concentração de sal. No entanto, neste mesmo sistema, um aumento da concentração de sal altera a temperatura de turbidez e por sua vez, a solubilidade do surfactante na água devido, principalmente, pela dessolvatação do grupo polar de óxido de etileno $\left(\mathrm{OCH}_{2} \mathrm{CH}_{2} \mathrm{O}\right)$, que apresenta uma influência bastante importante na temperatura de turbidez. É valido ressaltar que, apesar dos surfactantes não iônicos não possuírem carga em suas moléculas, eles apresentam uma parte lipofílica, proveniente do álcool graxo, e outra hidrofílica, proveniente da incorporação de óxido de eteno que se solubiliza na água através de pontes de hidrogênio (Borsato, 2004). [18,26]

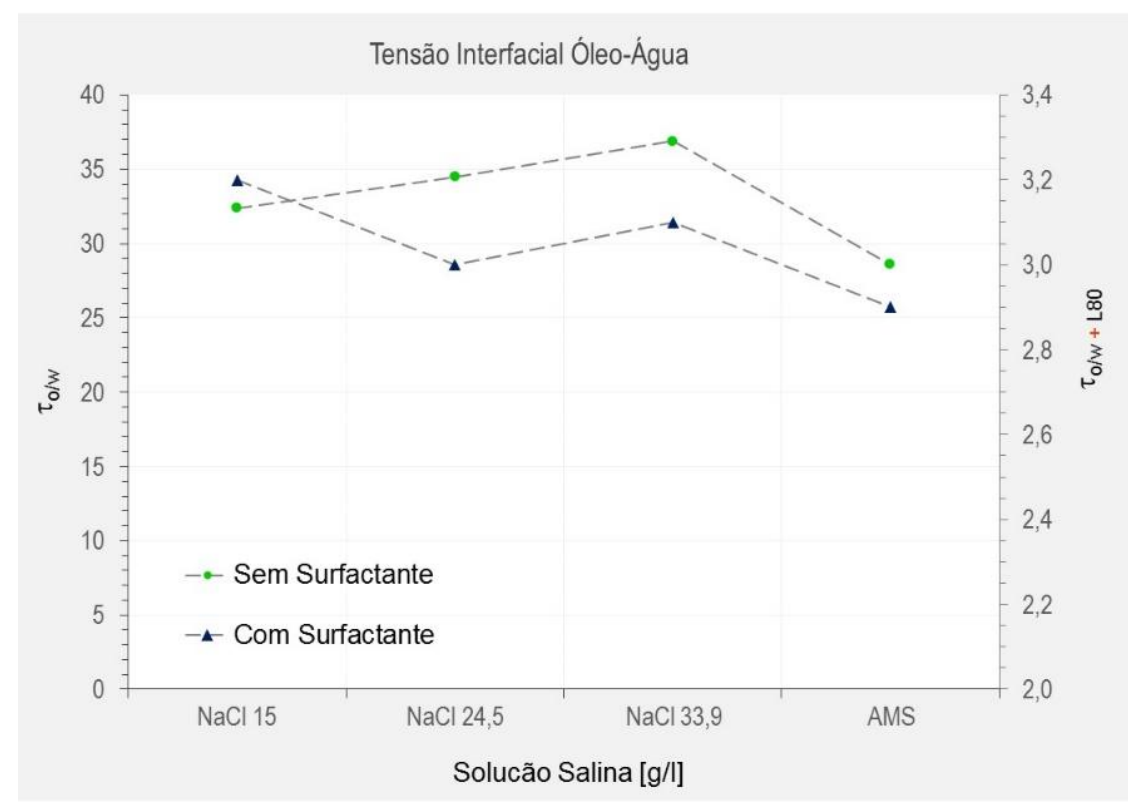

Figura 4-3: Tensão intefacial óleo-água a $40^{\circ} \mathrm{C}$. 
Resultados

Experimentalmente, observou-se também que, a adição de $\mathrm{NaCl}$ à água aumenta a tensão superficial. Uma explicação é a dissociação iônica, na qual os íons de $\mathrm{Na}^{+}$e $\mathrm{Cl}^{-}$são separados e rodeados pelas moléculas de água, fenômeno conhecido como solvatação. Durante este processo as forças de coesão entre as moléculas aumentam, exigindo maior trabalho para deslocar as moléculas da superfície ocasionando o aumento da tensão superficial da água.

Na Figura 4-3, pode-se observar também, que no caso das soluções de $\mathrm{NaCl}$ 33,94 g/l e água do mar, que contém a mesma concentração de sólidos totais dissolvidos (TDS), houve uma diferença numérica na tensão interfacial, tanto para o caso com surfactante, quanto para o caso sem surfactante, isto pode ser explicada pela diminuição da concentração de íons de $\mathrm{Na}+$ e presença dos íons bivalentes $\mathrm{Ca} 2+$ e $\mathrm{Mg} 2+$ na água do mar.

De acordo com a série de Hofmeister, os íons se classificam seguindo uma ordem decrescente do seu poder de ionização: os cátions $\left(\mathrm{Ba}^{2+}, \mathrm{Ca}^{2+}, \mathrm{Mg}^{2+}, \mathrm{Cs}^{+}\right.$, $\left.\mathrm{Rb}^{+}, \mathrm{NH}_{4}{ }^{+}, \mathrm{K}^{+}, \mathrm{Na}^{+}, \mathrm{Li}^{+}\right)$e os ânions $\left(\mathrm{SO}_{4}{ }^{2-}, \mathrm{CH}_{3} \mathrm{COO}^{-}, \mathrm{Cl}^{-}, \mathrm{Br}^{-}, \mathrm{NO}_{3}{ }^{-}, \mathrm{I}^{-}, \mathrm{SCN}^{-}\right.$, $\left.\mathrm{ClO}_{4}{ }^{-}\right)$. Nessa perspectiva, a repulsão dos íons na interface é mais forte para íons menores do que para íons maiores, como consequência, a força de atração é menor entre as moléculas de solvente e os íons, o que incrementa a tensão interfacial e diminui a solubilidade do componente na água. Assim, quanto maior for o tamanho do íon, maior será o número de moléculas de água que se aglomeram ao redor dele devido à atração eletrostática. A magnitude destas forças depende da estrutura química e do tamanho das moléculas de cada substância. [27]

Tensão Interfacial Soluções Salinas - Drakeol 7

\begin{tabular}{ccc}
\hline $\begin{array}{c}\text { Concentração } \mathrm{NaCl} \\
{[\mathrm{g} / \mathrm{l}]}\end{array}$ & $\begin{array}{c}\text { Condutividade } 40^{\circ} \mathrm{C} \\
{[\mu \mathrm{S}]}\end{array}$ & $\begin{array}{c}\text { Tensão Interfacial W/0 } \\
{[\mathrm{mN} / \mathrm{m}]}\end{array}$ \\
\hline \hline $\mathrm{DK} 7$ & $\mathrm{NA}$ & $\mathrm{NA}$ \\
$\mathrm{NaCl} 15$ & 65,8 & 32,4 \\
$\mathrm{NaCl} 24.5$ & 78,9 & 34,5 \\
$\mathrm{NaCl} 33.9$ & - & 36,9 \\
$\mathrm{AMS}$ & 53 & 28,6 \\
$\mathrm{NaCl} 15+\mathrm{L} 80$ & - & 3,2 \\
$\mathrm{NaCl} 24.52+\mathrm{L} 80$ & 40,8 & 3 \\
$\mathrm{NaCl} 33.92+\mathrm{L} 80$ & 55 & 3,1 \\
$\mathrm{AMS}+\mathrm{L} 80$ & 54,2 & 2,9 \\
\hline
\end{tabular}

Tabela 4-6: Tensão superficial DK7 e as soluções com e sem L80 a $40^{\circ} \mathrm{C}$. 


\subsection{1.}

\section{Número de Capilaridade}

Na Figura 4-4, observa-se o número de capilaridade calculado para cada uma das soluções salinas considerando uma vazão de injeção de $0,24 \mathrm{ml} / \mathrm{min}$. De forma geral, o aumento da concentração de sal incrementa as tensões interfaciais e diminui o número de capilaridade, este efeito é o contrário ao observado quando foi adicionado o surfactante na fase aquosa.

Neste estudo foi possível reduzir as tensões superficiais em até 10 vezes (3 $\mathrm{mN} / \mathrm{m}$ ). No entanto, estes valores foram insuficientes para melhora a eficiência de deslocamento, como será apresentado no decorrer deste capitulo.

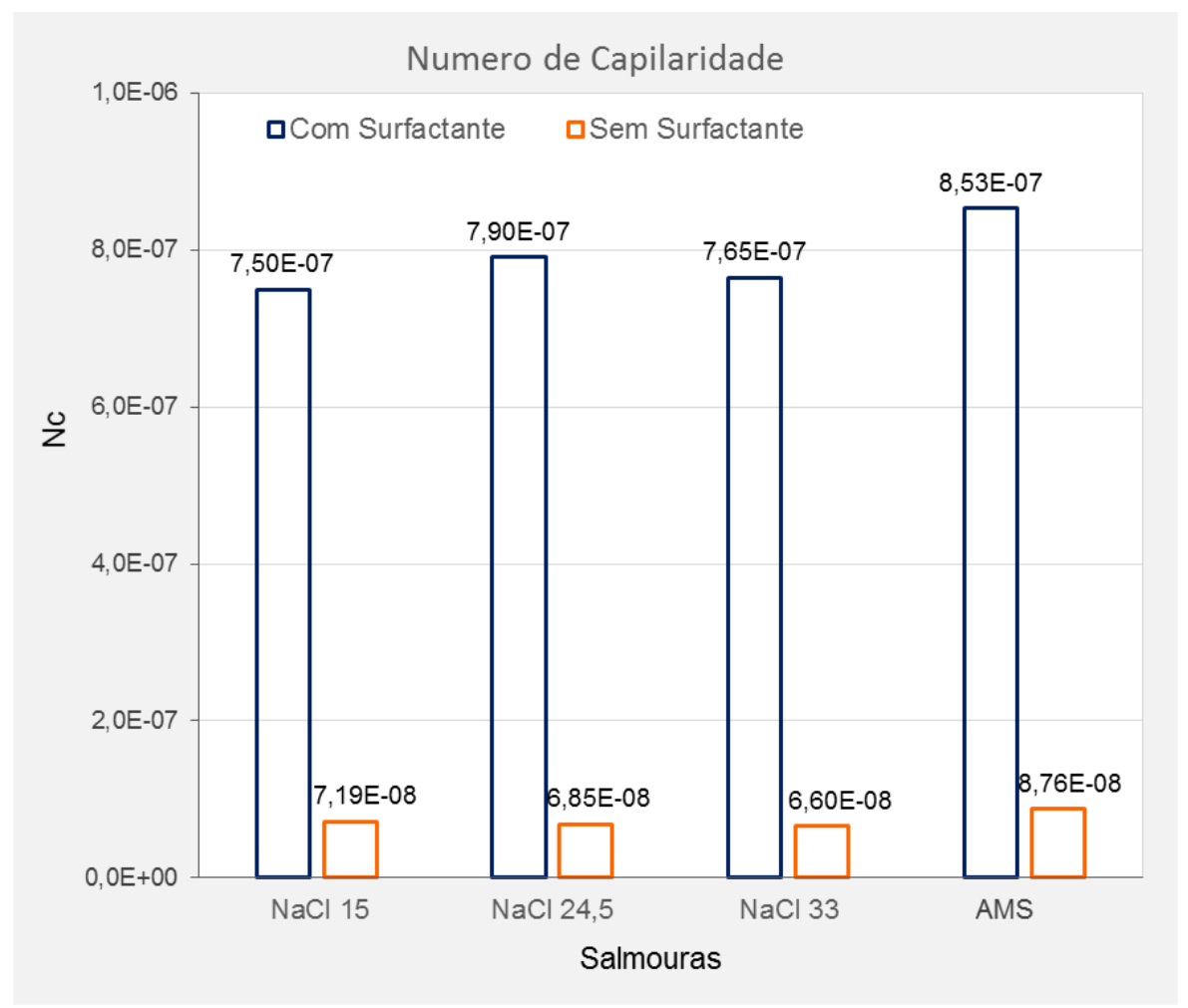

Figura 4-4: Numero de capilaridade soluções salinas.

\subsection{2.}

\section{Testes de Garrafa}

Os resultados dos testes de comportamento de fases ou garrafa são apresentados nas Figura 4-5 e Figura 4-6. Na Figura 4-5 pode-se observar a evolução da mistura água-óleo durante 5 dias a temperatura de $40^{\circ} \mathrm{C}$. Pode-se observar a formação de emulsões para todas as soluções com surfactante tanto na temperatura de sala, quanto à temperatura de trabalho. 


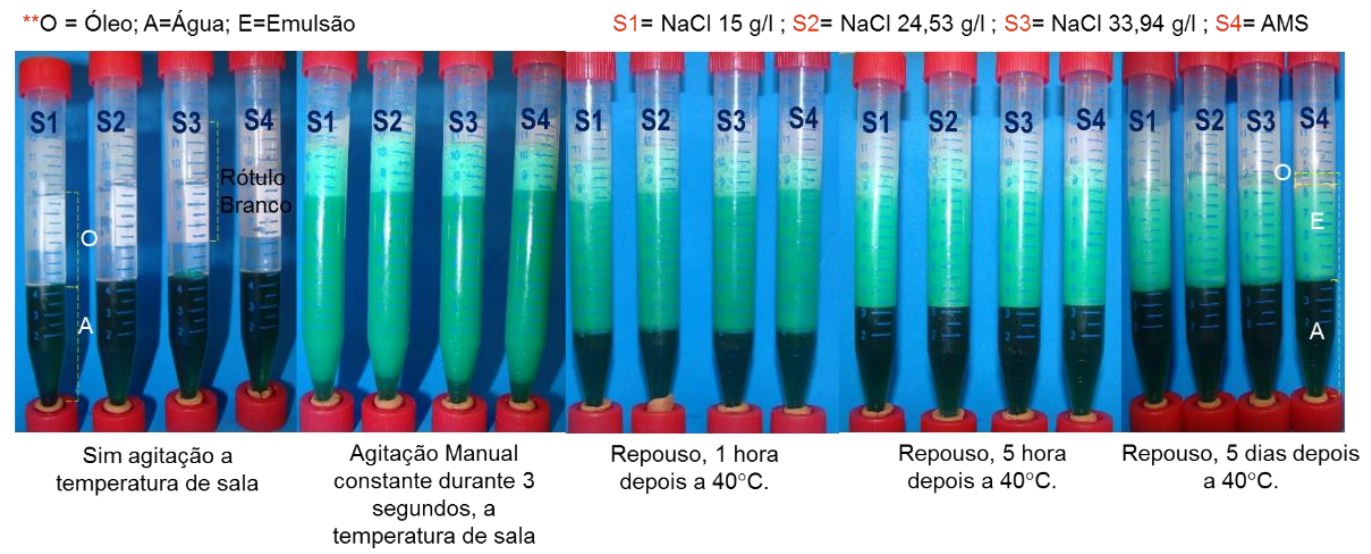

Figura 4-5: Teste de garrafa soluções com surfactante, relação água/óleo 50/50 V/V a $40^{\circ} \mathrm{C}$.

No entanto, as soluções sem surfactante não apresentam formação de uma terceira fase, conforme é observado na Figura 4-6. A figura representa o comportamento das fases a diferentes relações água-óleo a temperatura de $40^{\circ} \mathrm{C}$, durante 5 dias.

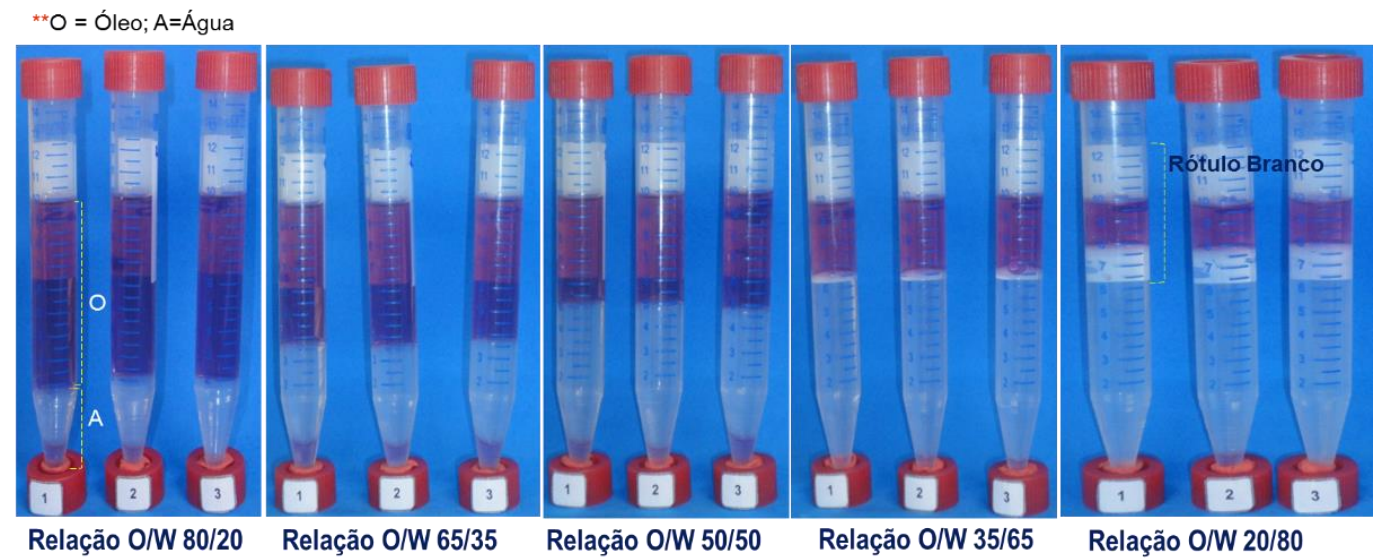

Figura 4-6: Teste de garrafa soluções sem surfactante, relação água/óleo 50/50 V/V a $40^{\circ} \mathrm{C}$.

\section{4.}

\section{Medidas de Concentração Micelar Crítica}

A concentração micelar crítica do surfactante Ultrol L80 foi determinada utilizando o método da gota pendente como descrito no Capítulo 3.

Na Tabela 4-7 são apresentados os valores da tensão superficial para as soluções preparadas com água do mar e diferentes concentrações de surfactante L80, a uma temperatura de $40^{\circ} \mathrm{C}$. 
Resultados

\begin{tabular}{ccc}
\multicolumn{3}{c}{ CMC AMS + L80 @ $40^{\circ} \mathrm{C}$} \\
\hline Ponto & $\begin{array}{c}\text { Concentração } \\
{[\mathrm{g} / \mathrm{l}]}\end{array}$ & $\begin{array}{c}\text { Tensão } \\
{[\mathrm{mN} / \mathrm{m}]}\end{array}$ \\
\hline \hline 1 & 0 & 66,26 \\
2 & 0,00 & 55 \\
3 & 0,01 & 42,15 \\
4 & 0,06 & 30,221 \\
5 & 0,09 & 28 \\
6 & 0,46 & 26,96 \\
7 & 0,85 & 25,04 \\
8 & 0,99 & 26,08 \\
9 & 1,11 & 25,26 \\
10 & 1,80 & 26,82 \\
\hline
\end{tabular}

Tabela 4-7: Tensão superficial da solução de água do mar com diferentes concentrações de Ultrol L80 a $40^{\circ} \mathrm{C}$.

Na Figura 4-7 apresenta-se a Isoterma de Gibbs, com a qual obtém-se o valor de CMC. Observa-se uma diminuição da tensão interfacial com o incremento da concentração de surfactante até atingir a CMC (0,08 g/l). A partir deste ponto, a concentração de surfactante na interface entre as fases atinge sua concentração máxima, a tensão interfacial é quase constante e começa o processo de formação de micelas.

O baixo valor obtido da $\mathrm{CMC}$, conforme esperado, está relacionado à redução da solubilidade do grupo hidrófilo do surfactante pela presença de íons na água do mar.

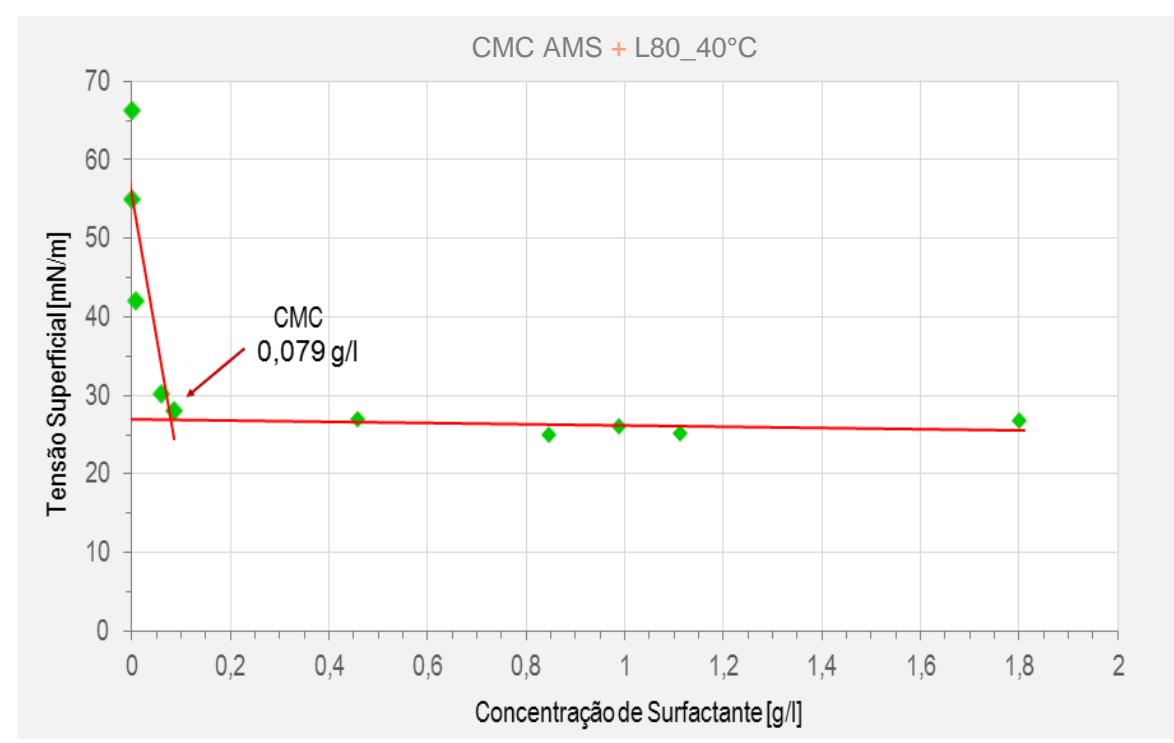

Figura 4-7: Tensão superficial $X$ concentração do Ultrol $L 8040^{\circ} \mathrm{C}$. 


\section{Resultados}

Apesar de ter quatro soluções com surfactante, a CMC só foi medida para água do mar. Além disso, tomou-se como referência o valor obtido da CMC por Engelke (2012), para uma solução preparada com de água deionizada e $15 \mathrm{~g} / \mathrm{l}$ de $\mathrm{NaCl}$, com o mesmo surfactante utilizado nesta pesquisa. $\mathrm{O}$ valor de referência foi $0,06 \mathrm{~g} / \mathrm{l}$ a $20^{\circ} \mathrm{C}$. Conhecido o valor da CMC, optou-se injetar a uma concentração bem acima deste, 1,8 g/l, para garantir o valor mínimo de tensão superficial.

\section{5.}

\section{Testes de Deslocamento}

As diferentes soluções e óleo foram filtradas antes da injeção em um filtro de policarbonato com malha de 5,0 $\mu \mathrm{m}$ (mícrometros). Também decidiu-se injetar o surfactante desde início do experimento, momento este em que foi medida a permeabilidade absoluta. As condições sob as quais foram desenvolvidos os testes são apresentadas na Tabela 4-8.

A vazão de injeção foi tal que a velocidade de Darcy fosse igual a 1 pé/dia. A fim de obter resultados comparáveis, foram utilizados os valores de pressão de confinamento e temperatura do trabalho de Engelke (2012), trabalho este também desenvolvido no Laboratório de Microhidrodinâmica e Escoamento em Meios Porosos PUC-RJ.

\begin{tabular}{clc}
\multicolumn{3}{c}{ Condições Testes Salinidade } \\
\hline Parâmetro & Valor & Unidades \\
\hline \hline Vazão & 0,24 & $\mathrm{ml} / \mathrm{min}$ \\
Pressão Confinamento & 2300 & Psi \\
Temperatura & 40 & ${ }^{\circ} \mathrm{C}$ \\
Concent. Surfactante & 1,8 & $\mathrm{~g} / \mathrm{l}$ \\
Filtro & 5 & $\mu \mathrm{m}$ \\
\hline
\end{tabular}

Tabela 4-8: Condições de injeção para os testes de deslocamento. 


\subsection{1.}

\section{Permeabilidade Absoluta}

As amostras utilizadas nos testes são partes de dois testemunhos de arenito de Bentheimer. A permeabilidade absoluta foi medida no início de cada um dos testes realizados.

Para o cálculo da permeabilidade absoluta, as soluções foram injetadas a vazões de 2 até $9 \mathrm{ml} / \mathrm{min}$, até completar $1 \mathrm{VP}$. Estes valores de vazão foram definidos devido à alta permeabilidade da amostra verificada na primeira injeção. Valores mais baixos, além de serem mais demorados, estariam vinculados a maiores erros com possíveis ruídos, devido às limitações dos transdutores de pressão. O registro da pressão foi feito no momento em que se atingiu o regime permanente, ou seja, até a pressão se estabilizar e o volume injetado de água for igual ao volume produzido. A Figura 4-8 apresenta o comportamento do diferencial de pressão para as diferentes vazões injetadas em função do tempo (representado pelos volumes porosos).

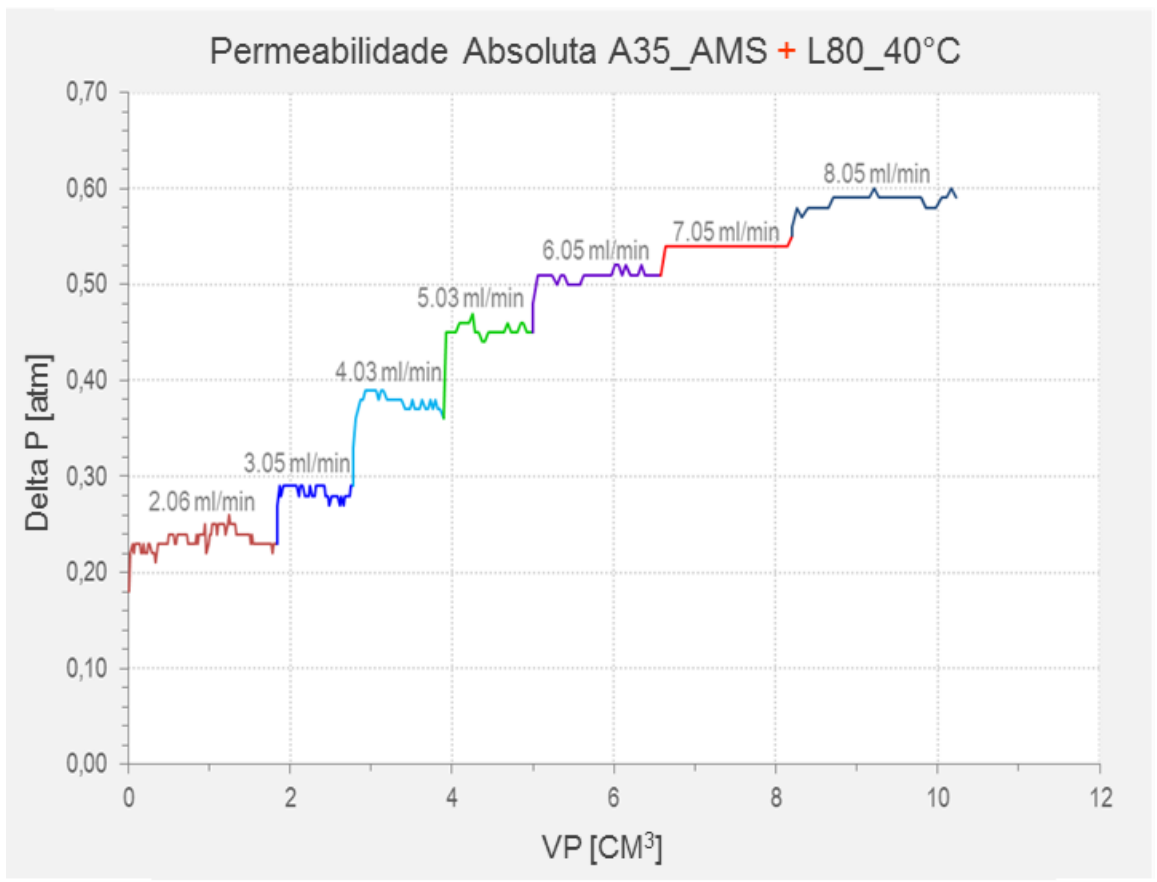

Figura 4-8: Comportamento da pressão em função do volume injetado de água do mar (em VP).

Na Tabela 4-9 estão apresentados os valores da média no momento em que o regime permanente foi atingido para a amostra A35. 
Resultados

\begin{tabular}{cc}
\hline \multicolumn{2}{c}{ Amostra A35 com Água do Mar $+\mathrm{L} 80$} \\
\hline \hline Vazão [ml/min] & Diferencial de pressão (psi) \\
\hline 2.06 & 0,23 \\
3.05 & 0,28 \\
4.03 & 0,37 \\
5.03 & 0,45 \\
7.05 & 0,54 \\
8.05 & 0,59
\end{tabular}

Tabela 4-9: Dados de vazões e diferencial de pressão usados no cálculo da permeabilidade absoluta amostra A35 com água do mar e surfactante L80.

A Figura 4-9 mostra o comportamento praticamente linear da pressão em função da vazão de água do mar com surfactante, que concorda com a Lei de Darcy. Desta forma, com a inclinação da reta, é possível calcular a permeabilidade absoluta da amostra A35, que é aproximadamente $2269 \mathrm{mD}$.

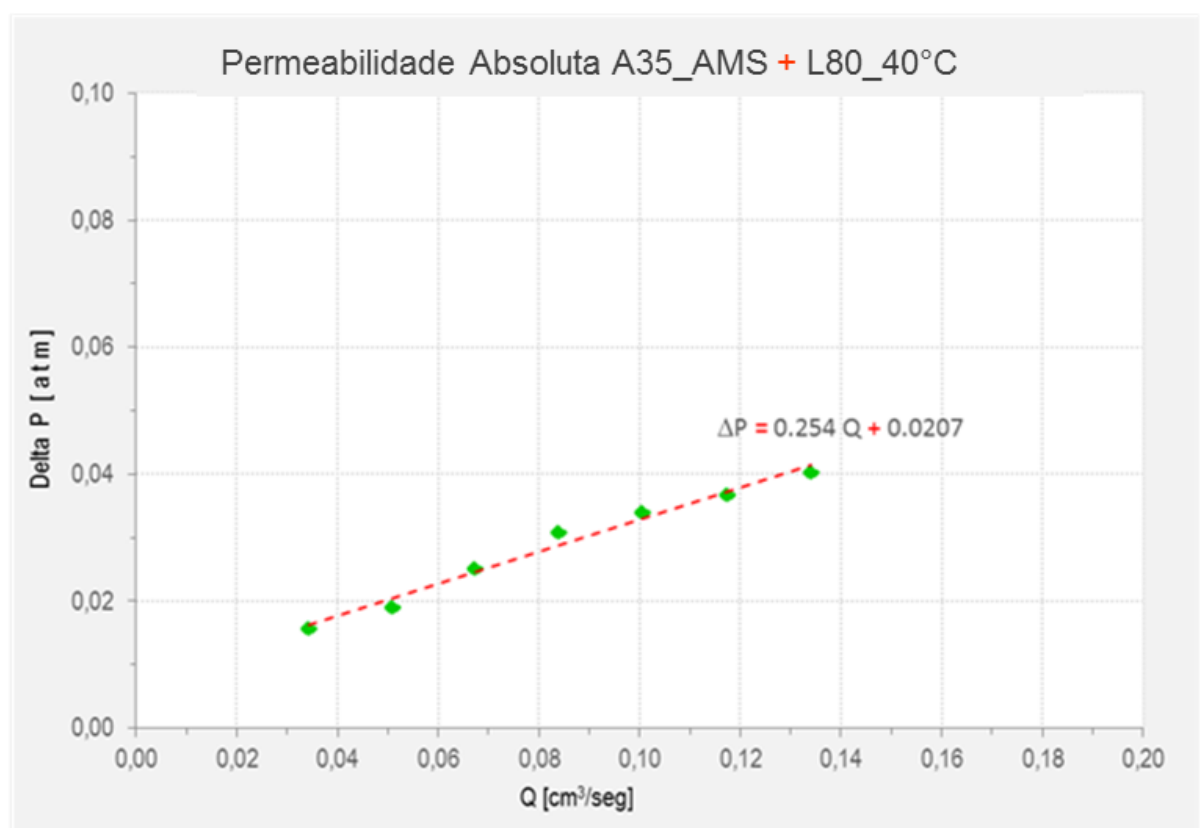

Figura 4-9: Comportamento dados de pressão X vazão amostra $A 35$.

Este procedimento foi realizado para calcular a permeabilidade absoluta de cada uma das amostras. Os valores de permeabilidade absoluta para cada um dos testes são apresentados na Tabela 4-10. As linhas ressaltadas na Tabela 4-10, fazem referência às amostras que apresentam maior variação na permeabilidade absoluta. 
Resultados

Soluções Salinas

\begin{tabular}{rcc}
\hline Amostra & Solução & Permeabilidade Absoluta [mD] \\
\hline \hline A35 & 15 & 1622,0 \\
A53 & 24 & 1281,2 \\
A33 & 33 & 1744,9 \\
A31 & AMS & 2165,8 \\
\hline \hline A32 & $15+$ L80 & 2295,8 \\
A55 & $24,53+$ L80 & 1348,9 \\
A33 & $33,9+$ L80 & 2260,9 \\
A35 & AMS+ L80 & 2269,4
\end{tabular}

Tabela 4-10: Permeabilidade absoluta medidas com as diferentes soluções para amostras arenito a $40^{\circ} \mathrm{C}$.

A Figura 4-10 apresenta o histórico dos testes realizados em cada uma das amostras de arenito de Bentheimer.

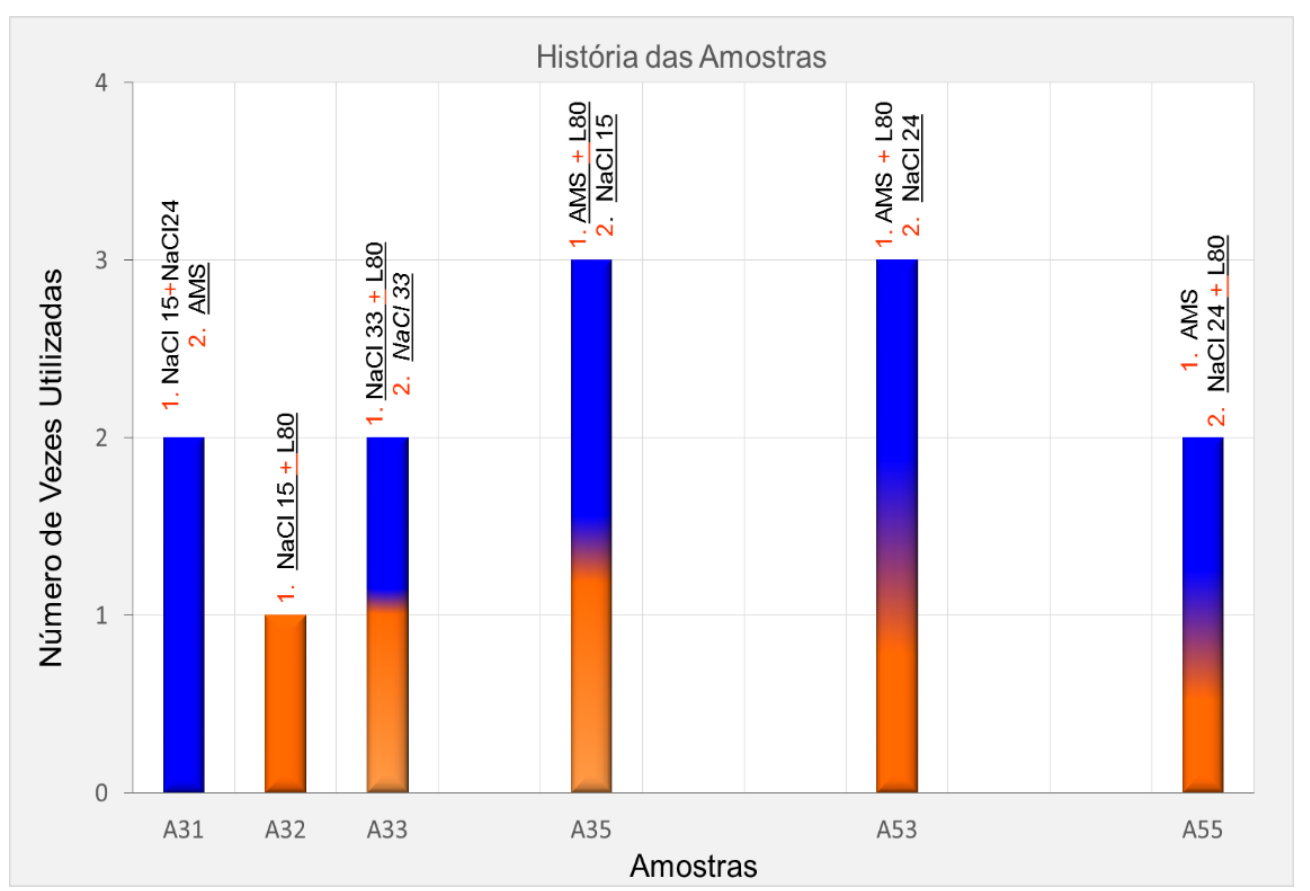

Figura 4-10: Históricos de uso das amostras Bentheimer.

1 Pode-se observar na Tabela 4-10, valores de permeabilidade semelhante para as amostras de arenito nas quais foram injetadas soluções com surfactante, com exceção da amostra (A55), amostra inicialmente submetida à injeção de água do mar sem surfactantes (Figura 4-10). Quanto, as 
amostras utilizadas para a injeção das soluções sem surfactante, todas elas foram submetidas ao processo de limpeza, como já foi dito no capítulo anterior, com exceção da amostra A31. Fica evidente que depois do processo de limpeza não foi possível recuperar a permeabilidade das amostras de arenito, tal como foi observado na Figura 4-10. Assim, foi decidido destacar com linhas descontínuas em todos os gráficos as amostras que foram classificadas como não comparáveis por seus valores de permeabilidade absoluta.

\subsection{2. \\ Permeabilidade Efetiva}

\subsubsection{1 \\ Drenagem}

Durante o processo de drenagem, o óleo penetra inicialmente no meio poroso através dos poros de maior diâmetro. Pelo fato do óleo ser mais viscoso do que a água observa-se durante o escoamento, que a água apresenta tendência a se deslocar com maior facilidade comparado ao óleo, o que faz com que a permeabilidade efetiva da água $\left(\mathrm{K}_{\mathrm{w}}\right)$ decline mais rapidamente durante o início do processo de injeção. A queda da permeabilidade efetiva da água continuará até que a saturação da fase aquosa seja igual à saturação de água irredutível ou conata e a permeabilidade efetiva da água seja igual a zero. Neste ponto, o fluxo da fase molhante é interrompido e se atinge o máximo valor de permeabilidade relativa do óleo $-\mathrm{K}_{\text {ro. }}$ O procedimento realizado para todas as amostras consistiu em injetar óleo a uma taxa constante de $0,24 \mathrm{ml} / \mathrm{min}$ monitorando-se os volumes das fases produzidas, assim como o diferencial de pressão ao longo da amostra (medido através dos transdutores de pressão) e a massa dos fluidos produzidos, até atingir a saturação de água conata. Neste ponto o óleo não consegue deslocar mais água dos poros e se alcança o regime permanente, sendo possível calcular a permeabilidade efetiva $\left(\mathrm{K}_{\mathrm{o}}\right)$ e relativa do óleo $\left(\mathrm{K}_{\mathrm{r}}\right)$ à saturação de água conata. Na Tabela 4-11 são apresentados os dados calculados de saturação de água conata e permeabilidade efetiva do óleo para as diferentes soluções salinas a $40^{\circ} \mathrm{C}$. As linhas ressaltadas na Tabela $4-11$, fazem referência às amostras que apresentam maior variação na permeabilidade absoluta. 
Drenagem Soluções Salinas

\begin{tabular}{ccccc}
\hline Solução & KAbsoluta [mD] & $\mathrm{S}_{\text {wc }}[$ Fração] & $\mathrm{K}_{\text {。 }}[\mathrm{mD}]$ & $\mathrm{K}_{\text {ro }}[-]$ \\
\hline \hline 15 & 1622,0 & 0,23 & 743,5 & 0,46 \\
24 & 1281,2 & 0,42 & 729, & 0,57 \\
33 & 1744,9 & 0,31 & 891 & 0,51 \\
AMS & 2165,8 & 0,32 & 1009,8 & 0,47 \\
\hline 15+ L80 & 2295,8 & 0,24 & 1109,1 & 0,48 \\
$24,53+$ L80 & 1348,9 & 0,25 & 682,5 & 0,51 \\
33,9 + L80 & 2260,9 & 0,10 & 621,7 & 0,27 \\
AMS + L80 & 2269,4 & 0,14 & 627,7 & 0,28
\end{tabular}

Tabela 4-11: Dados obtidos testes de drenagem soluções salinas a $40^{\circ} \mathrm{C}$.

Os diferenciais de pressão do processo de drenagem para as diferentes soluções são apresentados nas Figura 4-11 e Figura 4-12. É possível observar uma maior oscilação da pressão nas curvas das soluções que não tem surfactantes, visto que as tensões interfaciais são maiores (28 - $32 \mathrm{mN} / \mathrm{m}$ ) e, por consequência, os efeitos de capilaridade. Da mesma forma, foi observado durante os testes de drenagem que números de capilaridade mais baixos levam a diferenciais de pressão também mais baixos e saturação de água conata mais altas.

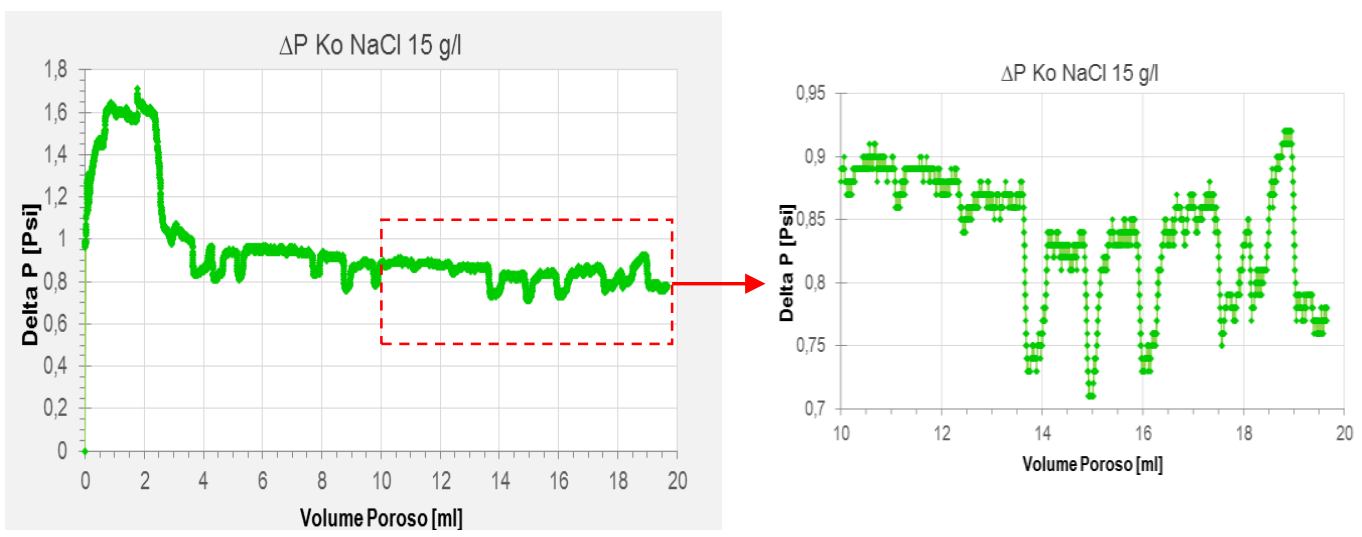


Resultados
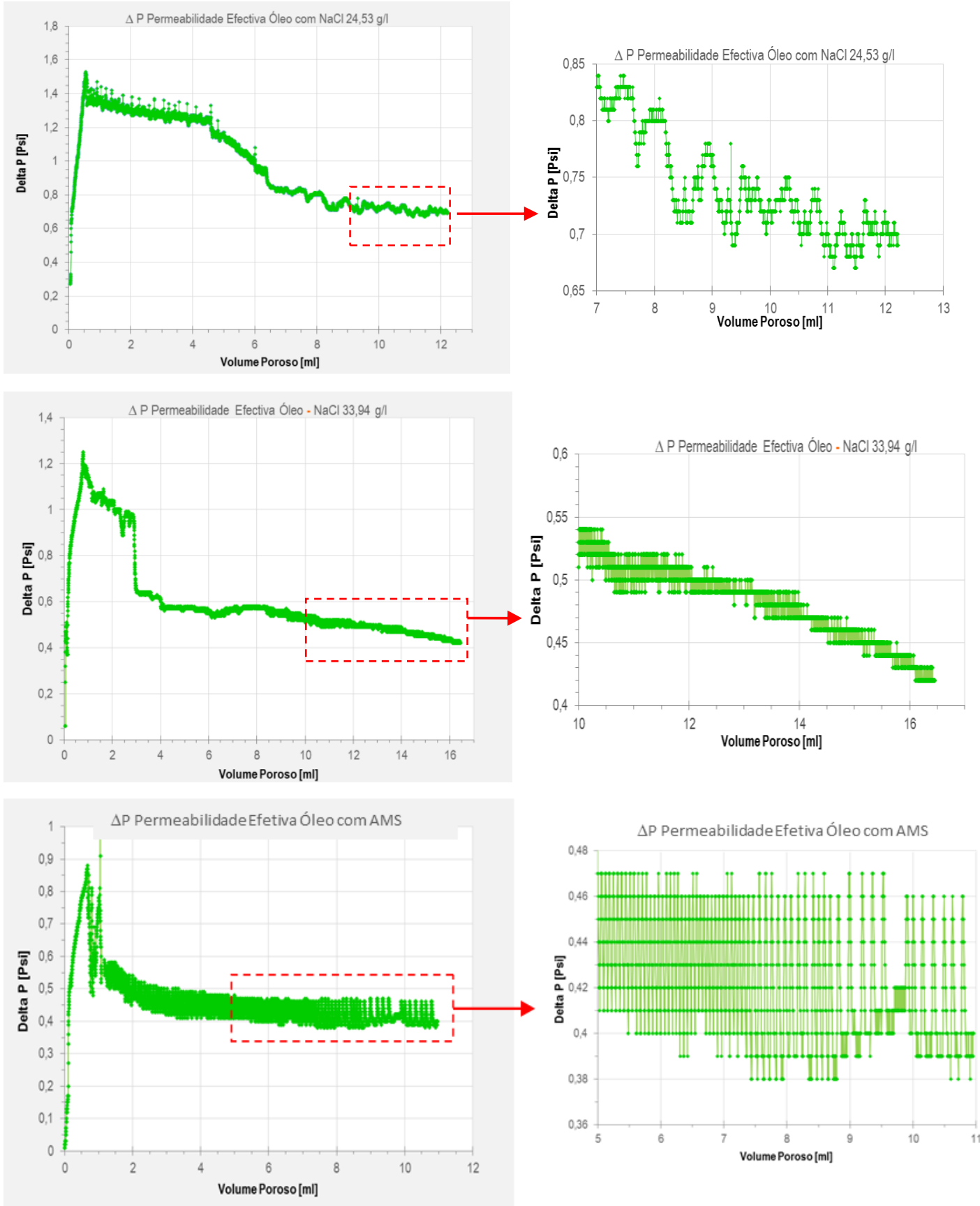

Figura 4-11: Comportamento do diferencial de pressão na injeção de óleo nas amostras saturadas com soluções sem surfactante - Drenagem a $40^{\circ} \mathrm{C}$.

É importante destacar na Figura 4-12 que o diferencial de pressão apresenta pouca oscilação em comparação as curvas obtidas com a injeção das soluções sem surfactante, isto se deve ao fato de que o surfactante reduziu os efeitos de capilaridade. 


\section{Resultados}
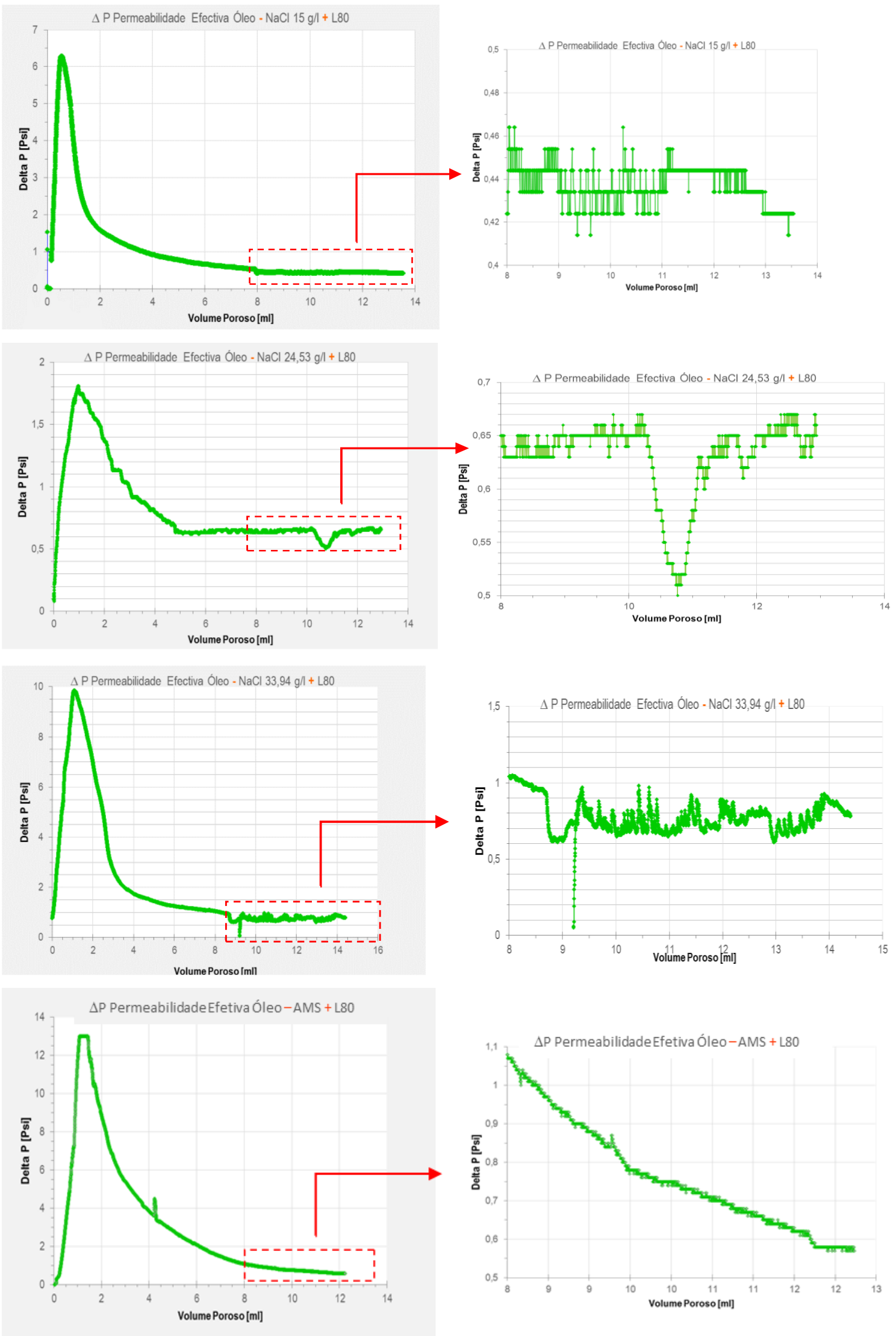

Figura 4-12: Comportamento do diferencial de pressão na injeção de óleo nas amostras saturadas com soluções com surfactante - Drenagem a $40^{\circ} \mathrm{C}$. 


\subsubsection{2 Embebição}

$\mathrm{Na}$ embebição, a solução salina desloca o óleo através do meio poroso até alcançar a saturação de óleo residual ( $\mathrm{S}_{\text {or }}$ ) ou, em outras palavras, a saturação na qual a água não consegue deslocar mais óleo do meio poroso. Finalmente, obtémse tanto a permeabilidade efetiva da água $\left(K_{w}\right)$ quanto a permeabilidade relativa da água $\left(K_{\mathrm{rw}}\right)$ na saturação de óleo residual e o fator de recuperação de óleo.

Os testes de embebição para todas as amostras foram realizados injetando a fase aquosa nas mesmas condições dos testes de drenagem. Nesta fase, esperava-se observar que, pelo fato das forças capilares serem maiores durante o deslocamento das soluções sem surfactante, houvesse maior instabilidade da pressão, um deslocamento mais não uniforme e uma maior saturação de óleo residual, em comparação com as soluções que contém surfactante. No entanto, isto não foi observado devido às interações das fases durante a injeção do surfactante e distribuição do tamanho de poro em cada uma das amostras, já que, não necessariamente, ao longo de um mesmo testemunho a distribuição de poros é igual o que gera diferentes emulsões in sito, tornando ainda mais complexa a análise dos resultados, como se pode observar na Tabela 4-12.

Embebição Soluções Salinas

\begin{tabular}{ccccc}
\hline Solução & $\mathrm{K}_{\text {Absoluta }}[\mathrm{mD}]$ & $\mathrm{S}_{\text {or }}[$ Fração] & $\mathrm{K}_{\mathrm{w}}[\mathrm{mD}]$ & $\mathrm{K}_{\text {rw }}[-]$ \\
\hline \hline 15 & 1622,0 & 0,39 & 88,2 & 0,05 \\
24 & 1281,2 & 0,17 & 75,4 & 0,06 \\
33 & 1744,9 & 0,25 & 34,2 & 0,02 \\
AMS & 2165,8 & 0,27 & 27,1 & 0,01 \\
\hline 15+ L80 & 2295,8 & 0,43 & 26,21 & 0,01 \\
$24,53+$ L80 & 1348,9 & 0,39 & 72,7 & 0,05 \\
33,9 + L80 & 2260,9 & 0,46 & 37,1 & 0,02 \\
AMS + L80 & 2269,4 & 0,49 & 39,0 & 0,02
\end{tabular}

Tabela 4-12: Dados obtidos testes de drenagem soluções salinas a $40^{\circ} \mathrm{C}$.

De forma geral, esperava-se encontrar nos testes representados na Tabela 4-12, que altos valores de tensão superficial resultariam em maiores pressões capilar e, consequentemente, maiores saturações residuais. Mas como mencionado, isso não foi o observado. Vale destacar que, o que também pode influenciar a tendência esperada no caso das soluções sem surfactante é o fato 
Resultados

de que as permeabilidades absolutas e saturações de água não são exatamente iguais.
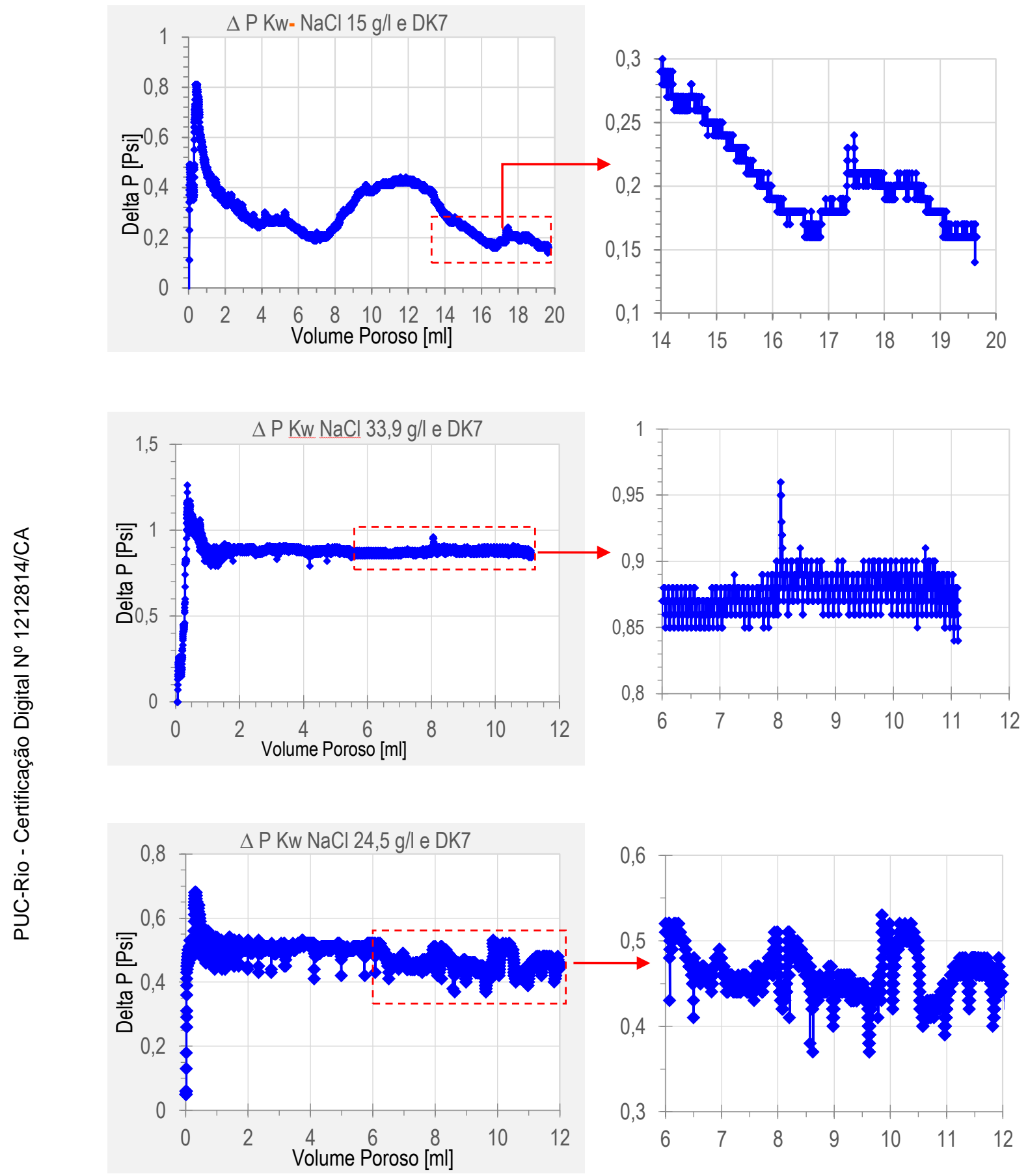


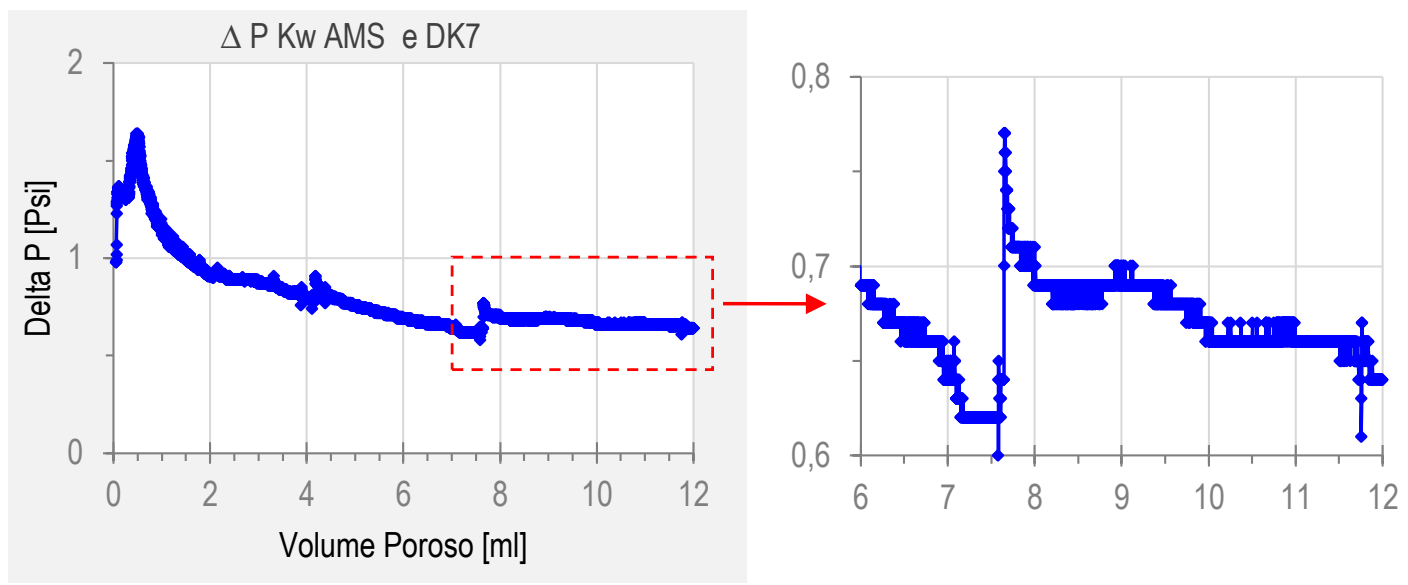

Figura 4-13: Comportamento do diferencial de pressão na injeção das soluções salinas nas sem surfactante - Embebição a $40^{\circ} \mathrm{C}$.

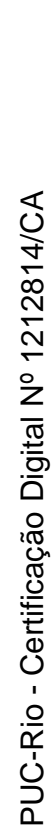
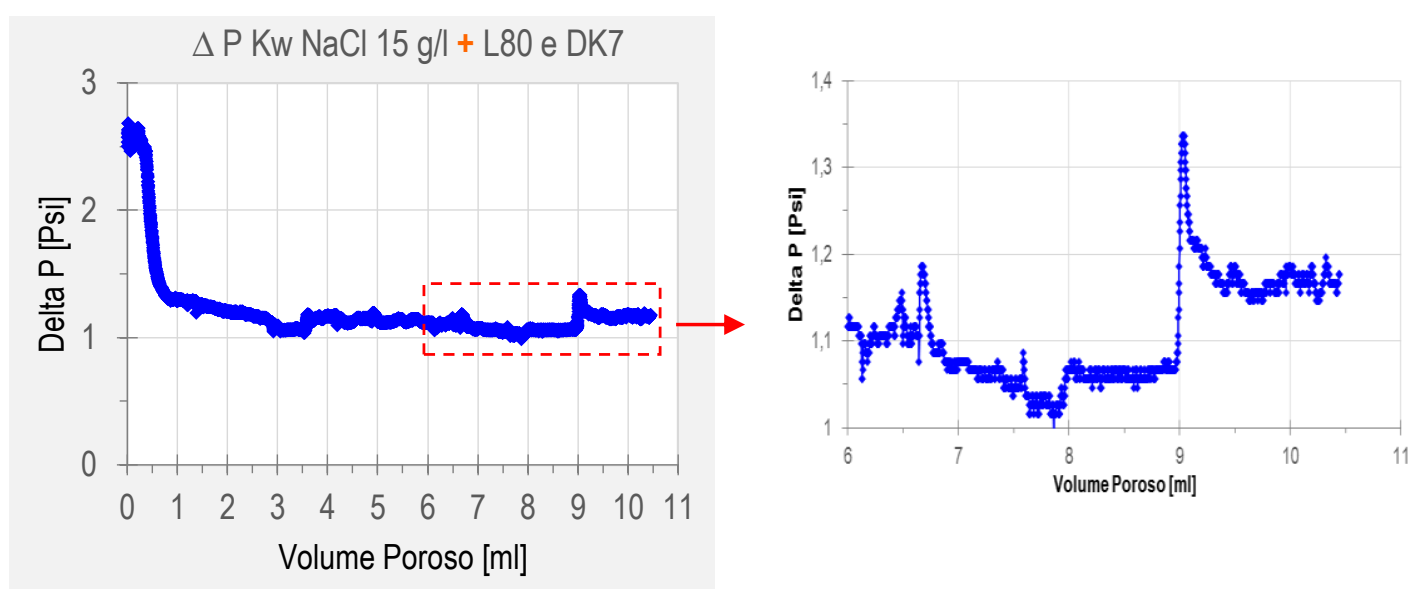

a)
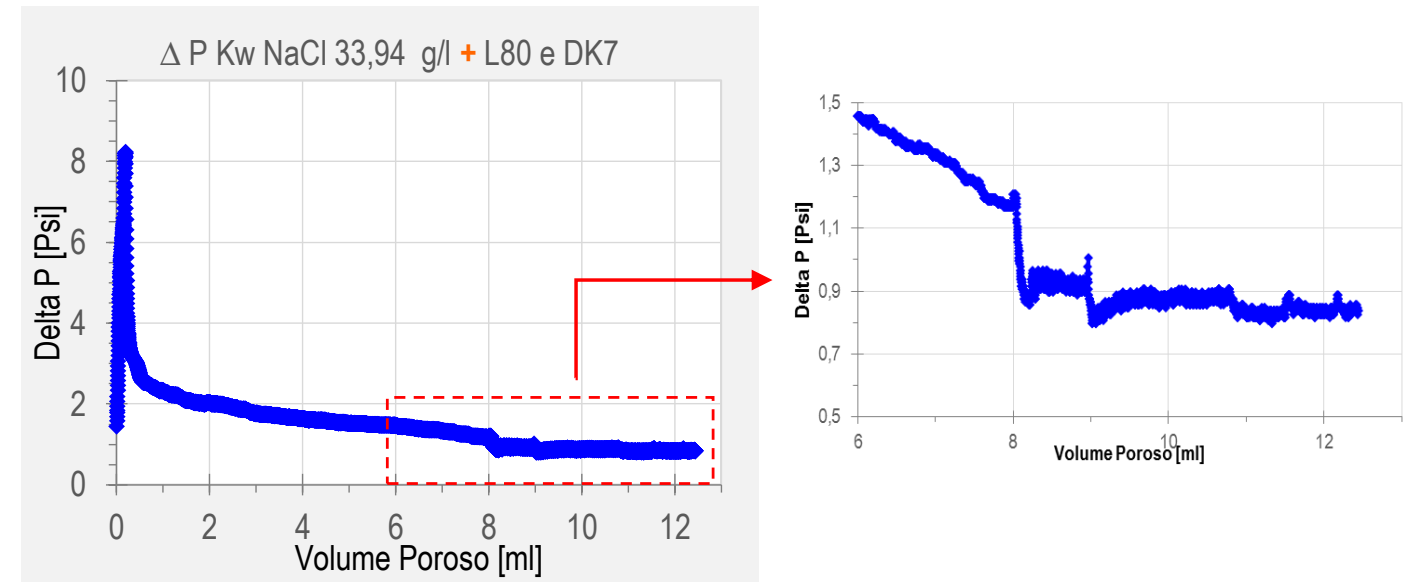

b)

Figura 4-14: Comportamento do diferencial de pressão na injeção de a) Solução $\mathrm{NaCl} 15$ $\mathrm{g} / \mathrm{l}$ e b) $\mathrm{NaCl} 33,9 \mathrm{~g} / \mathrm{l}$ - Embebição a $40^{\circ} \mathrm{C}$. 


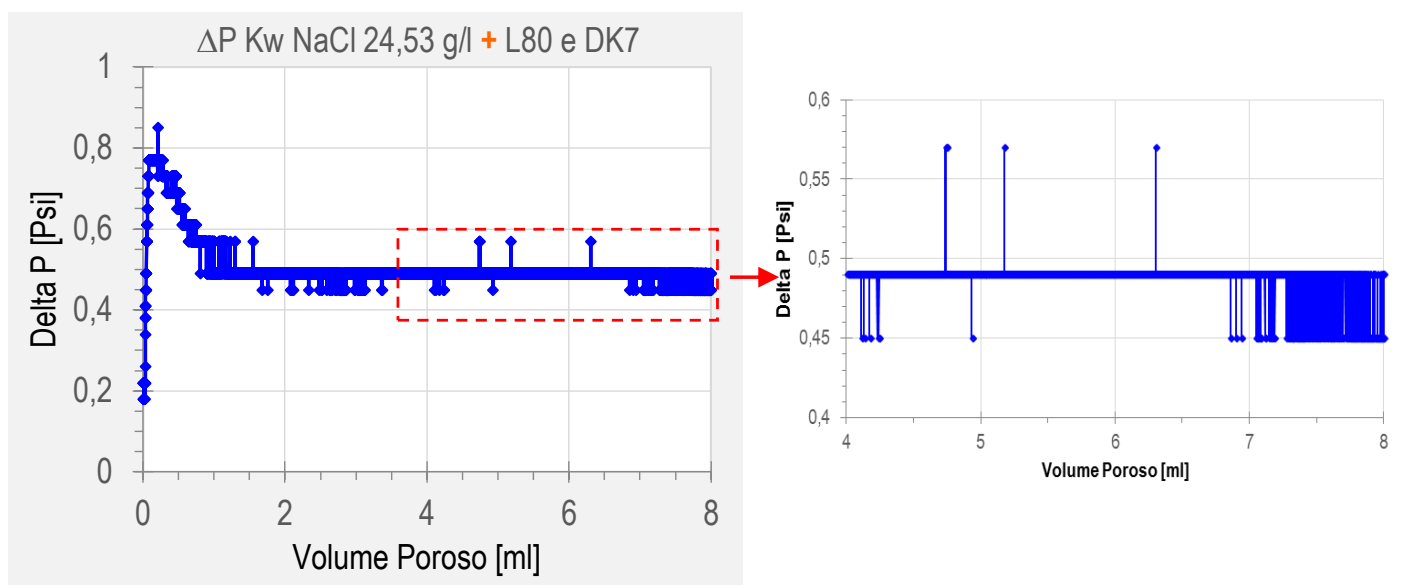

a)

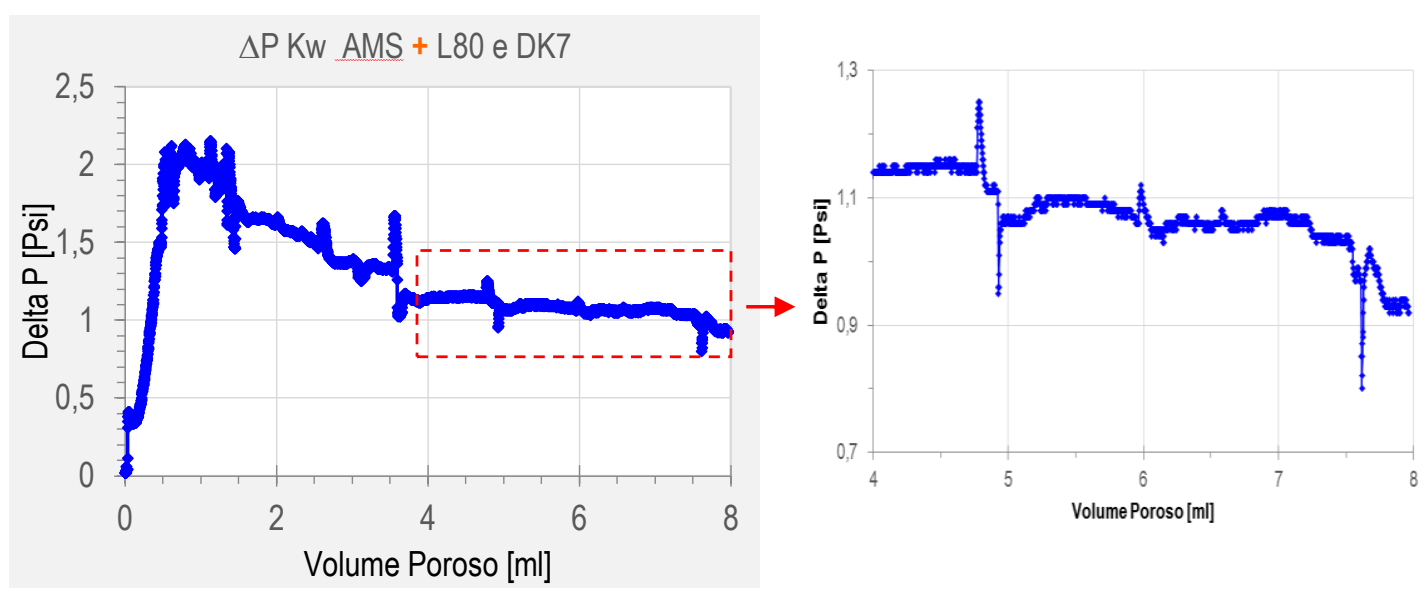

b)

Figura 4-15: Comportamento do diferencial de pressão na injeção de a) Solução $\mathrm{NaCl}$ $24,53 \mathrm{~g} / \mathrm{l} \mathrm{e} \mathrm{b)} \mathrm{Água} \mathrm{do} \mathrm{Mar} \mathrm{(SW)} \mathrm{-} \mathrm{Embebição} \mathrm{a} 40^{\circ} \mathrm{C}$.

Durante a injeção das soluções com surfactante foi observado um comportamento de pressão oscilante e com alguns picos, como mostra as Figura 4-14 e Figura 4-15. Provavelmente, os picos de pressão são resultados de entupimento das gargantas pela formação das emulsões geradas durante o escoamento nos canais de menor tamanho. $O$ incremento na pressão continuará até que a emulsão antiga o volume e pressão necessária para a emulsão avançar a os poros de maior diâmetro e escoar junto com as outras fases. Neste instante, a pressão cai novamente e se observa a produção da emulsão, conforme foi observado durante a injeção das soluções com surfactante e conforme é visualizado na Figura 4-16. Conclui-se que pequenos aumentos seguidos por reduções na pressão indicam gotas bloqueando determinados canais e se deformando até conseguir avançar e serem bloqueadas novamente ou até mesmo serem produzidas. Vale a pena observar que, a injeção das soluções com 
concentrações de 15 e 33,9 g/l de $\mathrm{NaCl}$ foram realizadas a diferentes proporções óleo-água, pelo qual, possivelmente, se conseguiu uma melhor recuperação em comparação com as soluções de $\mathrm{NaCl} 24,5 \mathrm{~g} / \mathrm{l}$.

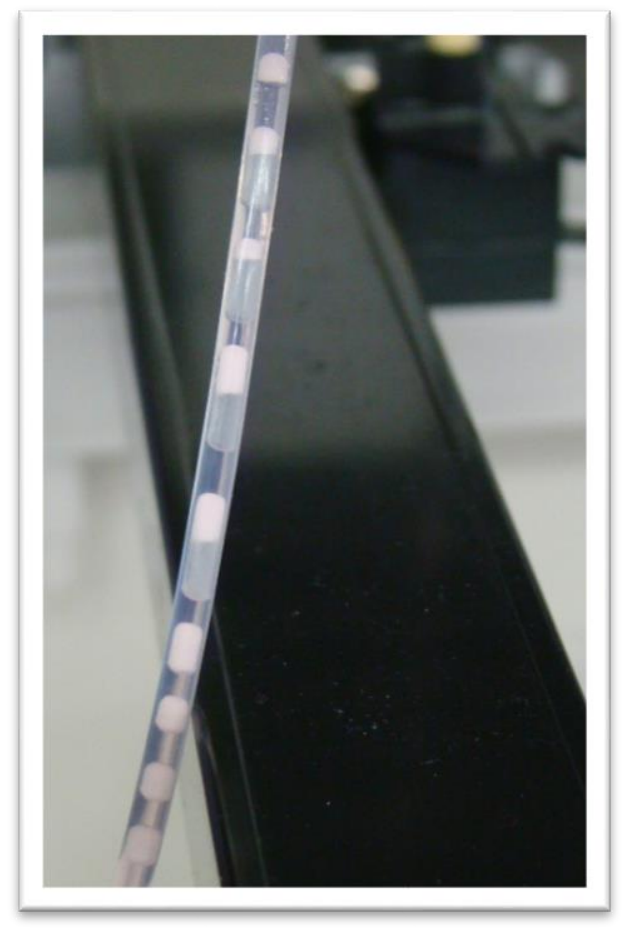

Figura 4-16: Linha de produção-efluente produzidos durante a embebição.

\section{6. \\ Medição de pH}

Na Figura 4-17, são apresentados os valores de $\mathrm{pH}$ medidos para as soluções salinas sem surfactante ao longo do teste de determinação de permeabilidade absoluta e do efluente coletado durante o drenagem e embebição, aproximadamente para cada 1,5 VP injetados. Dessa forma, foi medido o pH do efluente acumulado produzido, nos testes de drenagem e embebição. Pôde-se observar que não houve variação significativa no $\mathrm{pH}$ do efluente para as diferentes soluções. O pH dos efluentes é relativamente estável, sendo correto afirmar que as variações observadas nos valores podem estar dentro da faixa de erro. 


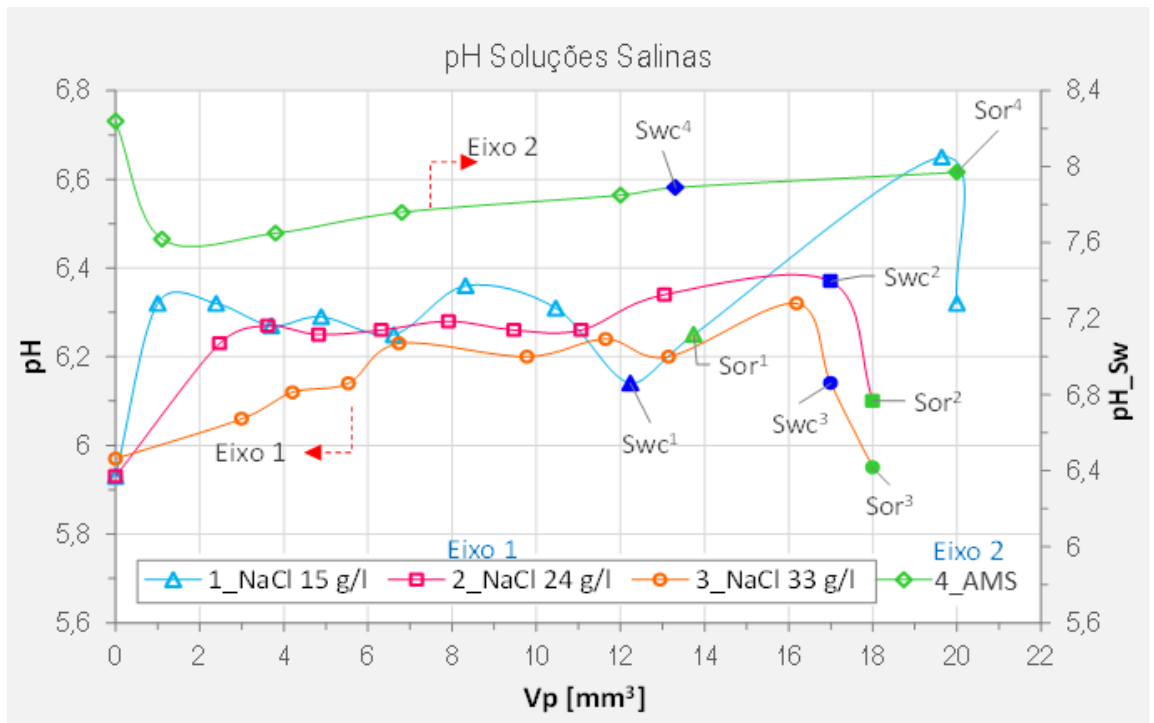

Figura 4-17: Comparação do pH dos efluentes das soluções salinas sem surfactante a $24^{\circ} \mathrm{C}$.

A Figura 4-17 observa-se que não existiram variações significativas no pH das soluções sem surfactante, isto pode ser explicado pelo fato de que não houve dessorção de catiões $\left(\mathrm{Ca}^{2+}\right.$ por $\left.\mathrm{H}^{+}\right)$já que a rocha tem pouca quantidade de argilas, como pode ser observado na Tabela 3-2.

Por outro lado, só o pH do efluente produzido da solução de $\mathrm{NaCl} 24,5 \mathrm{~g} / \mathrm{l}$ com L80 foi medido. Como pode ser observado na Figura 4-18, para o primeiro volume poroso obtem-se uma maior redução do $\mathrm{pH}$, isto pode ser explicado pela desestabilização do surfactante à temperatura de injeção (hidrólise) e foi observado também na diminuição do fator de recuperação.

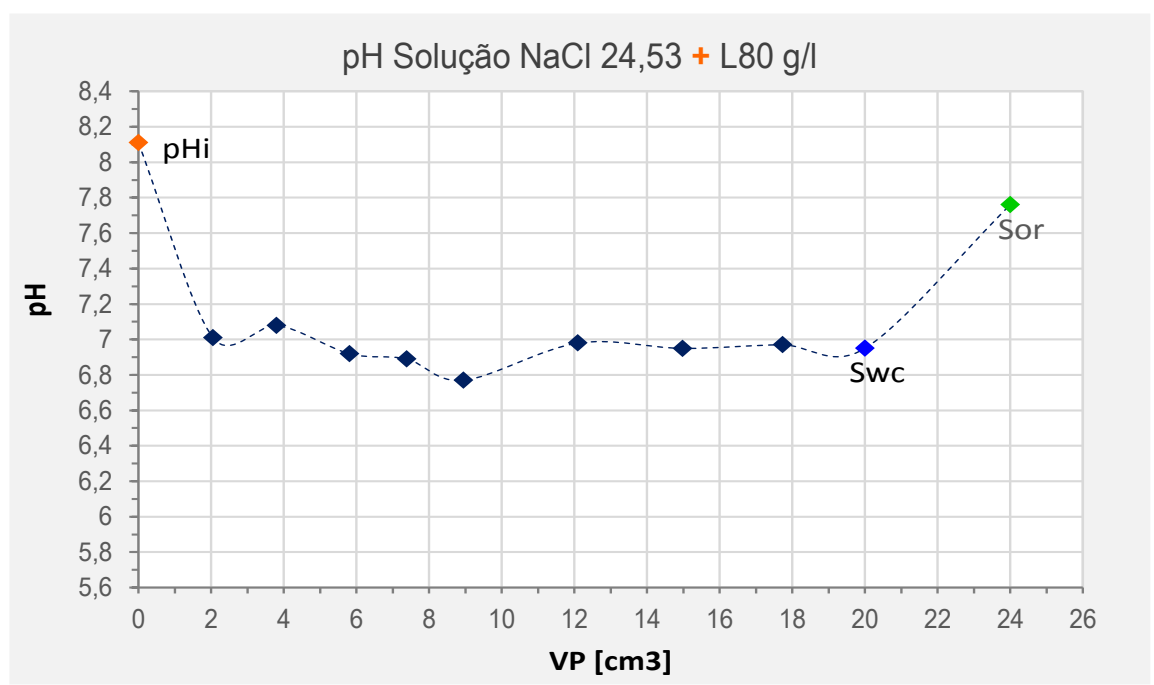

Figura 4-18: $\mathrm{pH}$ dos efluentes produzidos para a soluções de $\mathrm{NaCl} 24,5 \mathrm{~g} / \mathrm{l}$ e $\mathrm{L} 80$ a $24^{\circ} \mathrm{C}$. 


\section{7.}

\section{Resumo dos resultados finais}

O trabalho apresentado propôs estudar experimentalmente o efeito da salinidade da água (soluções com TDS entre 15 - $33.4 \mathrm{~g} / \mathrm{l}$ ) e concentração de surfactante (Ultrol L80) no processo de deslocamento de um óleo mineral (Drakeol 7). Com os resultados obtidos abre-se uma possibilidade para compreender e dar inicio a novos estudos que contribuam a esclarecer o efeito da salinidade da água injetada na recuperação de petróleo, e a iteração da salinidade com o surfactante (não iônico), que indubitavelmente trazem importantes efeitos no escoamento bifásico dentro do meio poroso. Em seguida, na Figura 4-19 serão apresentadas as tendências obtidas das saturações de água conata, saturação de óleo residual e volume de óleo inicial nas amostras, tanto para a injeção de soluções sem surfactate (Figura 4-19 a) quanto para a injeção de soluções com surfactante (Figura 4-19 b).
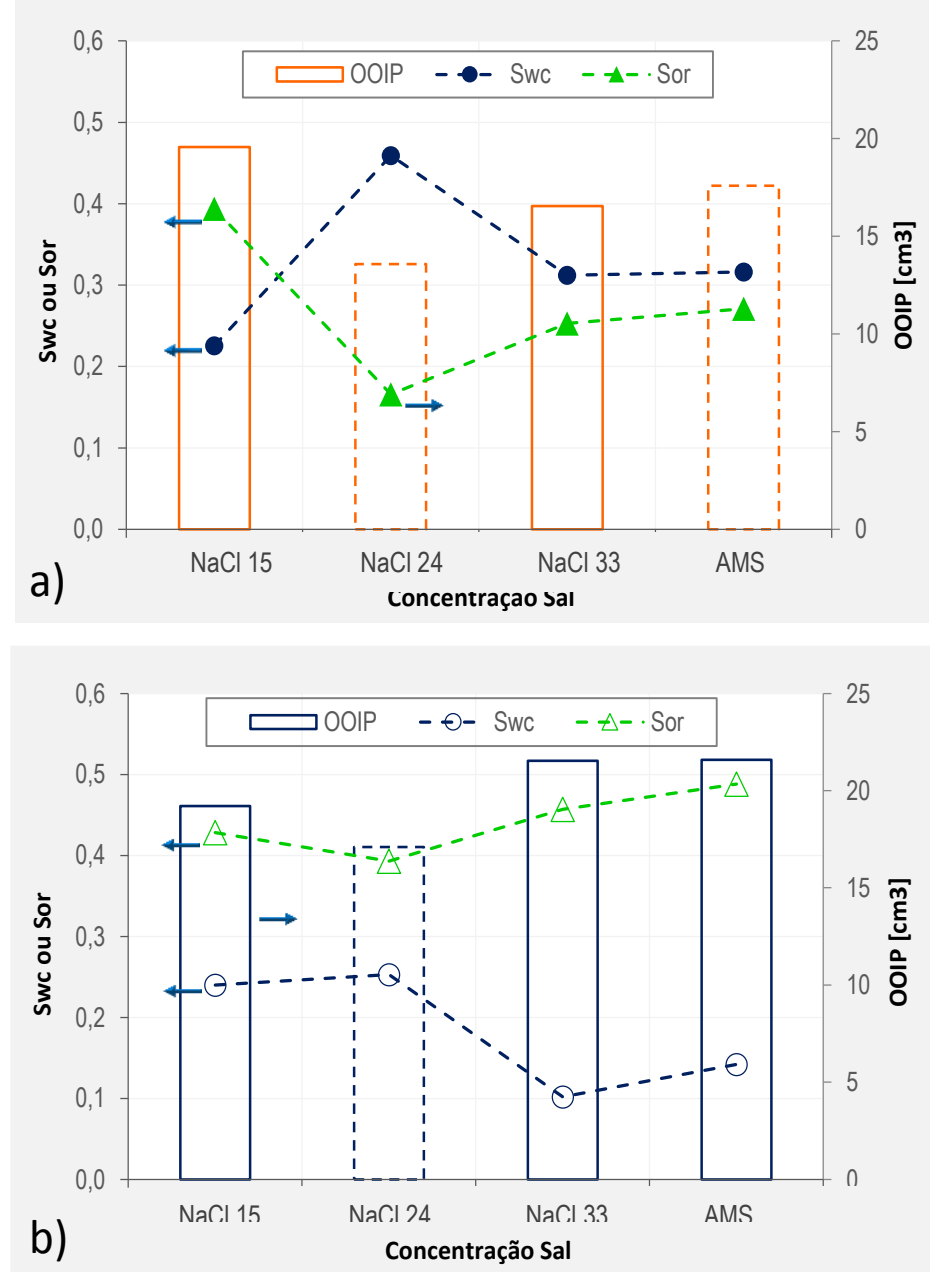

Figura 4-19: Saturações água conata e óleo residual: a) Soluções sem surfactante, b) Soluções com surfactante. 
Da Figura 4-19 (a), pode-se concluir que o efeito da tensão interfacial foi o esperado para a injeção de soluções sem surfactante. A saturação de água conata incrementa com o aumento da concentração sal; chama a atenção o comportamento do teste de drenagem com DK7 e NaCl $24 \mathrm{~g} / \mathrm{l}$, o qual não manteve a tendência dos outros testes, mas isto pode ser explicado pelo fato da rocha ter permeabilidade absoluta mais baixa.

Em relação às soluções com surfactante as tensões interfaciais estão na ordem de aproximadamente $3 \mathrm{mN} / \mathrm{m}$ para todos os sistemas óleo-água. Percebe-se na Figura 4-19 (b) que para a concentração de $\mathrm{NaCl} 33 \mathrm{~g} / \mathrm{l}$, a saturação de água conata foi menor $(S w c=0,1)$ em comparação com a saturação calculada para o sistema $\mathrm{NaCl} 15 \mathrm{~g} / \mathrm{l}(\mathrm{Swc}=0,23)$. Isto pode ser resultado da retenção e dispersão de pequenas quantidades de água nas emulsões formadas in situ, as quais contêm um maior volume de água em comparação com as emulsões formadas para as outras soluções. Tendência observada, também, nos testes de garrafa, onde uma pequena diferença no volume de água dispersado foi registrado para a concentração de $15 \mathrm{~g} / \mathrm{l}$ de $\mathrm{NaCl}$, conforme apresentado na Figura 4-5. Por conseguinte, existe um certo grau de incerteza no balanço de massa de água, uma vez que o valor pode corresponder a uma superestimação do cálculo de saturação pela solubilização e retenção de volume de água na rocha.

Dos resultados da embebição apresentados na Figura 4-19, era esperado para o caso das soluções sem surfactante que o aumento das forças capilares pela adição de eletrólitos levara-a à formação de fingers, o que por sua vez aumentaria o volume de óleo retido e reduziria a eficiência de deslocamento, no entanto, a tendência foi contraria ao esperado, postos que o Sor foi maior para as soluções com menor concentração de sal, isto possivelmente por efeitos de capilaridade isolados. Em relação aos resultados dos testes nos quais foram injetadas as soluções com surfactante, foi observado que o volume emulsionado aumenta com a diminuição da concentração de electrolitos. Foi encontrado também, que as emulsões formadas são do tipo água em óleo, e que elas bloqueiam os poros da rocha, como se evidenciou nos registros de pressão.

Fica evidente então, que durante um processo de recuperação por injeção de surfactantes, a aplicação de surfactante incompatíveis poderá formar macroemulsões altamente viscosas e difíceis de separar, que reduzem o fator de recuperação e aumentam a saturação de óleo residual, Figura 4-20. Pelo qual, a viscosidade das emulsões in situ é um fator crítico, que afetará diretamente a mobilidade das fases. 
Resultados

A Figura 4-21 apresenta a eficiência de deslocamento e a razão de mobilidade entre as fases. Observa-se na Figura 4-21 que as razões de mobilidade foram mais desfavoráveis para as soluções sem surfactante, o que implica que a fase aquosa tem maior mobilidade e tende a ultrapassar o óleo durante o escoamento e ser produzido antes do esperado. Em contrapartida, as razões de mobilidade menores podem ser consideradas como favoráveis e desejáveis.
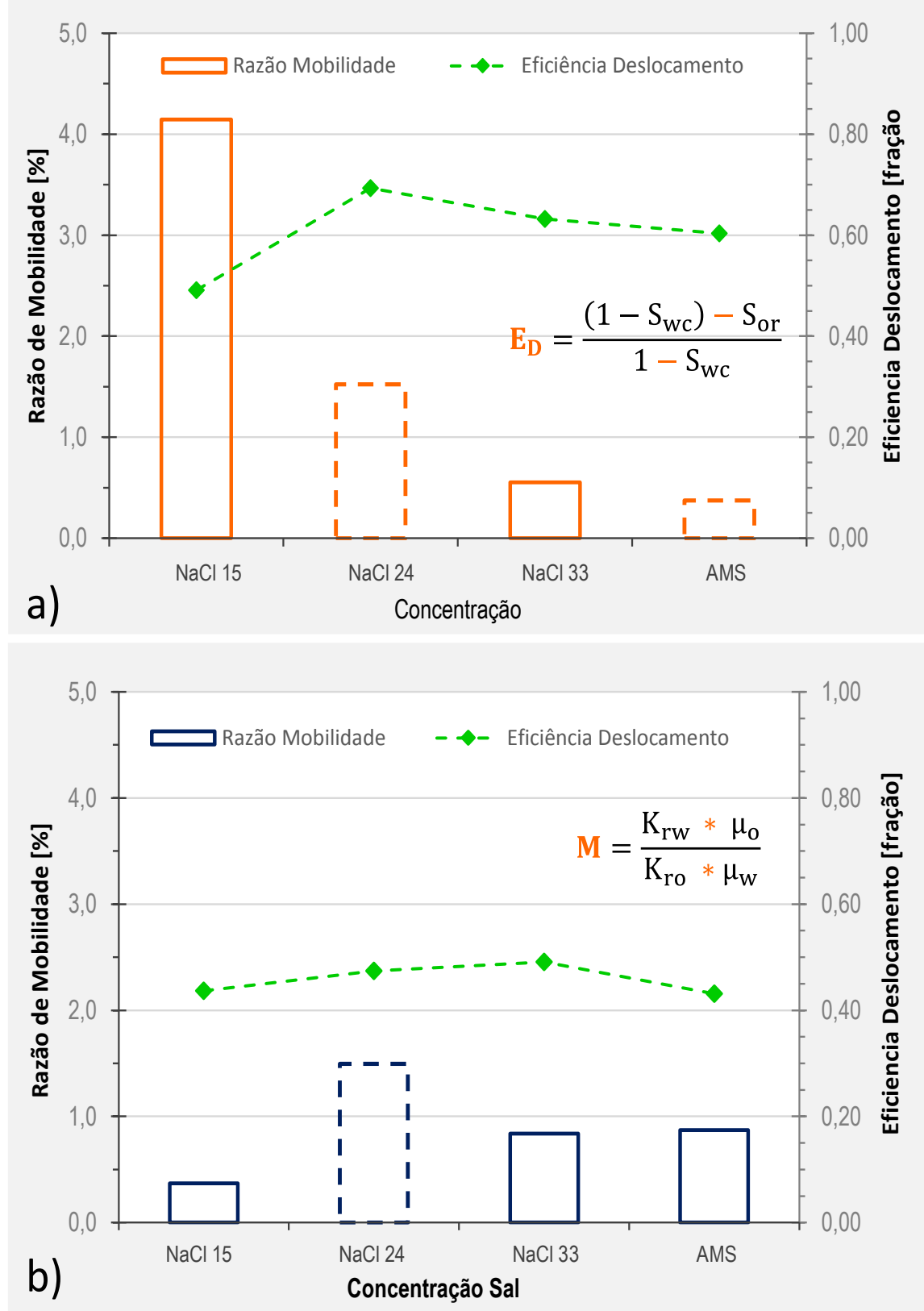

Figura 4-20: Razão de mobilidade e eficiência deslocamento: a) Soluções sem surfactante, b) Soluções com surfactante. 
Resultados

No que diz respeito aos fatores de recuperação de óleo das amostras injetadas com soluções sem surfactante, observou-se que elas alcançaram valores de $49 \%$ e $64 \%$ para as soluções de $\mathrm{NaCl} 15$ e 33,9 g/l, respectivamente. Era esperado uma maior recuperação para a solução com menor tensão interfacial, no entanto, tal como já foi mencionado, pelo fato das amostras de arenito utilizadas apresentarem maior heterogeneidade em suas propriedades os resultados foram consideravelmente afetados, conforme apresentado na Figura 4-21.

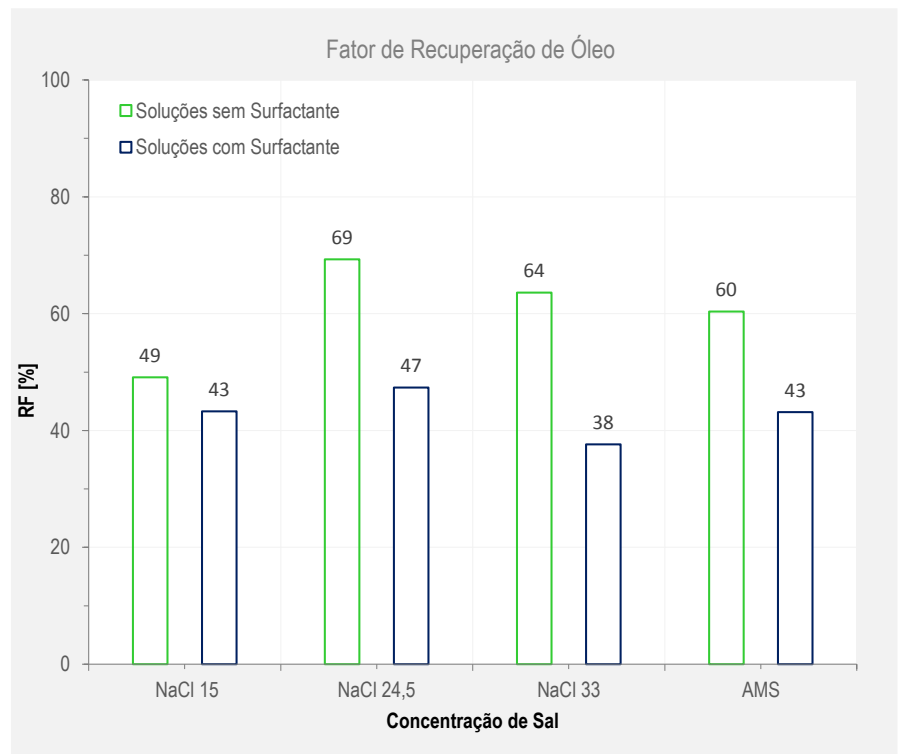

Figura 4-21: Fatores de recuperação soluções salinas com e sem surfactante.

Para a maioria dos testes, o óleo foi recuperado principalmente durante os primeiros volumes porosos injetados. Em 0,5 volume poroso de solução salina já tinha sido produzido cerca de $70 \%$ do óleo inicial na amostra (Figura 4-22).

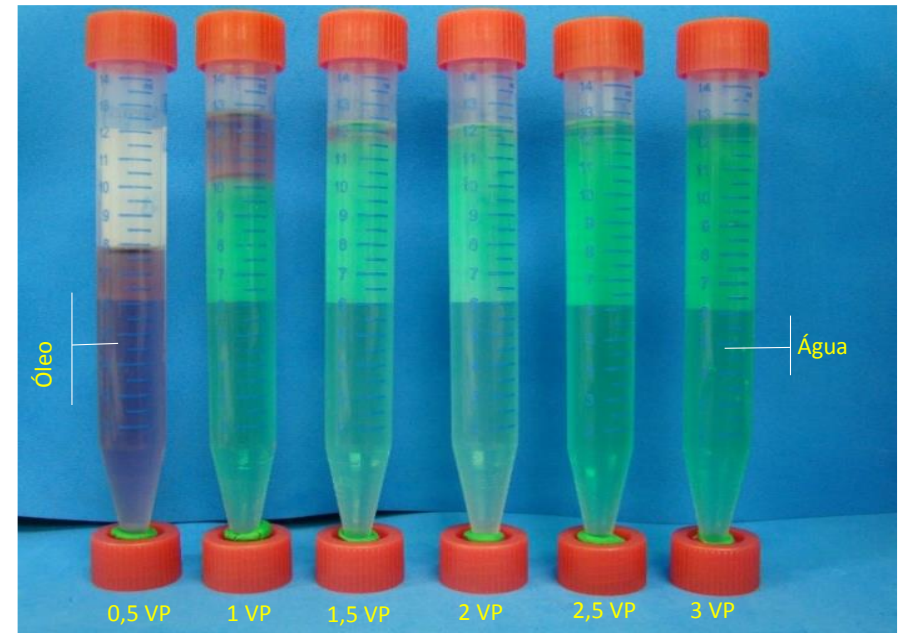

Figura 4-22: Breakthrough Solução $\mathrm{NaCl} 15 \mathrm{~g} / \mathrm{l}$. 
A rápida recuperação de óleo é uma resposta ao uso de um óleo de baixa viscosidade (10 cP) em uma amostra pouco heterogênea e de alta permeabilidade (aproximadamente 2,3 Darcy).

Finalmente, através da Figura 4-23, é possível observar os pontos extremos dos testes de deslocamento, realizados para cada uma das soluções. É importante destacar, que a tracejado das curvas apresentadas não se referem à curvatura da curva de permeabilidade relativa verdadeira, por conseguinte, no gráfico só se observam os pontos de permeabilidade relativa do óleo a saturação de água conata - $\mathrm{K}_{\mathrm{ro}}$ a $\mathrm{S}_{\mathrm{wc}}$ e permeabilidade relativa da água a saturação de óleo residual $-K_{r w}$ a $S_{o r}$

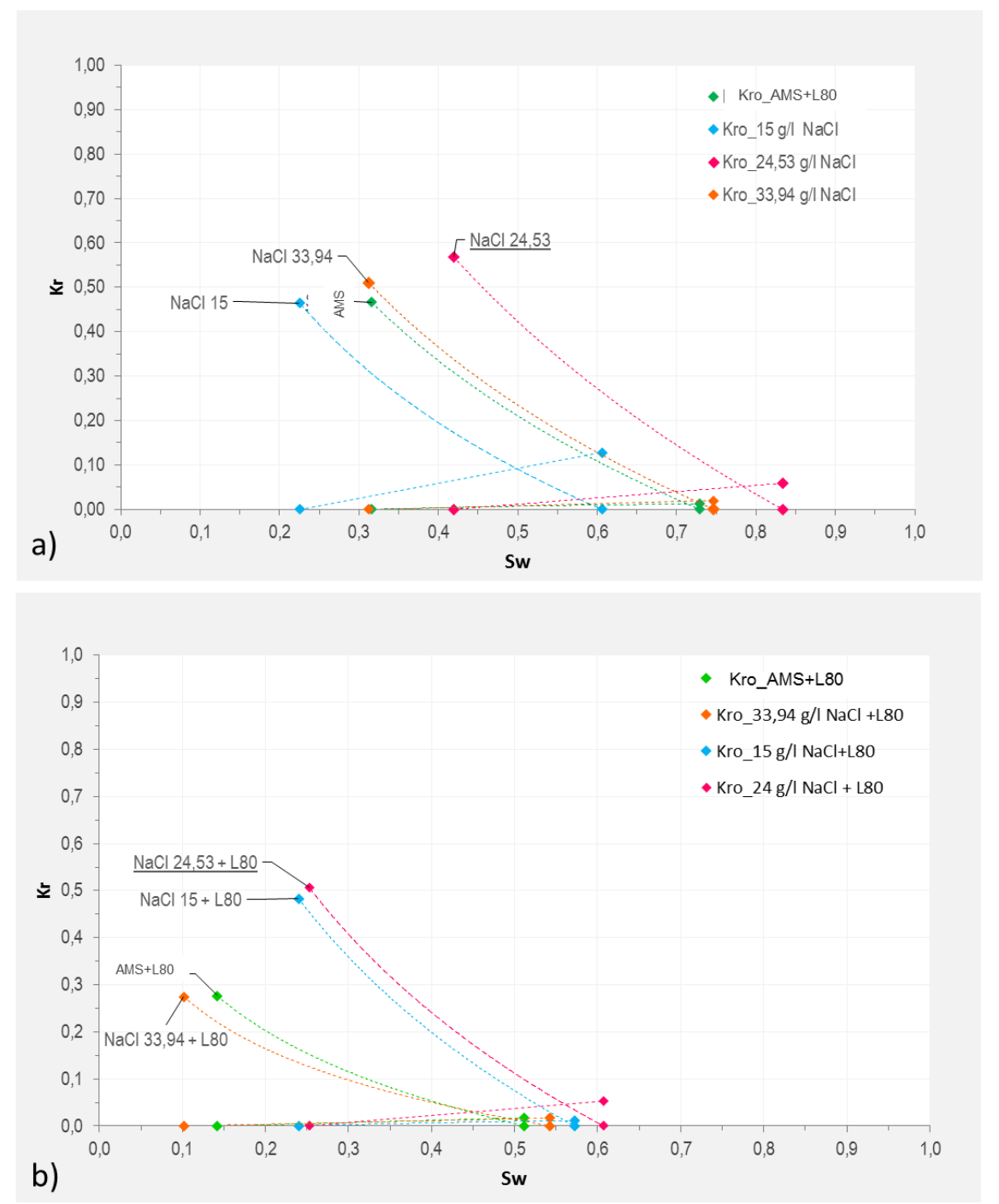

Figura 4-23: Permeabilidade relativa $X$ saturação de água: a) Soluções salinas sem surfactante; b) Soluções salinas com surfactante. 
Resultados

A redução dos valores da permeabilidade relativa observada na Figura 4-23 pode ser atribuída à formação de emulsões observada em todas as quatro amostras, tal como já foi mencionado, e ao bloqueio os poros, que por sua vez diminuiu a permeabilidade durante a injeção. 


\section{5 \\ Comentários Finais e Sugestões}

\section{1. \\ Comentários Finais}

Este capítulo apresenta os comentários finais da pesquisa e recomendações para trabalhos futuros.

Testes de deslocamento de óleo por uma fase aquosa a diferentes concentrações de sal, com e sem surfactante não iônico L80, foram realizados em amostras de arenito de Bentheimer, com permeabilidades absolutas em torno de 2,3 D. As permeabilidades e saturações residuais de óleo e água ao final do processo de drenagem e embebição junto com os fatores de recuperação, foram medidos para avaliar os efeitos da salinidade e concentração do surfactante na recuperação melhorada de óleo (EOR).

A variação da tensão interfacial com a salinidade para as soluções com surfactante foi desprezível. Para todas as soluções, a tensão interfacial foi aproximadamente $3 \mathrm{mN} / \mathrm{m}$. Para as soluções sem surfactante, a tensão interfacial varia com a salinidade. Experimentalmente observou-se que a adição de $\mathrm{NaCl}$ à água aumenta a tensão superficial, enquanto que a presença dos íons bivalentes $\mathrm{Ca}^{2+} \mathrm{e} \mathrm{Mg}^{2+}$ diminuem a tensão interfacial, pelo efeito da dissociação iônica.

Nos testes de drenagem, os resultados obtidos para as soluções sem surfactante mostraram a tendência esperada. A saturação de água conata aumenta com a salinidade. Esta variação pode ser explicada pela maior tensão interfacial óleo-água das soluções de maior concentração de sal, que torna os efeitos capilares mais fortes. Os resultados obtidos com as soluções com surfactante mostram uma redução da saturação de água irredutível com o aumento da salinidade. Esta variação não pode ser explicada pelo valor da tensão interfacial (quase igual para todas as soluções). Levando-se em consideração que os testes de garrafa mostraram a formação de maior volume de emulsão e o fato que a curva de pressão apresentou oscilações durante o processo de drenagem, o efeito observado pode ser devido à formação de emulsões água em óleo in situ.

Nos testes de embebição com soluções sem surfactante, esperava-se um aumento da saturação residual de óleo com a concentração de sal, já que a tensão 
interfacial aumenta com a salinidade. No entanto, observou-se um efeito contrário, a saturação residual de óleo obtida com a solução com $33 \mathrm{~g} / \mathrm{l}$ de $\mathrm{NaCl}(\sim 0,25)$ foi menor que a obtida com a solução com $15 \mathrm{~g} / /$ de $\mathrm{NaCl}(\sim 0,4)$. A razão do fenómeno observado não é clara, podendo estar relacionada ao diferente volume de óleo inicial nas amostras, e à diferença entre a tensão interfacial $(\sim 4 \mathrm{mN} / \mathrm{m})$ das soluções de $\mathrm{NaCl} 15$ e 33, que pode não ser suficiente para conseguir deslocar mais óleo, e diminuir a saturação de óleo residual.

Em relação aos resultados obtidos para as soluções injetadas com surfactante, foi observado que o incremento da concentração de eletrólitos aumenta a saturação de óleo residual, isto possivelmente pelo fato de que o volume de água solubilizado é menor para as soluções com maior concentração de sal. No entanto, devido à formação das emulsões água em óleo in situ, os resultados não foram o esperado, uma vez que essas emulsões bloqueiam os poros e diminuem a mobilidade da fase oleosa o que, por sua vez, aumenta a saturação de óleo residual

Concluiu-se que, a injeção de surfactantes incompatíveis com o sistema água-óleo causa formação de macroemulsões altamente viscosas e difíceis de serem separados, fato que reduz o fator de recuperação e aumenta a saturação de óleo residual.

A rápida recuperação de óleo observada nos testes, é uma resposta ao uso de um óleo de baixa viscosidade (10 cP) e amostras pouco heterogêneas de alta permeabilidade (aproximadamente 2,3 Darcy).

Foi determinado que a formação da terceira fase, formada durante a injeção de soluções salinas com surfactante com concentrações de $\mathrm{NaCl}$ entre 15 - 33,9 g/l, a uma temperatura de $40{ }^{\circ} \mathrm{C}$ e concentração constante de L80 $(1,8 \mathrm{~g} / \mathrm{l})$, corresponde a um Winsor Tipo II. A formação de emulsões tipo Winsor II, podem ser explicadas pelo fato de se estar utilizando um surfactante não iônico a uma temperatura acima do ponto de nevoa, com concentrações acima da CMC e altas salinidades.

Foi possível demostrar que, a injeção de surfactantes não iônicos em um meio poroso pode promover à formação de emulsões altamente viscosas do tipo água em óleo, que bloqueiam as gargantas de poro e diminuem a recuperação de óleo.

Foi observado, que o surfactante L80, utilizado para a recuperação do óleo mineral Drakeol 7 em amostras de arenito, apresenta baixa solubilidade a temperatura de $40^{\circ} \mathrm{C}$. 
O baixo valor obtido da CMC para o surfactante L80, é explicado pelo efeito da salinidade, que reduz o ponto de nevoa e por sua vez a solubilidade do surfactante na água.

\section{2.}

Sugestões

Algumas recomendações de possíveis trabalhos a serem realizados são:

- Fazer um estudo de comportamento de fases com diagramas de fases, para a formulação dos surfactantes antes da injeção. Isto, com o objetivo de entender o que acontece quando o surfactante está em contato com as diferentes soluções e as condições sob as quais as emulsões poderão ser formadas, além de encontrar a formulação na qual se alcancem tensões na ordem de $10^{-3}$, que permita às fases estar em equilíbrio e melhore as eficiência de deslocamento.

- Antes de realizar testes de deslocamento de óleo, é necessário criar uma metodologia que permita selecionar os surfactantes a serem utilizados, medir a concentração micelar crítica (CMC) de cada um deles e fazer testes de comportamento de fases, para posteriormente caracterizar os fluidos coletados nos efluentes. 


\section{Referências Bibliográfica}

1. LAKE, LARRY W. Enhanced Oil Recovery. 1. ed. EUA: Prentice Hall 1989, 1996. Cap. 1, p. 1-2.

2. SANABRIA, F. C. Avaliação da Injeção de Surfactantes como Metódo de Recuperação Avançada em Reservatórios de Arenito. Disertação de Mestrado, Faculdade de Engenharia Mecânica. Universiade Estadual de Campinas, p. 134. 2013.

3. CHOU, S. I.; \& SHAH, D. O. The optimal salinity concept for oil displacement by oil-external microemulsion and graded salinity slugs. Journal of Canadian Petroleum Technology - JEPT, Gainesville, Florida, v. 20, p. 9, July 1981.

4. MORROW, N.; \& BUCKLEY, J. Improved Oil Recovery by Low-Salinity Waterflooding. JPT-Society of Petroleum Engineers, May 2011.

5. NASRALLA, R. A.; NASR-EL-DIN, H. A. Coreflood Study of Low Salinity Water Injection in Sandstone Reservoirs. SPE149077, SPE/DGS Saudi Arabia Section Technical Symposium and Exhibition held in Al-Khobar, Saudi Arabia, January 2011.

6. SHARMA, M. M.; FILOCO, P. R. Effect of Brine Salinity and Crude-Oil Properties on Oil Recovery and Residual Saturations. SPE Journal, Vol. 5, No. 3, p. 293-300, September 2000.

7. ZHANG, Y., XIE, X., \& MORROW, N. R. Waterflood Performance By Injection Of Brine With Different Salinity For Reservoir Cores. SPE 109849-MS, January 2007.

8. LAGER, A.; WEBB, K. J.; BLACK, C. J. J.; SINGLETON, M.; \& SORBIE, K. S. Low Salinity Oil Recovery - An Experimental Investigation. International Symposium of the Society of Core Analysts in held, Norway, February 2008.

9. KINE CHRISTENSEN NAVRÁTIL. An experimental study of Low Salinity EOR effects on a core from the Yme field. Master's Thesis, Faculty of Science and Technology. University of Stavanger, p. 59. 2012. 
10. RIVAS, H.; GUTIERREZ, X. Los Surfactantes: Comportamiento y Algunas de sus Aplicaciones en la Industria Petrolera. Acta Científica Venezolana, Venezuela, v. 50, n. 1, p. 54-65, Julio 1999.

11. JEAN-LOUIS SALAGER. Cuaderno FIRP S357-C. Recuperción Mejorada del Petróleo. Laboratório Formulación, Interfases, Reología y Procesos (FIRP). Mérida-Venezuela, p. 35. 2005.

12. NAZAR, M. F. ; SHAH, S. S.; AND KHOSA, M. A. Microemulsions in Enhanced Oil Recovery: A Review. Petroleum Science and Technology, p. 14, May 2011.

13. SOCIETY OF PETROLEUM ENGINEERS. PetroWiki, 2012. Disponivel em: <http://petrowiki.org/Capillary_pressure>. Acesso em: 20 Fevereiro 2014.

14. FARIAS, M. L. R. D. Recuperação Avançada de Óleos Pesados por Injeção de Emulsões Diluídas em Óleo em Água. Tese de Doutorado, DEM, PUC. Rio de Janeiro, p. 219. 2013.

15. NEDDEN, A. G. P. Análise do processo de quebra de gotas de uma emulsão. Dissertação de Mestrado, DEM, PUC. Rio de Janeiro, p. 89. 2010.

16. ZAHOOR, M. K.; DERAHMAN, MOHD. N. ; YUNAN, M. H. Portal of Scientific Journals of Croatia. Hrčak, 2009. Disponivel em: <hrcak.srce.hr/file/61164>. Acesso em: 11 Novembro 2013.

17. WILLHITE, P. Waterflooding 3. ed. Richardson. Texas: [s.n.], v. SPE Textbook Series, 1986.

18. MELO, T. N. T. D. F. Utilização dos Tensoativos na Indústria do Petróleo. Bacharel em Ciência e Tecnologia - UFERSA. ANGICOS - RN, p. 49. 2013.

19. KOKAL, S., AL-KAABI, A. World Petroleum Council. Publications, 2009. Disponivel em: <http://www.worldpetroleum.org/docs/docs/publications/2010yearbook/P64-69_Kokal-

Al_Kaabi.pdf>. Acesso em: 18 Fevereiro 2014.

20. ENGElKE, B. S., CARVAlHO, M. S.; AlVARADO, V. Determinação das curvas de permeabilidade relativa no escoamento de emulsões e óle. Dissertação Mestrado, DEM, PUC. Rio de Janeiro, p. 118. 2012.

21. RIISøEN, S. Effect of Combined Low Salinity and Surfactant Injection on Oil Recovery in Aged Bentheimer Sandstones at Different Temperatures. Master Thesis, Department of Chemistry Centre of Integrate Petroleum Research (Uni CIPR), Univeristas Bergensis. [S.I.], p. 113. 2012. 
22. ASTM. Standard Practice for the Preparation of Substitute Ocean Wate, D1141-98 (2013). West Conshohocken. 2013.

23. DEMARQUETTE, N.; E KAMAL, M. R. Comparação entre o Método da Gota Pendente eo Método da Gota Girante para Medida da Tensão Interfacial entre Polímeros. Polímeros, São Carlos , v. 7, n. 3, Sept. 1997. Disponivel em: <http://www.scielo.br/pdf/po/v7n3/8889.pdf>. Acesso em: 14 maio 2014.

24. AMERICAN PETROLEUM INSTITUTE. Strategies for Today's Enviromentl Partnership. $\quad$ Energistics, $1990 . \quad$ Disponivel em: <http://w3.energistics.org/RP40/rp40.pdf>. Acesso em: 22 Setembro 2012.

25. OXITENO. Boletin Técnico Alkonat L. Oxiteno Evolution by Chemistry. Disponivel em: <http://www.oxiteno.com.br/cms/media/24618/alkonat___hc_port_dez11.p df>. Acesso em: 26 Janeiro 2013.

26. EMEGWALU, C. C. Enhanced Oil Recovery for Norne Field's E-Segment Using Surfactant Flooding. Master Thesis, Department of Petroleum Engineering and Applied Geophysics, NTNU. Norway, p. 117. 2010.

27 DOMINIK, H.; HERZ, A.; VRBKA, L.; SEDLMEIER. F.; MAMATKULOV, S.; NETZ, R. Specific Ion Adsorption at the Air/Water Interface: The Role of Hydrophobic Solvation. ScienceDirect Chemical Physics Letters. [S.I.], p. Volume 479, Issues 4-6, Pages 173-183. 2009. 